Universidade de Brasília

Faculdade de Tecnologia

Departamento de Engenharia Elétrica

\title{
Cálculo de desempenho, disponibilidade e interferências para radioenlaces
}

\author{
FÁBIO NEPOMUCENO SILVA
}

ORIENTADOR: FRANKLIN DA COSTA SILVA 
UNIVERSIDADE DE BRASÍLIA

FACULDADE DE TECNOLOGIA

DEPARTAMENTO DE ENGENHARIA ELÉTRICA

\title{
CÁLCULO DE DESEMPENHO, DISPONIBILIDADE E INTERFERÊNCIAS PARA RADIOENLACE
}

\author{
FÁBIO NEPOMUCENO SILVA
}

TRABALHO FINAL DE ESTÁGIO SUPERVISIONADO II SUBMETIDO AO DEPARTAMENTO DE ENGENHARIA

ELÉTRICA DA FACULDADE DE TECNOLOGIA DA UNIVERSIDADE DE BRASÍLIA, COMO PARTE DOS REQUISITOS NECESSÁRIOS PARA A OBTENÇÃO DO GRAU DE ENGENHEIRO ELETRICISTA.

APROVADO POR:

FRANKLIN DA COSTA SILVA, UnB

(ORIENTADOR)

Brasília, 14 de Julho de 2003 


\section{AGRADECIMENTOS}

Agradeço primeiramente a Deus, depois aos guias, e por fim, ao meu amigo Francisco José de Menezes Sousa, que teve paciência e compreensão, me ajudando nos momentos mais difíceis. Valeu mesmo. Sem vocês, sei que não teria conseguido. Obrigado!!!

Agradeço também aos meus pais e irmãos, em especial ao Thiago Nepomuceno Silva, que me ajudou na formatação deste projeto. Valeu !!! O padrinho ficou muito agradecido.

"Sem saber que era impossível, ele foi lá e fez"

Fábio Nepomuceno Silva. 


\section{ÍNDICE}

CAPÍTULO 1 - INTRODUÇÃO.

1.1 Padronização Para CRITÉRIos de Qualidade

CÁlCulo de DeSEMPENHO, DisPonibilidade E INTERFERÊNCIAS PARA RADIOENLACE

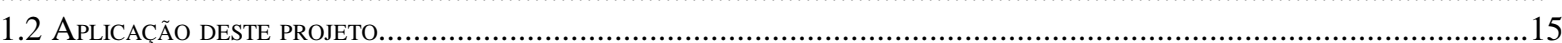

1.3 Sistema RÁdio PONTO a PONTO.

RESUMIDAMENTE, ESTE CAPÍTULO DE INTRODUÇÃO VEM COM O INTUITO DE MOSTRAR OS CRITÉRIOS DE QUALIDADE QUE DEFINIRÁ OS OBJETIVOS ESTABELECIDOS PELO ITU-R A SEREM COMPARADOS NO CÁLCULO DE DESEMPENHO E DISPONIBILIDADE. ALÉM DISSO, É APRESENTADO DE FORMA DIRETA OS TIPOS DE SISTEMAS QUE ESTE PROJETO PODE SER APLICADO, TODOS DE ACORDO COM A REGULAMENTAÇÃO DA ANATEL.

CAPÍTULO 2 - CONFIGURAÇÃO SISTÊMICA.

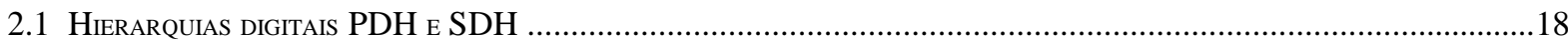

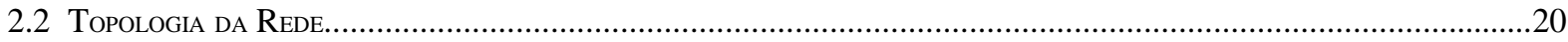

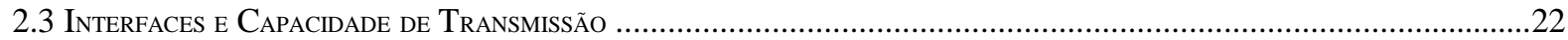

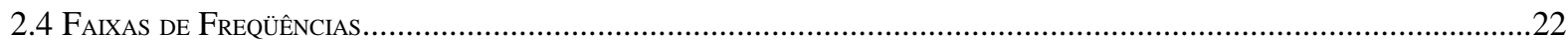

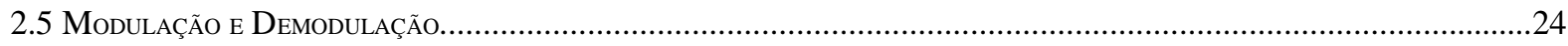

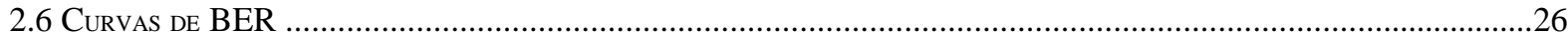

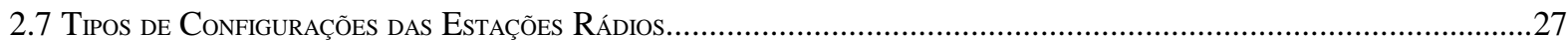

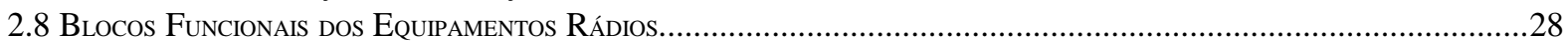

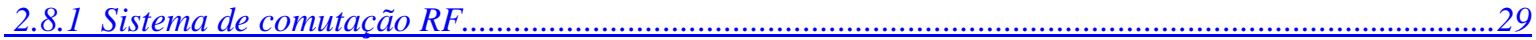

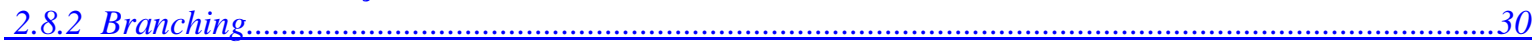

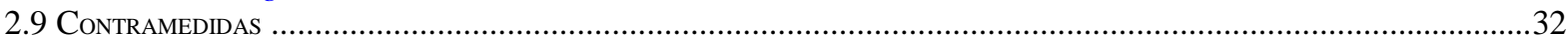

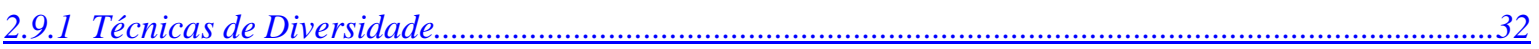

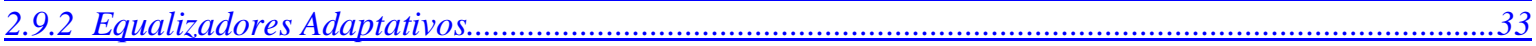

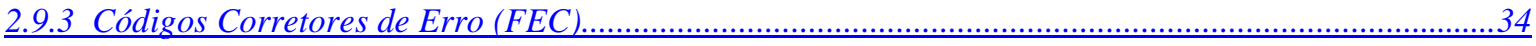

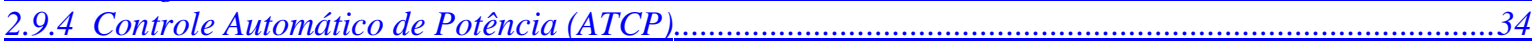

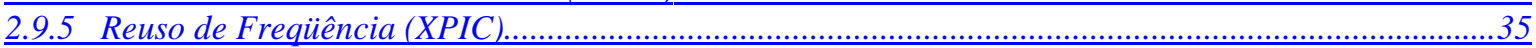

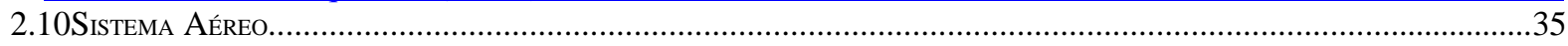

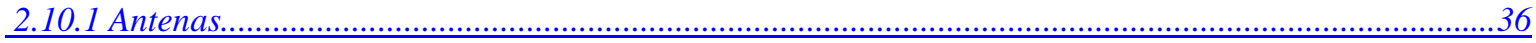

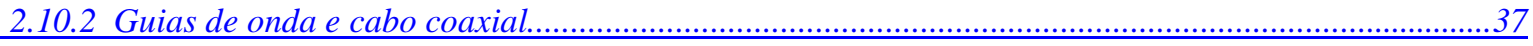

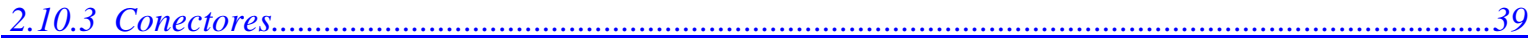

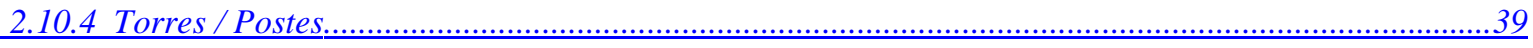

CAPÍTULO 3 - DEFINIÇÃ̃ DOS PARÂMETROS DE EQUIPAMENTOS..............................................40

CAPÍTULO 4 - PROPAGAÇÃO

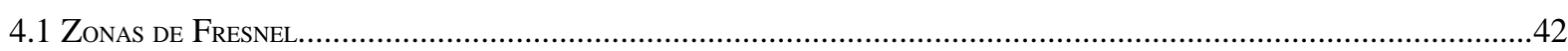

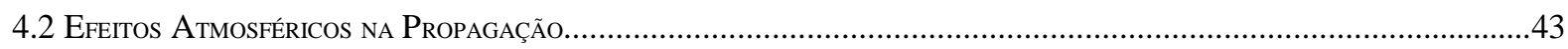

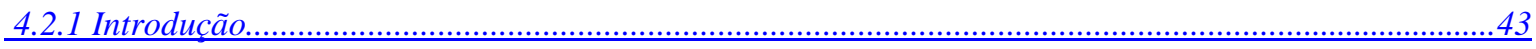

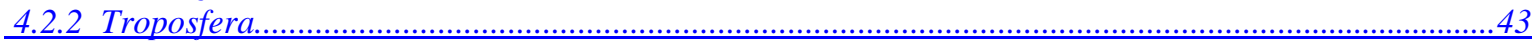

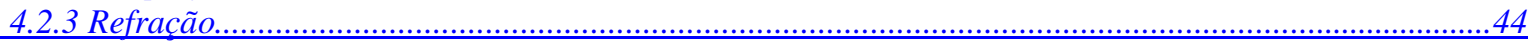

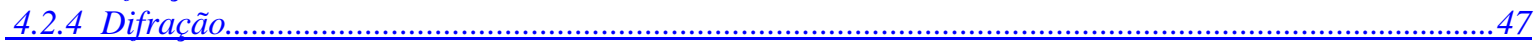

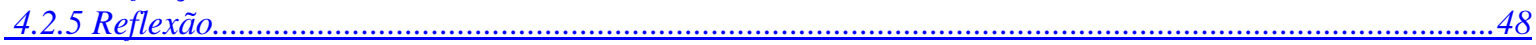

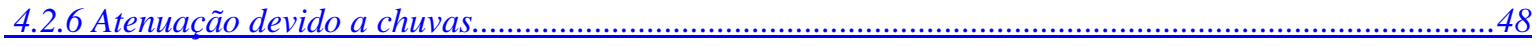

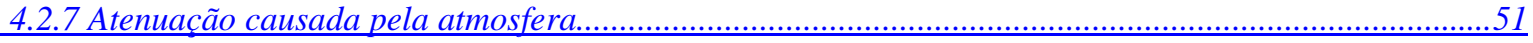

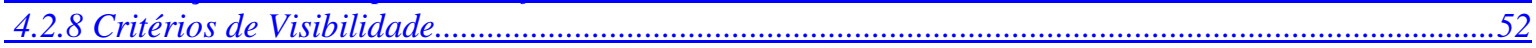

CAPÍTULO 5 - DIMENSIONAMENTO DE RADIOENLACES..........................................................56

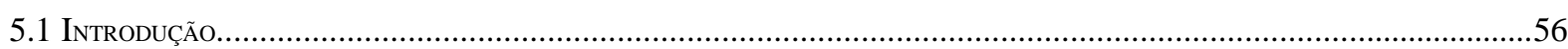

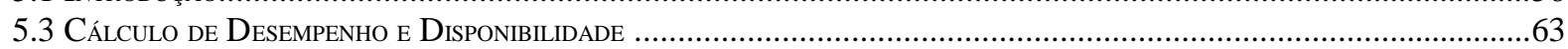




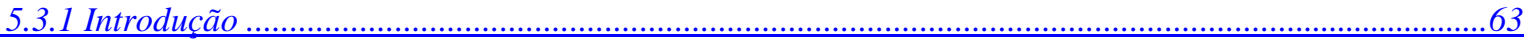

5.3.2 Metodologia do Cálculo de Desempenho e Disponibilidade ....................................................64

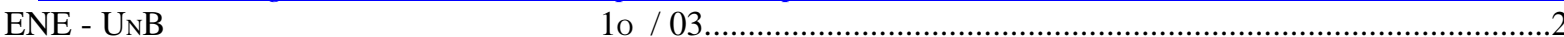

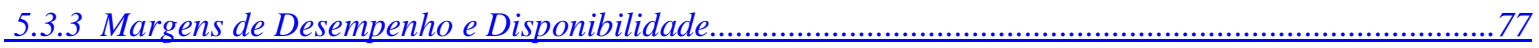

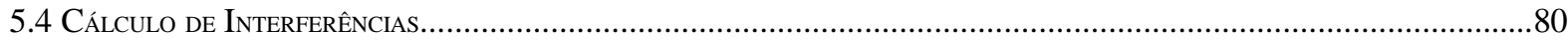

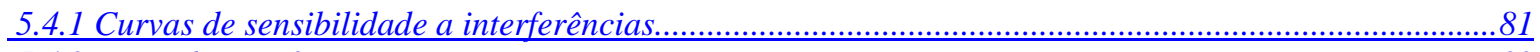

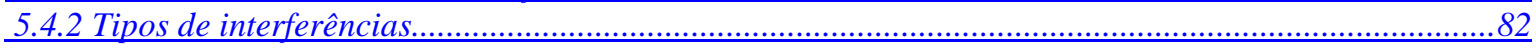

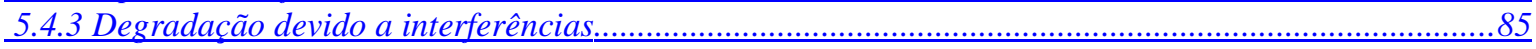

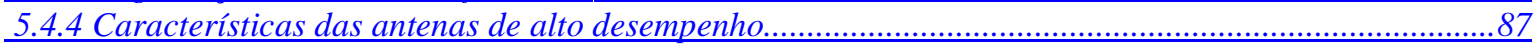

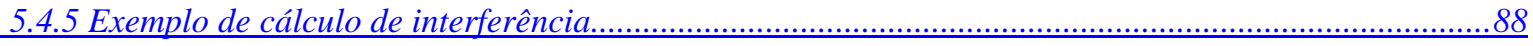

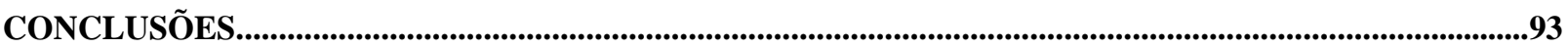

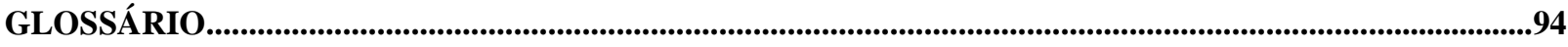

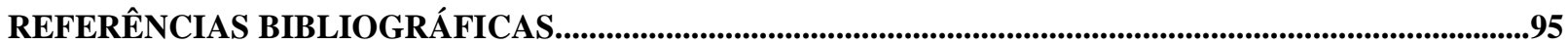




\section{ÍNDICE DE FiguraS}

FIGURA 1: CIRCUITOS HIPOTÉTICOS DE REFERÊNCIA. .12

FIGURA 2. ROTA COM CINCO ENLACES .14

FIGURA 3. HIERARQUIA PDH. .19

FIGURA 4. HIERARQUIA SDH. .19

FIGURA 5. BACKBONE SDH DE LONGA DISTÂNCIA COM ENTROCAMENTO SECUNDÁRIO EM PDH.

FIGURA 6. BACKBONE SDH DE LONGA DISTÂNCIA .21

FIGURA 7. REDE METROPOLITANA EM ANEL DE RÁDIOS SDH...........................................................21

FIGURA 8. REDE METROPOLITANA CONSTITUÍDA DE RÁDIOS E FIBRA............................................21

FIGURA 9. CONCEITO DE FATOR DE “ROLL-OFF",...........................................................................................25

FIGURA 10. CURVA C/N TÍPICAS DE EQUIPAMENTOS RÁDIOS..............................................................27

FIGURA 11. ESTAÇÃO REPETIDORA COM DROP-INSERT T..................................................................28

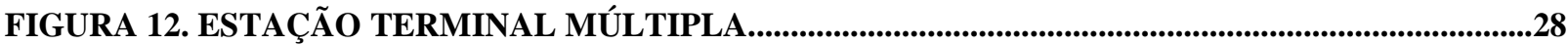

FIGURA 13. COMUTAÇÃO DO SISTEMA TWIN-PATH...............................................................................29

FIGURA 14. "BRANCHING” NO SISTEMA “TWIN PATH”.......................................................................31

FIGURA 15. "BRANCHING” NO SISTEMA "HOT STANDBY"'........................................................................32

FIGURA 16. DIVERSIDADE DE FREQÜÊNCIA........................................................................................33

FIGURA 17. DIVERSIDADE DE ESPAÇO..............................................................................................................33

FIGURA 18. FUNCIONAMENTO DO ATPC........................................................................................34

FIGURA 19. PLANO INTERCALADO PARA FAIXAS DE FREQÜÊNCIAS DE 5 GHZ...............................35

FIGURA 20. REUSO DE FREQÜÊNCIAS PARA A FAIXA DE 5 GHZ.......................................................35

FIGURA 21. TIPOS DE TORRES...........................................................................................................................40

FIGURA 22. LIMITE GEOMÉTRICO X LIMITE RÁDIO......................................................................................44 
Cálculo de desempenho, disponibilidade e interferências para radioenlace

FIGURA 23. EFEITOS DA VARIAÇÃ̃O DO FATOR K NA ATMOSFERA.......................................................46

FIGURA 25. ATENUAÇÃO DEVIDO À ATMOSFERA DEVIDO AO AR SECO E VAPOR D'ÁGUA A

7,5G/M3

FIGURA 26. CANALIZAÇÃO NA FREQÜÊNCIA DE 7,5 GHZ......................................................................59

FIGURA 27. PLANO DE FREQÜÊNCIA DA ROTA A-E...........................................................................60

FIGURA 28. IMPLANTAÇÃO DE UM QUINTO ENLACE................................................................................62

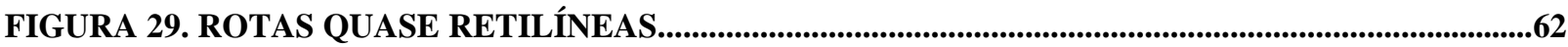

FIGURA 30. PL PARA OS MESSES DE FEVEREIRO, MAIO, AGOSTO E NOVEMBRO...........................72

FIGURA 31. CURVA BER X S/I PARA INTERFERÊNCIA CO-CANAL_.....................................................81

FIGURA 32. CÁLCULO INTERFERÊNCIA CO-CANAL ............................................................................83

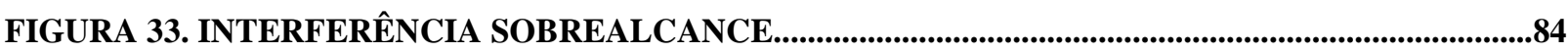

FIGURA 34. INTERFERÊNCIAS INTERSISTEMAS.............................................................................84

FIGURA 35. POTÊNCIA DE RECEPÇÃO SEM INTERFERÊNCIAS X BER...............................................86

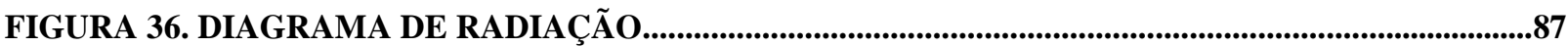

FIGURA 37. DIAGRAMA DE RADIAÇÃO DA ANTENA HPX6-71W.............................................................88

.89

FIGURA 38. DESCRIÇÃO DOS SISTEMAS INTERFERENTES................................................................89

ÍNDICE DE TABELAS

TABELA 1. RECOMENDAÇÕES DO ITU-R........................................................................................................12

TABELA 2. DADOS ENLACES DA FIGURA 2 - MEDIUM GRADE - CLASSE 1........................................14 
Cálculo de desempenho, disponibilidade e interferências para radioenlace

TABELA 3. HIERARQUIA SDH.

TABELA 4. TIPO DE RÁDIOS POR CAPACIDADE DE TRANSMISSÃO.....................................................22

TABELA 5. CAPACIDADE PERMITIDA POR FAIXA DE FREQÜÊNCIA (ABAIXO DE 10 GHZ)........23

TABELA 6. CAPACIDADE PERMITIDA POR FAIXA DE FREQÜÊNCIA (ACIMA DE 10 GHZ)...........24

TABELA 7. EFICIÊNCIA ESPECTRAL E BANDA OCUPADA........................................................................25

TABELA 8. RELAÇÃ̃ C/N X MODULAÇÃO...............................................................................26

TABELA 9. CARACTERÍSTICAS PARA ANTENAS DE MICROONDAS PARA FREQÜÊNCIA DE 8,5

GHZ.

.37

TABELA 10. CARACTERÍSTICA.

TABELA 11. ATENUAÇÃO. . .38

TABELA 12. TAXAS PLUVIOMÉTRICAS POR REGIÃO PARA VÁRIAS PORCENTAGENS DE TEMPO. 49

TABELA 13. VALORES DE K E A EM FUNÇÃO DA POLARIZAÇÃO E FREQÜÊNCIA...........................50

TABELA 14. PORCENTAGEM DO RAIO DE FRESNEL X FREQÜÊNCIA...................................................52

TABELA 15. CÁlCULO DA ALTURA DAS ANTENAS PARA FREQÜÊNCIA ACIMA DE 3GHZ..........53 96.

.2

TABELA 16. FREQÜÊNCIA DE 15, 18, 23 E 38 GHZ X DISTÂNCIA DO ENLACE....................................56

TABELA 17. CAPACIDADE QUE A FAIXA DE 7,5 GHZ PODE OPERAR..................................................57

TABELA 18. CO EM FUNÇÃO DA ALTITUDE DAS ANTENAS E TIPO DE TERRENO...........................71

TABELA 19. FATOR DE PIORA PARA DIVERSIDADE NA CONFIGURAÇÃO (N+1).............................73

TABELA 20. EXEMPLO PLANILHA DE CÁLCULO DE DESEMPENHO E DISPONIBILIDADE.........78

TABELA 21. INTERFERÊNCIA CANAL ADJACENTE.......................................................................

TABELA 22. CÁLCULO DE INTERFERÊNCIA (EST1-EST2)....................................................................89

TABELA 23. CÁLCULO DE INTERFERÊNCIA (EST2-EST1)_....................................................................92 


\section{RESUMO}

Apesar da grande concorrência com o sistema via fibra óptica, o rádio digital possui suas aplicações asseguradas, tornando o estudo do cálculo de desempenho, disponibilidade e interferências necessários. $\mathrm{O}$ organismo internacional que define a padronização de desempenho é o ITU-R, onde foi estabelecido que o SES (segundos severamente afetados) é o parâmetro mais crítico, definindo o limiar de operação do sistema. De acordo com o ITU-T a disponibilidade de um sistema é avaliada durante um período de um ano (sendo a média anual), enquanto o desempenho é avaliado mensalmente (escolhendo-se o pior mês).

Neste projeto será discutido um dos métodos para a validação e verificação do desempenho e disponibilidade de sistemas de radioenlace, tendo como objetivo final, atender todas as especificações definidas pelo ITU, para que o usuário tenha uma conexão de qualidade e capacitada para atender os serviços solicitados. Também será mostrado uma metodologia para o cálculo de interferência, parâmetro muito importante que deve sempre ser verificado, pois em diversas situações é capaz de derrubar o sistema provocando o SES.

Antes da metodologia do cálculo em questão, será apresentado a configuração sistêmica, discutindo e conhecendo os equipamentos e sistema aéreo, tais como o tipo de topologia, freqüência utilizada, configuração do rádio, modulação e demodulação, branching, entre outros, além das possíveis contramedidas realizáveis, para o caso da necessidade de melhorar o desempenho e a disponibilidade, como para 0 caso onde se têm problemas de propagação. Para o caso da propagação, 

diversos fenômenos ocorridos na propagação de uma onda de rádio serão vistos, originando a partir destas observações, critérios de visibilidade que auxiliará na definição dos cálculos das alturas das antenas, que dependem, fundamentalmente, da porcentagem do raio de Fresnel que necessariamente estará liberado.

Para o caso do dimensionamento de radioenlace é necessário a definição do plano de freqüência a ser utilizado. Para esta seleção utilizam-se diversos mecanismos, que possuem a finalidade de minimizar, ao máximo, as interferências, pois qualquer tipo de degradação é prejudicial ao desempenho e disponibilidade do sistema.

Para finalizar, serão desenvolvidas planilhas, onde o cálculo de desempenho e disponibilidade, além do cálculo das interferências, serão demonstrados, contabilizando todas as atenuações e ganhos referentes ao problema em questão. Serão mostrados todos os passos, com todas as fórmulas, tentando ser o mais didático possível. 


\section{Capítulo 1 - Introdução}

Devido a crescente demanda de serviços, as empresas de telecomunicações estão digitalizando as suas redes, como a única maneira racional e econômica de solucionar este problema. Não obstante, a área de rádio também vem acompanhando esta tendência. Atualmente, todos os novos sistemas implantados via rádio são digitais, onde os rádios analógicos foram substituídos gradativamente pela empresas de telecomunicação. Apesar de sofrer uma grande concorrência com o sistema de transmissão via fibra óptica, para grandes rotas e com alta capacidade, o rádio digital continua tendo sua faixa assegurada principalmente para sistemas de média e baixa capacidade. A tecnologia de rádio digital introduziu parâmetros adicionais que requer maior cuidado em comparação com a tecnologia analógica. É sabido que o rádio digital é muito mais vulnerável às variações de propagação do que os rádios analógicos, merecendo cuidados especiais no dimensionamento destes sistemas.

\subsection{Padronização para critérios de qualidade}

O dimensionamento de radioenlace possui uma padronização cujo objetivo é de assegurar uma qualidade mínima para os serviços de telecomunicações como também integrá-los a nível regional, nacional e internacional. O órgão que define estes padrões de desempenho é o ITU-R. Esta padronização é apresentada na forma de Recomendações e "Reports" para circuitos hipotéticos de referência. A sua aplicação em circuitos reais deve ser feita com bastante discernimento.

O ITU-R estabelece critérios de qualidade em porcentagens de tempo qualificados para diferentes comprimentos de rota e classes de qualidade ${ }^{[1]}$. A Fig. 1.a mostra uma conexão hipotética de referência de $27.500 \mathrm{~km}$ que inclui a maioria dos casos reais de uma conexão internacional com equipamentos de transmissão, multiplexadores, comutação e rede local. A Fig. 1.b representa o circuito hipotético de referência de $280 \mathrm{~km}$ ou $50 \mathrm{~km}$ com diferentes classificações. As recomendações de ITU-R 594-5 e 695-5 estabelecem objetivos para as seções entre 280 e 2.500 km. Para seções menores que 280 km o ITU-R ainda não concluiu os seus estudos de 

forma definitiva, entretanto alguns países têm adotado valores próximos enquanto aguarda a conclusão dos estudos.

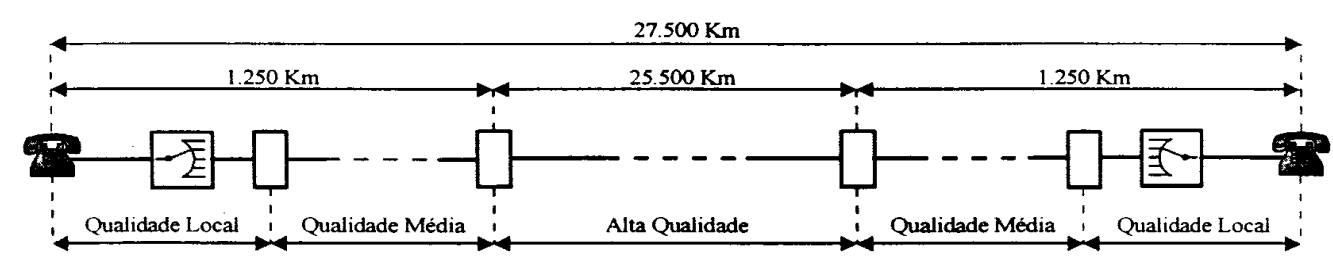

(a)

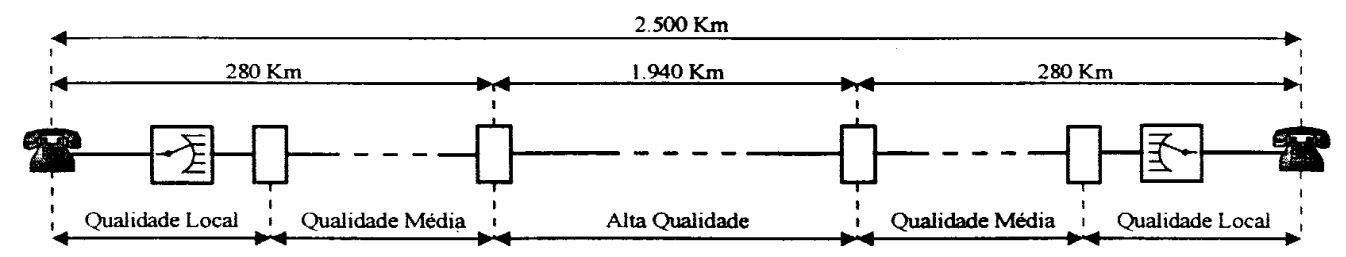

(b)

Figura 1: Circuitos hipotéticos de referência.

A tabela $1^{[1]}$ apresenta os objetivos de qualidades estabelecido pelo ITU-R, através das recomendações 557-4, 594-2, 696-1 e 697-2, com base no circuito hipotético de referência de $2.500 \mathrm{~km}$ da figura 1.b.

Tabela 1. Recomendações do ITU-R.

\begin{tabular}{|c||c||c|c|c|c||c||}
\hline \hline Recomendações & \multicolumn{1}{|c||}{$\begin{array}{c}\text { Alta Qualid. } \\
\text { High Grade }\end{array}$} & \multicolumn{3}{c||}{ QUALIDADE MÉDIA - MEDIUM GRADE } & QUAL. \\
LOCAL \\
\hline \hline Distância Máxima & $\begin{array}{c}\text { Classe 1 } \\
2.500 \mathrm{~km}\end{array}$ & $\begin{array}{c}\text { Classe 1 } \\
280 \mathrm{~km}\end{array}$ & $\begin{array}{c}\text { Classe 2 } \\
280 \mathrm{~km}\end{array}$ & $\begin{array}{c}\text { Classe 3 } \\
50 \mathrm{~km}\end{array}$ & $\begin{array}{c}\text { Classe } 4 \\
50 \mathrm{~km}\end{array}$ & $50 \mathrm{~km}$ \\
\hline $\begin{array}{c}\text { Taxa de Segundos Severamente } \\
\text { Errados - SES - BER }=10^{-3}\end{array}$ & 0,00054 & 0,00006 & 0,000075 & 0,00002 & 0,00002 & 0,00005 \\
\hline $\begin{array}{c}\text { Taxa de Segundos com Erro - } \\
\text { ES }\end{array}$ & 0,0032 & 0,00036 & 0,0016 & 0,0016 & 0,004 & 0,012 \\
\hline $\begin{array}{c}\text { Minutos Degradados DM - BER } \\
=10^{-6}\end{array}$ & 0,004 & 0,00045 & 0,002 & 0,002 & 0,005 & 0,012 \\
\hline INDISPONIBILIDADE & 0,003 & 0,00033 & 0,0005 & 0,0005 & 0,001 & $0,001 \mathrm{a} 0,01$ \\
\hline
\end{tabular}

Pela tabela 1, verificam-se diferentes qualidades de desempenho, que podem ser divididos em classes. Cada classe possui sua especificação, assim:

1. Alta Qualidade (High Grade): Sistema de Transmissão nacionais ou internacionais de longa distância com altas taxas de transmissão.

2. Média Qualidade (Médium Grade): Podem ser divididos em classes. 
$>$ Classe 1 - Enlaces / Rotas de rádios SDH/155Mbits.

> Classe 2 - Enlaces / Rotas de rádios 16E1/PDH/34Mbits.

> Classe 3 - Enlaces / Rotas de rádios 2E1 a 8E1.

$>$ Classe 4 - Enlaces / Urbanos de rádios 2E1 a 8E1.

3. Qualidade Local (Local Grade): Enlaces / Urbanos de rádios de acesso / em circuitos de 64 kbps.

De acordo com recomendações do ITU-R, tem-se a definição de cinco parâmetros básicos que avaliam a qualidade de sistemas de rádios digitais.

1. Segundos Severamente Afetados (SES): Corresponde à taxa de bits errados pior (maior) que $10^{-3}$, medidos em 1 segundo, que não deve ser superada, em qualquer mês, aos valores estabelecidos pelo ITU-R para os circuitos hipotéticos de referência e calculados de forma equivalente para sistemas reais.

2. Minutos Degradados (DM): Corresponde à taxa de erro pior (maior) que $10^{-6}$ medida em um tempo de 1 minuto, que não deve ultrapassar, em qualquer mês, aos valores estabelecidos pelo ITU-R para os circuitos hipotéticos de referência adaptados proporcionalmente aos sistemas reais.

3. Segundos com pelo Menos um Bit Errado (ES): Não deve ultrapassar o percentual estabelecido por cada mês.

4. Taxa de Erro Residual (R): É a taxa de erro, sem desvanecimento, medida com o tempo de integração de 15 minutos, que não deve ser maior que o valor calculado em função do comprimento da rota.

5. Indisponibilidade: Inicia-se quando a BER em cada segundo é pior que $10^{-3}$ durante um período de 10 segundos consecutivos. Assim estes segundos decorridos fazem parte do tempo de indisponibilidade.

Dentre todos os parâmetros definidos, os únicos a serem utilizados na realização do dimensionamento de radioenlace é o SES e o DM (que corresponde ao SES para a $\left.B E R=10^{-6}\right)$.

Para enlaces individuais de uma rota, calcula-se de forma proporcional em relação ao comprimento da rota. A tabela 2 mostra os dados calculados para cada enlace (exemplo) que têm um comprimento total de $210 \mathrm{~km}$ (fig. 2). 
ROTA DE 5 ENLACES COM L $=210 \mathrm{Km}$

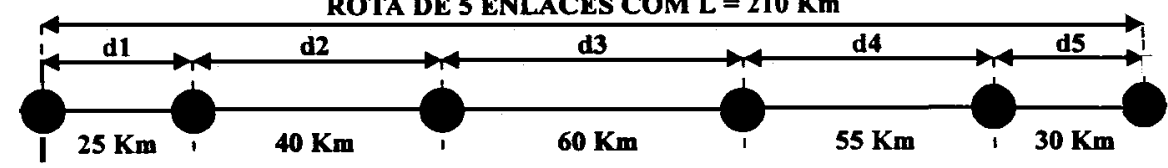

Figura 2. Rota com cinco enlaces.

Tabela 2. Dados enlaces da figura 2 - Medium Grade - Classe 1.

\begin{tabular}{||c||c||ccc||}
\hline Enlace & Comprimento & SES (\%) & DM (\%) & ES (\%) \\
\hline \hline $\mathrm{d} 1$ & $25 \mathrm{~km}$ & 0,0005357 & 0,004018 & 0,003214 \\
\hline $\mathrm{d} 2$ & $40 \mathrm{~km}$ & 0,0008570 & 0,006429 & 0,005143 \\
\hline $\mathrm{d} 3$ & $60 \mathrm{~km}$ & 0,0012860 & 0,009643 & 0,007714 \\
\hline $\mathrm{d} 4$ & $55 \mathrm{~km}$ & 0,0011786 & 0,008839 & 0,007072 \\
\hline $\mathrm{d} 5$ & $30 \mathrm{~km}$ & 0,0006428 & 0,004821 & 0,003857 \\
\hline Total & $\mathbf{2 1 0} \mathbf{~ k m}$ & $\mathbf{0 , 0 0 4 5 0 0 0}$ & $\mathbf{0 , 0 3 3 7 5 0}$ & $\mathbf{0 , 0 2 7 0 0 0}$ \\
\hline
\end{tabular}

Como a rota inteira é menor que $280 \mathrm{~km}$, tem-se que sua modalidade é Medium Grade Classe 1. Assim:

$$
\begin{aligned}
& \mathrm{SES}=\frac{\mathrm{L}}{280} \cdot(0,006 \%)=\frac{210}{280} \cdot(0,006 \%)=0,0045 \% \\
& \mathrm{DM}=\frac{\mathrm{L}}{280} \cdot(0,045 \%)=\frac{210}{280} \cdot(0,045 \%)=0,03375 \% \\
& \mathrm{ES}=\frac{\mathrm{L}}{280} \cdot(0,036 \%)=\frac{210}{280} \cdot(0,036 \%)=0,027 \%
\end{aligned}
$$

Para o enlace de $60 \mathrm{~km}$, tem-se:

$$
\begin{aligned}
& \mathrm{SES}=\frac{\mathrm{L}}{280} \cdot(0,006 \%)=\frac{60}{280} \cdot(0,006 \%)=0,001286 \% \\
& \mathrm{DM}=\frac{\mathrm{L}}{280} \cdot(0,045 \%)=\frac{60}{280} \cdot(0,045 \%)=0,009643 \% \\
& \mathrm{ES}=\frac{\mathrm{L}}{280} \cdot(0,036 \%)=\frac{60}{280} \cdot(0,036 \%)=0,007714 \%
\end{aligned}
$$

Para os demais enlaces segue-se o mesmo procedimento. O resultado encontra-se na tabela 2. 


\subsection{Aplicação deste projeto}

Este projeto é aplicável a todos os rádios digitais ponto a ponto na tecnologia $\mathrm{PDH}$ e SDH, operando em todas as faixas de freqüência regulamentadas pela ANATEL, incluindo as faixas entre $400 \mathrm{MHz}$ e $38 \mathrm{GHz}$. É também aplicável a sistemas de rádios de pequeno, médio e grandes portes, tanto para redes metropolitanas como em redes de longa, médias e curtas distâncias em com capacidade de transmissão variando de 2 a 155 Mbps por canal de RF.

A intenção deste projeto é o dimensionamento de sistemas radioenlace apresentando um roteiro com seus procedimentos e normas envolvidas no projeto de cada enlace por meio de cálculo de desempenho, disponibilidade e interferência. Para tal será utilizado a definição de plano de freqüência.

Outro aspecto a ser levado em conta é que o projeto a ser desenvolvido deve ser elaborado "sob medida" para atender às finalidades a que se destina, sendo assim, um Projeto Sistêmico Otimizado. Isto significa que todos os recursos empregados, como tipo de equipamento, sua configuração, antenas, etc... são escolhidos na medida justa, sem que haja superdimensionamento (desperdícios). Os cálculos devem utilizar margens em certos parâmetros a serem regulados, dependendo do grau de precisão desses parâmetros. Um caso típico são os parâmetros climáticos e topográficos de propagação utilizados no cálculo de desempenho, em que, por não existirem medidas precisas em todas as regiões do país, adotam-se valores aproximados baseados em estatísticas do ITU-R. Assim, a utilização de recursos caros como diversidade de espaço devem ser aplicados somente em enlaces críticos, com elevado comprimento ou com problemas de propagação, e quando outras contramedidas mais econômicas não atenderem às necessidades do link em questão. Para o caso de antenas de alto desempenho devem ser utilizadas somente onde as condições de interferência são mais críticas. No caso de projetos na configuração de rádio $(1+1)$, devem ser utilizados diversidade de freqüência somente em enlaces mais longos, procurando desta forma não desperdiçar os canais de RF disponíveis, não poluindo o espectro desnecessariamente.

Outro parâmetro a ser considerado no Projeto Sistêmico Otimizado, são as interferências nos sistemas existentes, sobretudo em regiões com grande número de 

precisa dos canais de freqüência e polarização combinado com um cálculo preciso não somente das interferências recebidas dos sistemas existentes, mas se os enlaces a serem implantados não irão interferir os existentes.

Existem situações onde para determinadas freqüências em uma região 0 espectro encontra-se saturado, não existindo canais de RF disponíveis para a ligação de um enlace. Nesta situação, é necessário à escolha de outra freqüência, podendo acarretar em um gasto maior, como a utilização de guias de onda ou a aquisição de antenas com maior diâmetro, por exemplo.

\subsection{Sistema rádio ponto a ponto}

O sistema rádio ponto a ponto (ou radiovisibilidade) caracterizou-se por muito tempo como o principal meio de transmissão de alta capacidade. Em um sistema de radiovisibilidade, é possível o transporte de informação entre duas estações distantes entre si de $50 \mathrm{~km}$ ou mais, dependendo das condições topográficas, faixa de freqüências e capacidade.

Basicamente, o sistema de cada estação é composto por um conjunto de transceptores, uma linha de transmissão e um elemento radiante.

A principal função do transceptor é adequar a informação às características elétricas necessárias à sua transmissão, em termos de freqüências, amplitude e fase. Isto é possível por intermédio de processos conhecidos por modulação, conversão e amplificação.

Quanto à linha de transmissão, tem-se que ela permite a transferência do sinal modulado (portadora) no transceptor até o elemento radiante.

Por fim, o elemento radiante é um transdutor de energia eletromagnética guiada para energia eletromagnética radiada no lado da estação transmissora, e vice-versa no lado da receptora ${ }^{[2]}$.

Para o rádio ponto a ponto digital, a principal característica é a transmissão de informações ou sinais modulantes digitais, como por exemplo, os feixes padrões de 2 , 8, 16, 34, 140 e 155 Mbps. 
A primeira etapa para a transmissão de sinal digital é a modulação, onde 0 modulador digital é constituído de alguns circuitos para o tratamento e codificação do sinal de informação. O processo de modulação digital consiste na geração de uma portadora senoidal, em uma freqüência intermediária $(\mathrm{FI})$. Esta portadora gerada é modulada com o sinal modulante digital. Os tipos de modulação mais utilizados são as PSK e QAM. O processo de transmissão de um sinal no rádio digital é finalizado no transmissor que, primeiramente, translada o sinal modulado em freqüência intermediária $(\mathrm{FI})$ para a faixa de radiofrequêencia $(\mathrm{RF})$ em que o rádio opera, então o sinal modulado em RF é amplificado e encaminhado para a antena. No receptor o sinal de radiofreqüência é transladado da faixa de $\mathrm{RF}(\mathrm{GHz})$ para freqüência intermediária $(\mathrm{MHz})$ e o sinal modulado em $\mathrm{Fl}$ é enviado para o demodulador, que retira a informação digital pelo processo de demodulação e decodificação ${ }^{[5]}$.

Resumidamente, este capítulo de introdução vem com o intuito de mostrar os critérios de qualidade que definirá os objetivos estabelecidos pelo ITU-R a serem comparados no cálculo de desempenho e disponibilidade. Além disso, é apresentado de forma direta os tipos de sistemas que este projeto pode ser aplicado, todos de acordo com a regulamentação da Anatel. 


\section{Capítulo 2 - Configuração sistêmica}

Para a escolha da solução mais adequada para um projeto de radioenlace, é preciso o conhecimento das possibilidades referente à composição sistêmica do sistema rádio, incluindo equipamentos e sistema aéreo. De uma forma sucinta, tem-se a seguir, todos os aspectos relativos à composição e configuração dos radioenlaces ponto a ponto, a saber:

- Hierarquias Digitais (PDH e SDH);

- Topologias da Rede;

- Interfaces e Capacidade de Transmissão;

- Faixas de Freqüências;

- Tipos de Equipamentos;

- Tipos de Modulação;

- Composição dos equipamentos;

- Contramedidas;

- Sistema Aéreo.

Todos estes tópicos são baseados no que existe e são utilizados atualmente no mercado existente pelos principais fabricantes e fornecedores.

\subsection{Hierarquias digitais PDH e SDH}

O sistema PDH possui sua divisão em nível de hierarquias, não existindo um padrão mundial. Como conseqüência, há três hierarquias diferentes no mundo. $\mathrm{A}$ figura $3^{[7]}$ mostra os tipos de hierarquias PDH adotadas no mundo.

No caso do SDH, teve-se como objetivo a criação de uma rede digital síncrona com uma interface padrão, objetivando a compatibilização dos vários fabricantes. A partir daí, evoluiu-se para um padrão internacional que compatibiliza as hierarquias existentes (americana, japonesa e européia) a uma taxa bruta de 155,520 Mbps (STM-1). A tabela 3 mostra as taxas de transmissão das hierarquias SDH. 

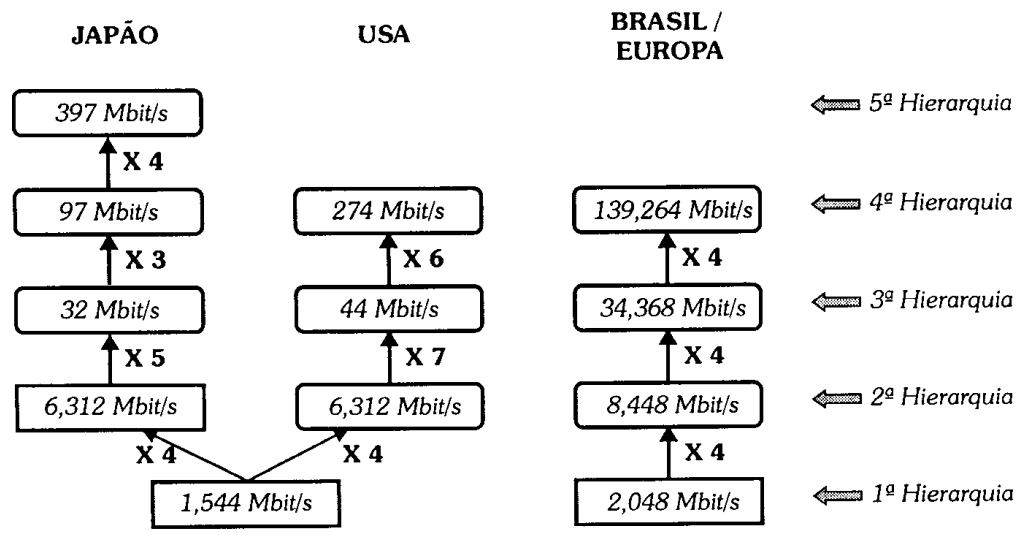

Figura 3. Hierarquia PDH.

Tabela 3. Hierarquia SDH.

\begin{tabular}{|c||c||c|}
\hline STM-N & Taxa de Transmissão & Observação \\
\hline \hline STM-1 & $155,52 \mathrm{Mbps}$ & \\
\hline STM-4 & $622,08 \mathrm{Mbps}$ & $4 \times$ STM-1 \\
\hline STM-16 & $2488,32 \mathrm{Mbps}$ & $16 \times$ STM-1 \\
\hline STM-64 & $9953,28 \mathrm{Mbps}$ & $64 \times$ STM-1 \\
\hline
\end{tabular}

Verifica-se pela figura 3 diferentes sinais de entrada, chamados tributários, na terminologia SDH. Um enlace E1, por exemplo, é um tributário de $2 \mathrm{Mbps}$, onde o processo pelo qual este tributário é encaixado na estrutura de quadro STM-N está mostrado na figura $4^{[7]}$.

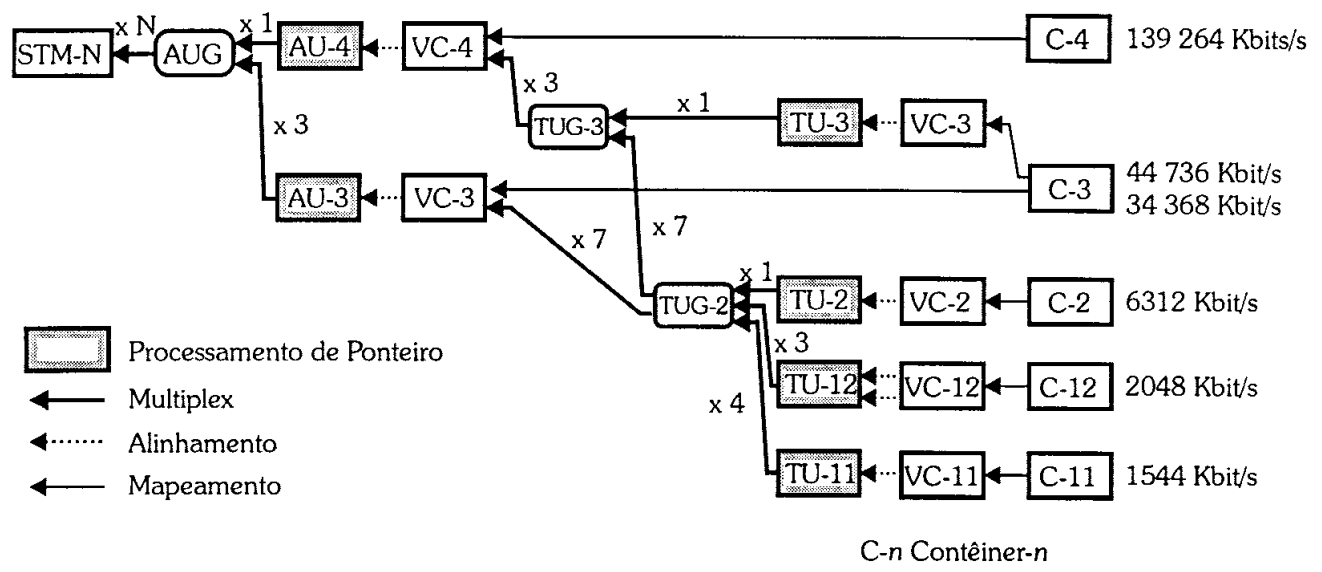

Figura 4. Hierarquia SDH.

Para um rede SDH tem-se os seguintes benefícios:

- Simplificação: Fácil extrair e inserir PCM da rede SDH. 
- Sobrevivência: Todos os elementos de rede estão constantemente supervisionando o funcionamento da transmissão.

- Controle por Software: Os canais disponíveis da estrutura SDH permitem que toda rede seja controlada via software.

- Velocidades maiores sob demanda: Largura de banda suficiente para o estabelecimento de conexões velozes.

- Padronização: Interconexão redes SDH de fabricantes distintos.

Em sistemas rádio ponto a ponto tem-se que as redes $\mathrm{PDH}$ e SDH são largamente utilizadas em conjunto com outros componentes da rede, como multiplexadores e sistemas de fibra óptica. Dentro de uma mesma rede de transporte coexistem sistemas PDH e SDH, onde para os enlaces de acesso, normalmente são constituídos de equipamentos PDH de baixa capacidade.

\subsection{Topologia da Rede}

Será mostrado exemplos de topologia de rede de transporte, constituída somente por radioenlaces ponto a ponto ou em combinação com sistemas de fibra óptica ${ }^{[7]}$.

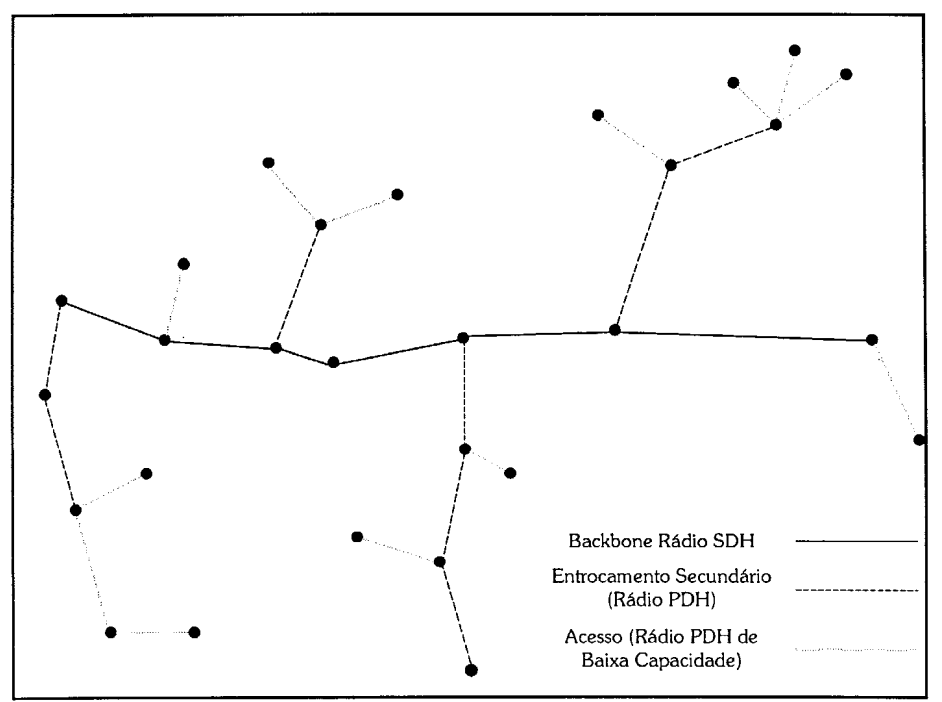

Figura 5. Backbone SDH de longa distância com entrocamento secundário em PDH. 


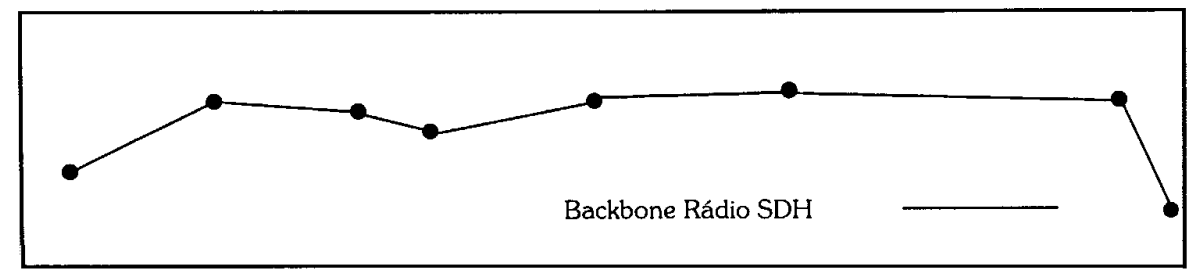

Figura 6. Backbone SDH de longa distância.

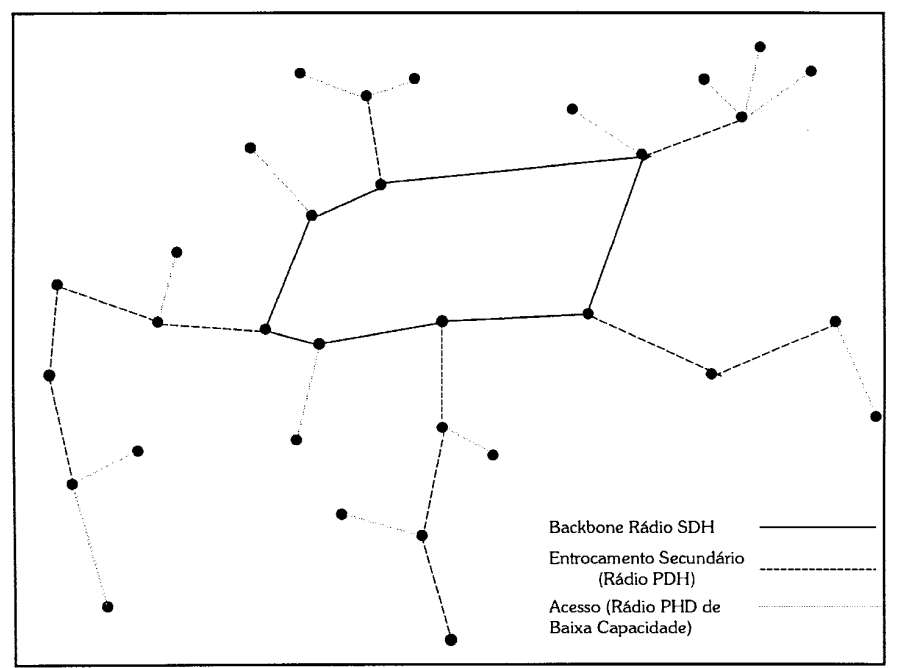

Figura 7. Rede metropolitana em anel de rádios SDH.

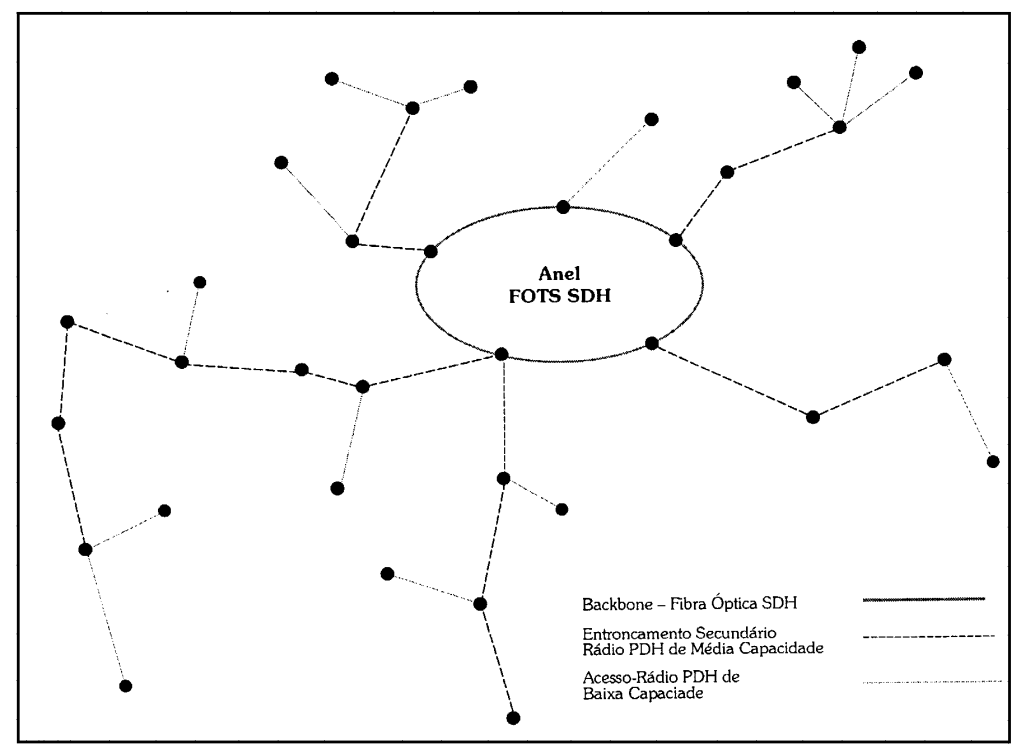

Figura 8. Rede metropolitana constituída de rádios e fibra. 


\subsection{Interfaces e Capacidade de Transmissão}

Dentre os diversos tipos de interfaces, será apresentado as duas mais utilizadas na aplicação rádio ponto a ponto.

- Interface E1 (2 Mbps): Os rádios digitais operam, em muitos casos, em conjunto com multiplexadores $\mathrm{PDH}$, de forma que a interface mais usual é a de $2048 \mathrm{kbps}$, conhecida como interface E1. A quantidade de E1 transmitido depende da capacidade total do rádio. Casos comuns são 2, 4, 8 e $16 \mathrm{E} 1$, onde estes rádios dispensam o uso de equipamentos multiplexadores de ordens superiores.

- Interface STM-1 (155,52 Mbps): Os rádios SDH fornecem interfaces STM-1 por canal de RF (como regra geral), onde para prover interfaces E1 (63 $\mathrm{x}$ E1), utiliza-se multiplexadores SDH.

Para os rádios digitais, a capacidade de transmissão, define três faixas, que possuem uma aplicação típica, como mostra a tabela 4.

Tabela 4. Tipo de rádios por capacidade de transmissão.

\begin{tabular}{|c||c|c|}
\hline Capacidade & Taxa de Transmissão & Aplicação Típica \\
\hline Baixa & Até 4E1 & Acesso \\
\hline Média & 8E1 a 32E1 & Ponto Concentrador \\
\hline Alta & $63 \mathrm{E} 1$ & Backbone / Ponto Concentrador \\
\hline
\end{tabular}

\subsection{Faixas de Freqüências}

Para a aplicação de radioenlace têm-se as seguintes faixas utilizadas:

- Faixas de VHF (30 MHz - $300 \mathrm{MHz})$ e UHF (300 MHz - $3 \mathrm{GHz})^{[5]}$ : Sistemas de propagação em visibilidade, onde as antenas focalizam as ondas, ocasionando uma diminuição da influência do terreno na energia propagada. Utiliza-se o fenômeno da difração, sendo possível operar com sistemas semi-obstruídos. Esta vantagem reflete na determinação das alturas das antenas, pois para freqüências superiores, seria necessária a utilização de torres mais elevadas. Os rádios possuem pequena capacidade de transmissão devido à pequena banda destinada para cada canal. 
- Faixas de SHF (3 GHz - $30 \mathrm{GHz})$ e EHF (30 GHz - $300 \mathrm{GHz}$ ) ${ }^{[7]}$ : Sistemas de propagação em visibilidade, uma vez que as antenas permitem focalizar as ondas, diminuindo a influência do terreno na energia propagada. Para alta capacidade, as faixas de 4 a $8 \mathrm{GHz}$ são mais apropriadas para a utilização em comunicações de rádios, projeto de equipamentos, dimensões das antenas e guias de onda, atingindo enlaces de 30 a $50 \mathrm{~km}$, podendo atingir maiores distâncias, dependendo das condições do enlace e utilização de diversidade de espaço em casos críticos. Para as faixas superiores a $10 \mathrm{GHz}$ a atenuação devido a chuvas atua com maior propriedade, limitando, as distâncias dos enlaces para estas faixas. Com a saturação do espectro, freqüências mais altas estão sendo mais utilizadas, apesar das limitações de distâncias. Entre elas temse as freqüências de 15, 18, 23 e $38 \mathrm{GHz}$. Isto foi possível com a utilização de equipamentos outdoor ou split onde a unidade de RF fica situada na torre, juntamente com a antena, devido à compactação das unidades e componentes, inclusive de RF e a conseqüente eliminação do guia do onda, cuja perda também aumenta muito em função da distância.

Nas tabelas 5 e 6 são apresentados quadros-resumos das capacidades de transmissão por faixa de freqüência regulamentada para a utilização no Brasil ${ }^{[7]}$.

Tabela 5. Capacidade permitida por faixa de frequiência (abaixo de $10 \mathrm{GHz}$ ).

\begin{tabular}{|c|c|c|c|c|c|c|c|c|c|}
\hline $\begin{array}{c}\text { Capacidade } \\
\text { Permitida }\end{array}$ & $\begin{array}{l}400 \\
\mathrm{MHz}\end{array}$ & $\begin{array}{l}1,5 \\
\mathrm{GHz}\end{array}$ & $\begin{array}{c}4 \\
\mathrm{GHz}\end{array}$ & $\begin{array}{c}5 \\
\mathrm{GHz}\end{array}$ & $\begin{array}{c}6 \\
\mathrm{GHz}\end{array}$ & $\begin{array}{l}6,7 \\
\mathrm{GHz}\end{array}$ & $\begin{array}{l}7,5 \\
\mathrm{GHz}\end{array}$ & $\begin{array}{c}8 \\
\mathrm{GHz}\end{array}$ & $\begin{array}{r}8,5 \\
\mathrm{GHz}\end{array}$ \\
\hline $2 \mathrm{E} 1$ & 0 & 0 & $x$ & $x$ & $x$ & $x$ & $\mathrm{O}$ & $x$ & $x$ \\
\hline $4 \mathrm{E} 1$ & 0 & 0 & $x$ & $x$ & $x$ & $\mathrm{X}$ & $\mathrm{O}$ & $\mathrm{X}$ & $\mathrm{X}$ \\
\hline $8 \mathrm{E} 1$ & $x$ & $x$ & $x$ & $x$ & $x$ & $x$ & $\mathrm{O}$ & $x$ & $\mathrm{O}$ \\
\hline 16E1 & $\mathrm{X}$ & $x$ & $\mathrm{X}$ & $x$ & $x$ & $\mathrm{O}$ & $\mathrm{O}$ & $x$ & $\mathrm{O}$ \\
\hline $32 \mathrm{E} 1$ & $x$ & $x$ & $x$ & $x$ & $X$ & $\mathrm{O}$ & $\mathrm{X}$ & $\mathrm{X}$ & $X$ \\
\hline 140MB / STM-1 & $X$ & $x$ & $\mathrm{O}$ & $\mathrm{O}$ & $\mathrm{O}$ & $x$ & $\mathrm{O}$ & $\mathrm{O}$ & $X$ \\
\hline
\end{tabular}


Cálculo de desempenho, disponibilidade e interferências para radioenlace

Tabela 6. Capacidade permitida por faixa de frequiência (acima de $10 \mathrm{GHz}$ ).

\begin{tabular}{|c|c||c||c||c||c||c||c||}
\hline $\begin{array}{c}\text { Capacidade } \\
\text { Permitida }\end{array}$ & $\begin{array}{c}\mathbf{1 1} \\
\mathbf{G H z}\end{array}$ & $\begin{array}{c}\mathbf{1 5} \\
\mathbf{G H z}\end{array}$ & $\begin{array}{c}\mathbf{1 8} \mathbf{G H z} \text { (baixa } \\
\text { capacidade) }\end{array}$ & $\begin{array}{c}\text { 18 GHz (média } \\
\text { e alta } \\
\text { capacidade) }\end{array}$ & $\begin{array}{c}\mathbf{2 3} \\
\mathbf{G H z}\end{array}$ & $\begin{array}{c}\mathbf{2 3} \mathbf{G H z} \text { (alta } \\
\text { capacidade) }\end{array}$ & $\begin{array}{c}\mathbf{3 8} \\
\mathbf{G H z}\end{array}$ \\
\hline $2 \mathrm{E} 1$ & $\mathrm{X}$ & $\mathrm{O}$ & $\mathrm{O}$ & $\mathrm{X}$ & $\mathrm{O}$ & $\mathrm{X}$ & $\mathrm{O}$ \\
\hline $4 \mathrm{E} 1$ & $\mathrm{X}$ & $\mathrm{O}$ & $\mathrm{O}$ & $\mathrm{X}$ & $\mathrm{O}$ & $\mathrm{X}$ & $\mathrm{O}$ \\
\hline $8 \mathrm{E} 1$ & $\mathrm{X}$ & $\mathrm{O}$ & $\mathrm{X}$ & $\mathrm{O}$ & $\mathrm{O}$ & $\mathrm{X}$ & $\mathrm{O}$ \\
\hline $16 \mathrm{E} 1$ & $\mathrm{X}$ & $\mathrm{X}$ & $\mathrm{X}$ & $\mathrm{O}$ & $\mathrm{O}$ & $\mathrm{X}$ & $\mathrm{O}$ \\
\hline $32 \mathrm{E} 1$ & $\mathrm{X}$ & $\mathrm{X}$ & $\mathrm{X}$ & $\mathrm{X}$ & $\mathrm{X}$ & $\mathrm{X}$ & $\mathrm{X}$ \\
\hline $140 \mathrm{MB} / \mathrm{STM}-1$ & $\mathrm{O}$ & $\mathrm{X}$ & $\mathrm{X}$ & $\mathrm{O}$ & $\mathrm{O}$ & $\mathrm{O}$ & $\mathrm{O}$ \\
\hline
\end{tabular}

O: Permitida

X: Não Permitida

Os enlaces de rádios trabalham no sistema Full Duplex, transmitindo e recebendo ao mesmo tempo. Assim, ao se determinar uma freqüência de operação, define-se tanto a freqüência de ida como a de volta, chamado de par de freqüências. Assim, ao se definir a freqüência de Ida F1, a freqüência de Volta $F 1$ ' obrigatoriamente também está definida. A Anatel é o órgão responsável pela definição de todo os pares de freqüências utilizados no Brasil.

\subsection{Modulação e Demodulação}

A modulação e demodulação refletem diretamente no Projeto Sistêmico dos enlaces em nível de desempenho e disponibilidade. Para a modulação, observa-se que quanto mais simples, são menos sensíveis a ruídos, distorções e interferências, mas possui baixa eficiência espectral, ou seja, ocupam uma banda maior por quantidade de informações transmitidas. Para o caso de modulações mais complexas, os equipamentos ficam mais sensíveis a esses fatores citados, e são necessários contramedidas adicionais para garantir o desempenho e a confiabilidade dentro dos padrões exigidos.

A modulação consiste em uma técnica empregada para modificar um sinal com a finalidade de possibilitar o transporte de informações pelo meio de transmissão e recuperar o sinal, na sua forma original, na outra extremidade.

A modulação consiste na alteração de uma ou mais características de uma onda padrão, como a amplitude, fase e freqüência. Os tipos de modulação mais conhecidos são: ASK, FSK, PSK e QAM. Para cada técnica de modulação é estabelecido a largura de banda do sinal modulado. 
A largura de banda do rádio digital em comparação com os analógicos, necessitam de uma banda muito maior. E por este motivo que os sistemas digitais utilizam modulações multiníveis.

Outro aspecto a ser considerado para a largura de banda é o fator de "roll-off" [3] do filtro de $\mathrm{FI}$ do receptor. O filtro ideal para um amplificador $\mathrm{FI}$ no receptor digital deveria ser do tipo Nyquist. Na prática, é muito difícil de ser realizado de forma econômica, tendo curvas que diferem do modelo ideal provocando distorções que dificultam a tomada de decisão dos decodificadores entre os estados 0 ou 1 , provocando um conseqüente aumento na taxa de erro.

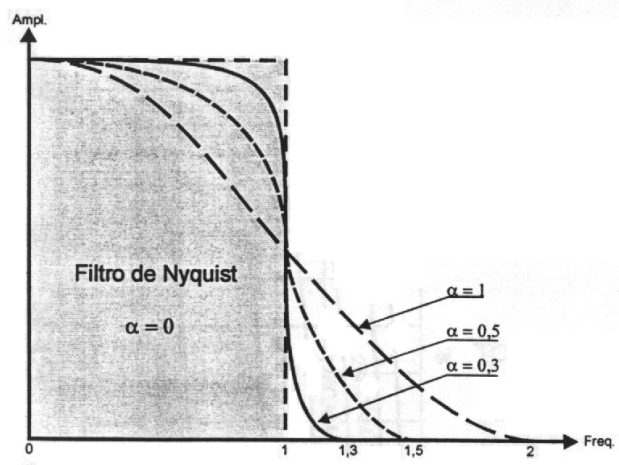

Figura 9. Conceito de fator de "roll-off".

Pela figura 9 observa-se que o fator de "roll-off" indica a posição da banda adicional requerida acima da freqüência de Nyquist. A banda passante do filtro pode ser calculada pela seguinte fórmula ${ }^{[3]}$ :

$$
B=B_{0} \cdot(1+\alpha)
$$

onde: $\mathrm{B}=$ largura de faixa do filtro;

$\mathrm{B}_{0}=$ largura de faixa desejada para o sinal;

$\alpha=$ fator de "roll-off".

Verifica-se na tabela 7 que o nível de modulação é um fator determinante na largura de faixa ocupada pelo transmissor/receptor digital para uma determinada taxa de transmissão[7].

Tabela 7. Eficiência Espectral e banda ocupada. 
Cálculo de desempenho, disponibilidade e interferências para radioenlace

\begin{tabular}{|c||c||c||c||c||c||c||}
\hline Modulação & $\begin{array}{c}\text { Bits / } \\
\text { Símbolo }\end{array}$ & $\begin{array}{c}\text { Capacidade de } \\
\text { transmissão } \\
\text { (Mbps) }\end{array}$ & $\begin{array}{c}\text { Taxa bruta de } \\
\text { transmissão } \\
\text { (Mbps) }\end{array}$ & $\begin{array}{c}\text { Banda } \\
\text { ocupada } \\
\text { (MHz) }\end{array}$ & $\begin{array}{c}\text { Banda } \\
\text { autorizada } \\
\text { (MHz) }\end{array}$ & $\begin{array}{c}\text { Eficiência } \\
\text { espectral } \\
\text { (bits/Hz) }\end{array}$ \\
\hline \hline 4 PSK & 2 & 8,448 & 9,0 & 4,5 & 7 & 1,2 \\
\hline 16 QAM & 4 & 34,368 & 36,6 & 9,15 & 14 & 2,4 \\
\hline 64 QAM & 6 & 155,52 & 180,0 & 30,0 & 40 & 3,9 \\
\hline 128 QAM & 7 & 155,52 & 175,0 & 25,0 & 29,65 & 5,2 \\
\hline
\end{tabular}

\subsection{Curvas de BER}

A qualidade de uma transmissão digital é representada pela BER (taxa de erro de bit), onde o principal parâmetro introdutório de erros para o sinal recebido é o ruído térmico, causado pelo desvanecimento plano; interferência intersimbólica; ao desvanecimento seletivo, e finalmente, as interferências externas.

Baseado na teoria de probabilidade e nos limiares de decisão de um sinal multinível, chega-se à relação entre a $\mathrm{BER}$ e a relação $\mathrm{C} / \mathrm{N}$ (relação portadora-ruído). A tabela 8 mostra a relação $\mathrm{C} / \mathrm{N}$ teóricos por tipo de modulação para as BER de $10^{-6} \mathrm{e}$ 10-3. A figura 10 mostra a relação $\mathrm{C} / \mathrm{N}$ por BER teórico e prático por tipo de modulação. Na prática, devido às imperfeições que ocorrem nos equipamentos, encontram-se curvas até $5 \mathrm{~dB}$ pior em relação às teóricas, isto é, deslocadas para a direita ${ }^{[7]}$.

Tabela 8. Relação C/N x Modulação.

\begin{tabular}{||c||c||c||c||}
\hline \multirow{2}{*}{ Sistema } & Modulação & $\begin{array}{c}\text { Relação C/N para } \\
\text { BER = 10 }\end{array}$ & $\begin{array}{c}\text { Relação C/N para } \\
\text { BER = 10 }\end{array}$ \\
\hline \hline \multirow{2}{*}{ FSK } & 2 & 13,4 & 9,9 \\
& 4 & 23,1 & 19,6 \\
\hline \multirow{4}{*}{ PSK } & 2 & 10,5 & 7,0 \\
& 4 & 13,5 & 10,0 \\
& 8 & 18,8 & 16,3 \\
& 16 & 24,4 & 20,9 \\
\hline \multirow{6}{*}{ QAM } & 16 & 20,5 & 17,0 \\
& 32 & 23,5 & 20,0 \\
& 64 & 26,5 & 23,0 \\
& 128 & 29,5 & 26,0 \\
& 256 & 32,6 & 29,1 \\
& 512 & 35,5 & 32,1 \\
\hline
\end{tabular}




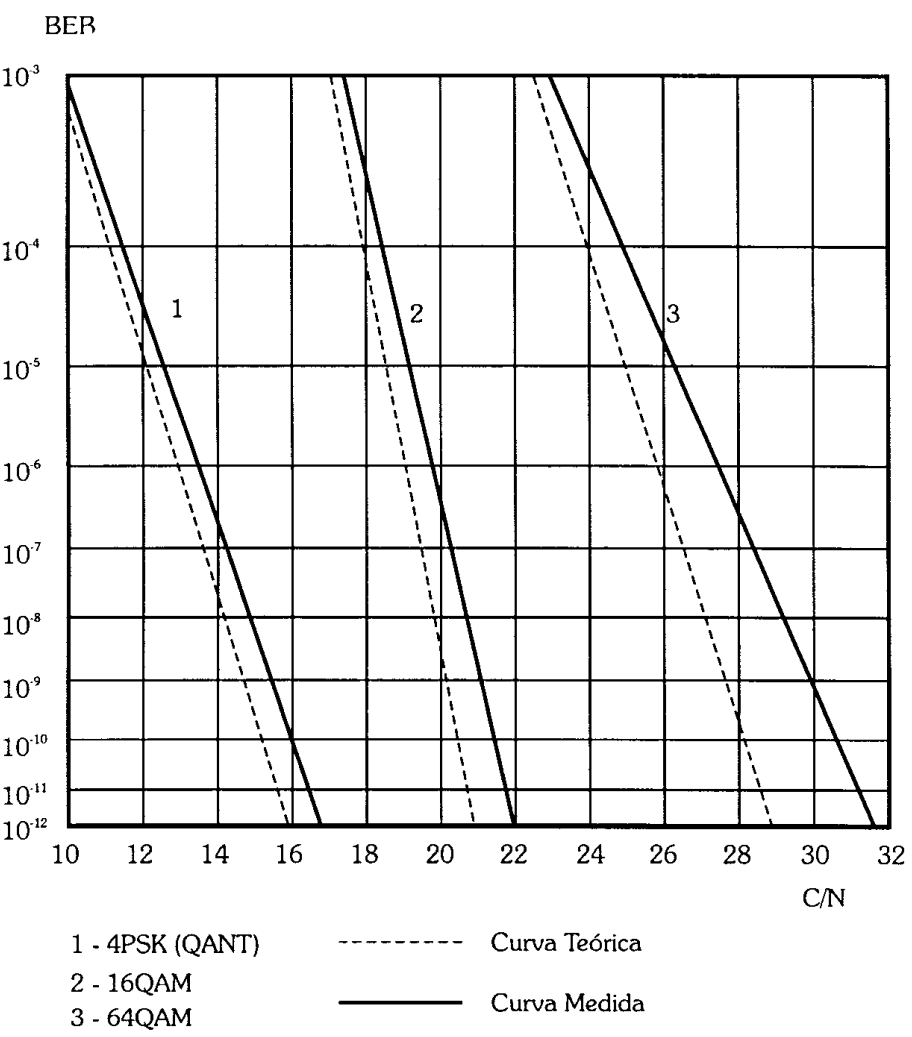

Figura 10. Curva $\mathrm{C} / \mathrm{N}$ típicas de equipamentos rádios.

\subsection{Tipos de Configurações das Estações Rádios}

- Estação Terminal: Estação situada na extremidade da rota, possuindo assim, uma única direção. Possuem modems tipo terminal (ou seja, são providos de funções de comutação de RF e de interface de banda básica).

- Estação Repetidora Simples: Estação com duas direções, sem inserção ou extração de informação. Possui modems mais simples tipo repetidora, provido apenas da função de regeneração do sinal, sem as funções de comutação de RF e interface da banda básica.

- Estação Repetidora com Drop-Insert (D-I): Estação com duas direções, com inserção ou extração de parte do tráfego. Possuem modems tipo terminal nos canais de RF em que há extração/inserção. Nos demais os modems é do tipo repetidora.

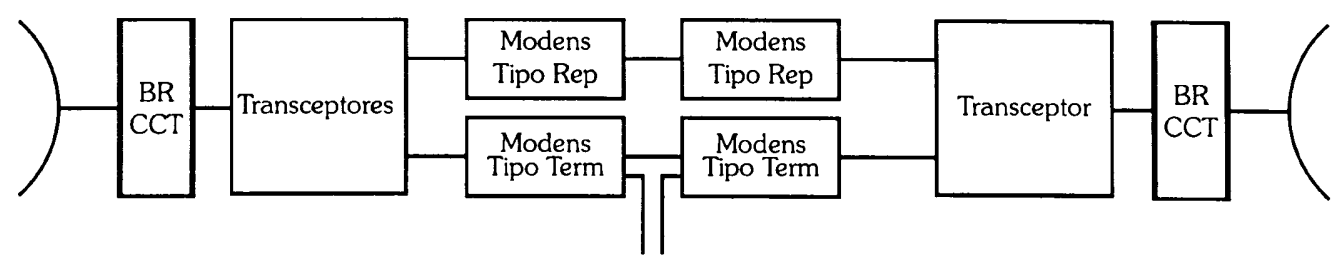


- Repetidora Passiva: É o caso onde a repetição do sinal é realizada por meios de dispositivos passivos, como refletores ou duas antenas conectadas por guia de onda. Este tipo de repetição é usado somente em casos onde não há visada direta entre as duas estações desejadas, sendo possível escolher um ponto de repetição próximo a uma das estações.

- Estação Terminal Múltipla (Back to Back): Estação com duas ou mais direções, situadas em pontos de junções entre uma rota principal e rotas secundárias.

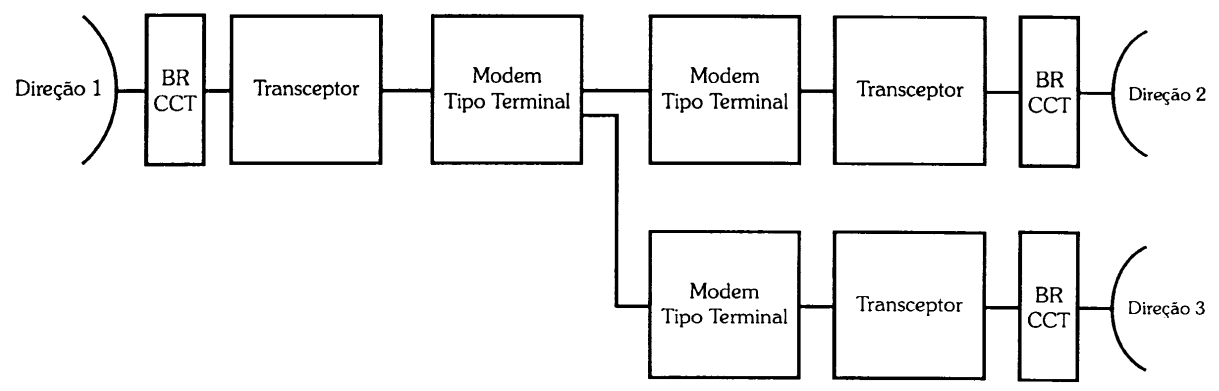

Figura 12. Estação Terminal Múltipla.

\subsection{Blocos Funcionais dos Equipamentos Rádios}

Um rádio enlace é composto de:

- Equipamentos rádios;

- Sistemas radiantes.

Os equipamentos rádios na configuração tipo terminal podem ser subdivididos nos seguintes blocos funcionais:

- Sistema de comutação automática;

- Processamento Digital;

- Modulador - Demodulador (Modem);

- Transmissor - Receptor (Transceptor);

- Circuito de ramificação (Branching).

Em rádios utilizando altas freqüências (superiores a $15 \mathrm{GHz}$ ), a parte correspondente a $\mathrm{RF}$ e $\mathrm{Fl}$, ou seja, o transceptor, é acomodada na torre, junto à antena, sendo conhecida como unidade ODU (outdoor unit), e a parte correspondente 

ao processamento digital e modem fica acomodada na sala de equipamentos, correspondendo à unidade IDU (indoor unit). A conexão entra as unidades ODU e IDU, transportando sinais de $\mathrm{FI}$, alimentação, canais de serviços, supervisão e alarmes, é realizado por um cabo coaxial, possuindo assim, as seguintes vantagens de: Eliminação do guia de onda; Economia de espaço; Diminuição da potência de Transmissão; e economia de energia.

\subsubsection{Sistema de comutação RF}

Todos os equipamentos rádios, com exceção dos rádios na configuração (1+0), são providos de um sistema de comutação RF, tendo como principal finalidade o de proteção do tráfego contra falha de equipamentos e degradação do sinal devido a problemas de propagação.

O sistema de comutação é composto basicamente de:

\section{- Configuração (1+1) Twin Path ou Hot Standby}

Lado de Transmissão: 1) Circuito derivador (híbrida) de banda básica.

Lado de Recepção: 1) Circuitos detectores da qualidade do sinal, também conhecido como iniciadores. Esses detectores monitoram a qualidade em termos da BER e perda de sincronismo; 2) Chave de banda básica.

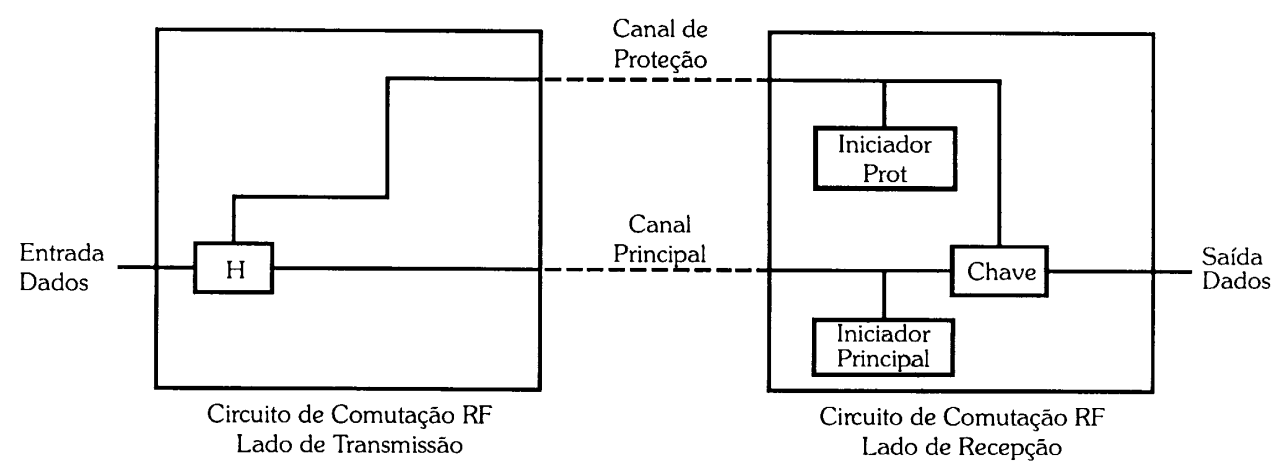

Figura 13. Comutação do Sistema Twin-Path.

No caso dos rádios na configuração $(1+1)$, o mesmo sinal transmitido é entregue simultaneamente ao canal principal e ao de proteção, onde na recepção, o sinal a ser entregue é selecionado mediante certos critérios. O critério mais usual é comutar para o canal de proteção quando o sinal recebido pelo canal principal está pior do que o limiar selecionado. 


\section{- Configuração $(\mathbf{n + 1})$}

Lado de Transmissão: 1) Circuito derivador (híbrida) de banda básica;

2) Chave de banda básica.

Lado de Recepção: 1) Circuitos detectores da qualidade do sinal;

2) Chave de banda básica.

Para os rádios na configuração $(n+1)$, pelo fato de $n$ canais compartilharem um único canal de proteção, este último é ocupado pelo tráfego de um canal principal quando ocorrer falha ou degradação dele, ou seja, só ocorre à comutação da chave de transmissão e conseqüente paralelismo do sinal quando o sistema de controle de comutação solicita este paralelamento na transmissão.

\subsubsection{Branching}

Nos rádios ponto a ponto utiliza-se, normalmente, uma única antena e guia de onda por polarização, operando com vários transmissores e receptores. Para que haja esta acoplamento de diferentes sinais no sentido da transmissão sem interferências mútuas e desacoplá-los novamente na recepção, são utilizados os circuito de derivação ou ramificação ou branching. $O$ branching consiste basicamente de duplexador, cadeias de filtros (passa-faixa), circuladores, isoladores e circuitos de guia de onda ou cabos coaxiais. Os circuladores possuem a característica peculiar de enviar um sinal de RF injetado em uma das portas sempre e somente à porta imediatamente adjacente num determinado sentido de rotação. Para as demais portas, o sinal é bloqueado. A Fig. 14 mostra um branching para o caso do sistema $(1+1)$ "Twin Path" e a figura 15 para o caso do sistema "Hot standby"[]]. 


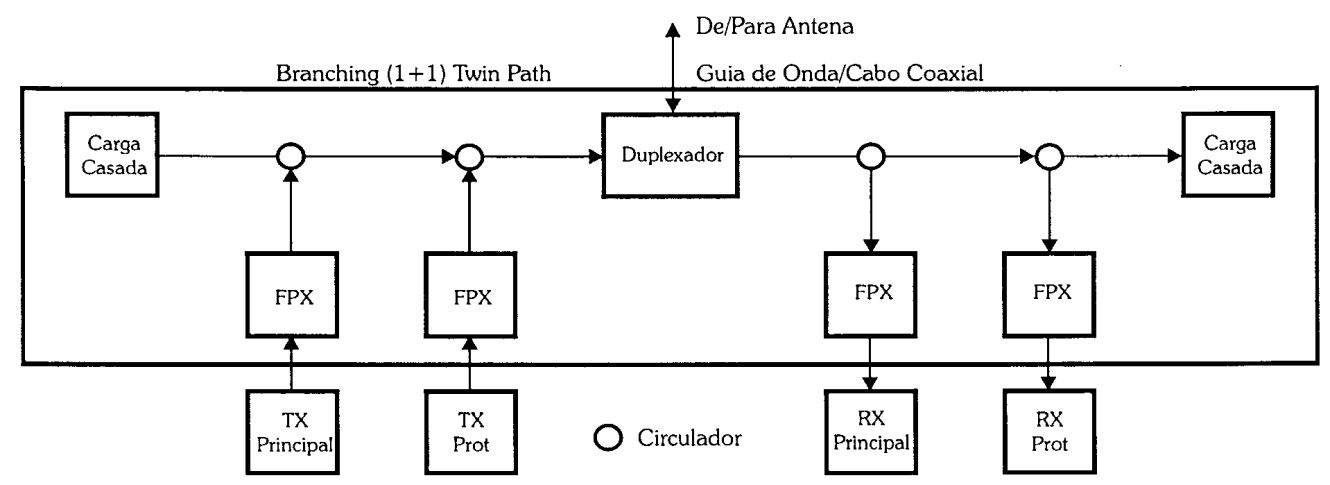

Figura 14. "Branching" no sistema "Twin Path".

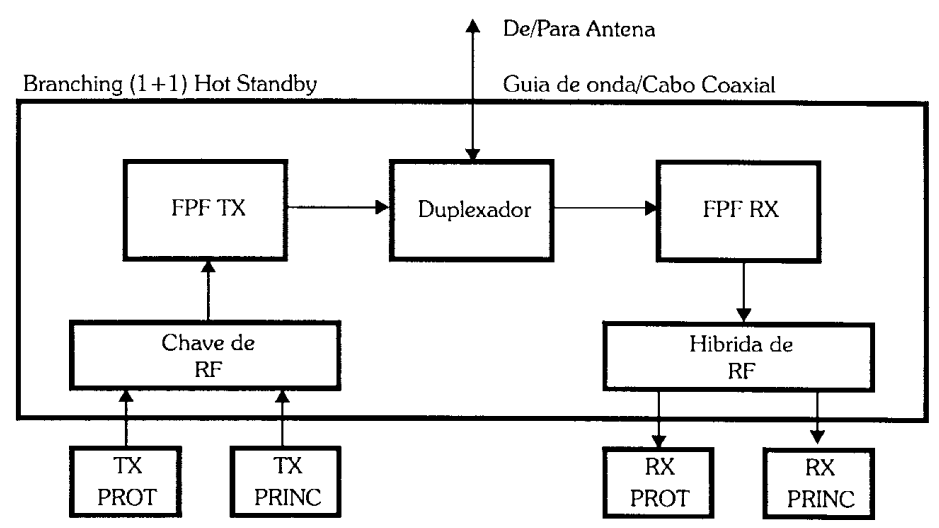

Figura 15. "Branching" no sistema "Hot Standby".

\subsection{Contramedidas}

Os sistemas rádio ponto a ponto utilizam contramedidas para melhorar o seu desempenho e disponibilidade em situações críticas já descritas anteriormente. Alguns recursos, como diversidade de freqüência, são "default" em rádios de alta capacidade, enquanto para rádios de média capacidade são considerados "opcionais". Além dito, com a evolução da tecnologia, alguns recursos considerados caros, como os equalizadores adaptativos e hitless switch que eram inicialmente utilizados somente em rádios de alta capacidade como default, e opcionais em rádios de média capacidades, atualmente, são utilizados em praticamente todos os rádios, exceto em alguns rádios de baixa capacidade. 


\subsubsection{Técnicas de Diversidade}

São técnicas que procuram reduzir os efeitos dos desvanecimentos, na tentativa de obter uma melhor recepção possível. Desvanecimentos são anomalias das características de propagação da atmosfera que tem como conseqüência a degradação dos parâmetros de qualidade dos rádios enlaces digitais. Para implementação da técnica de diversidade, existem diversas possibilidades, onde as mais comumente utilizadas são:

- Diversidade de Freqüência: É a contramedida na qual o mesmo sinal é enviado por dois canais de RF com freqüências diferentes, havendo na recepção a seleção do melhor sinal ou a comutação quando o sinal principal fica indisponível. A Fig. 16 ilustra a diversidade de frequência ${ }^{[1]}$.

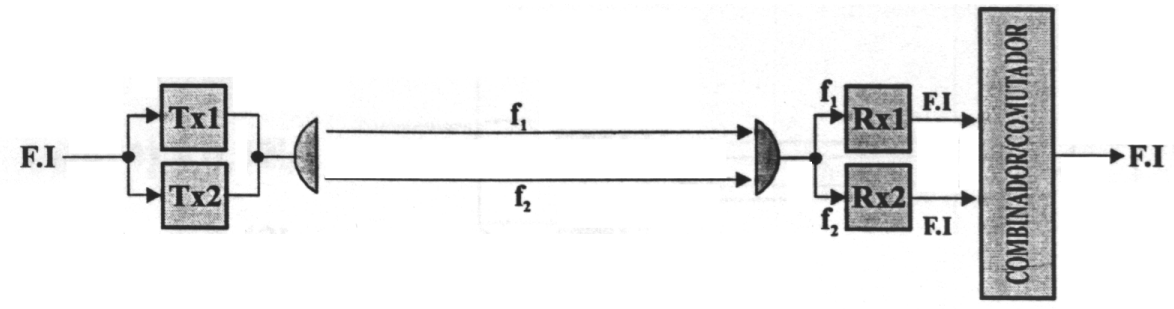

Figura 16. Diversidade de Freqüência.

- Diversidade de Espaço: Consiste em colocar duas antenas de recepção (uma principal e outra de diversidade), onde, a antena principal fica no ponto mais alto e a de diversidade encontram-se alguns metros abaixo, montadas na mesma torre. A Fig. 17 ilustra este fato[1]. Na recepção, o sinal é escolhido através seleção do melhor sinal recebido entre as duas antenas ou a combinação dos dois sinais recebidos.

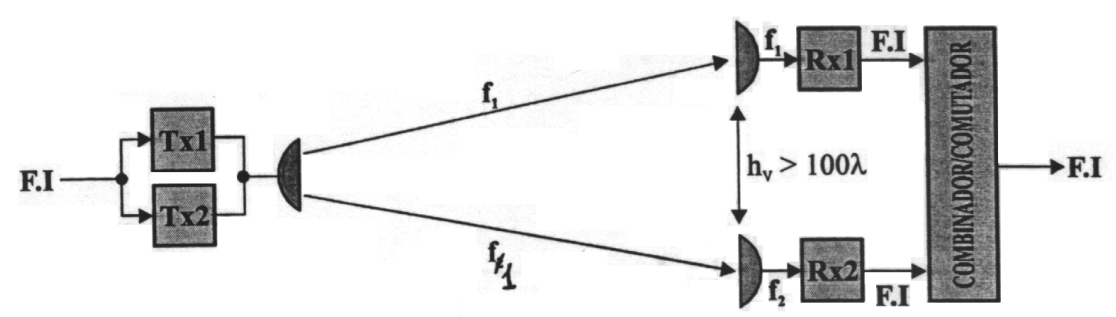

Figura 17. Diversidade de Espaço. 


\subsubsection{Equalizadores Adaptativos}

A função do equalizador adaptativo é de reduzir de forma significativa à dispersão do sinal na faixa de transmissão. Um equalizador adaptativo, por sua vez, possui a capacidade de mudar dinamicamente a função de transferência de sua rede, no sentido de compensar a distorção de forma de onda ou de espectro que está passando naquele momento pelo equalizador do equipamento de recepção.

\subsubsection{Códigos Corretores de Erro (FEC)}

Para rádios que utilizam esquemas de modulação multiníveis superiores a 16 QAM necessitam de contramedidas para melhorar o seu desempenho em termos de BER. O FEC incrementa a melhoria de desempenho do sistema por meio da introdução de bits de redundância pelo codificador de FEC. Estes bits adicionais aumentam a taxa de transmissão, sendo que sua eficiência cresce, com o aumento dessa taxa de redundância. Para rádios ponto a ponto, não é possível utilizar FECs com taxa de redundância alta, para não aumentar a taxa de transmissão e conseqüentemente aumento do espectro do sinal.

\subsubsection{Controle Automático de Potência (ATCP)}

O controle automático de potência (ATPC) é utilizado pra reduzir a interferência entre enlaces adjacentes ou próximos, compartilhando a mesma faixa de freqüências. Essa redução de interferência é conseguida por meio da redução da potência transmitida nas condições normais dos enlaces, aumentando gradativamente até o nível máximo somente na ocorrência de desvanecimento. Assim, o ATPC controla o nível do sinal recebido, por meio de uma monitoração contínua, como pode ser verificado na figura $18^{[7]}$. 


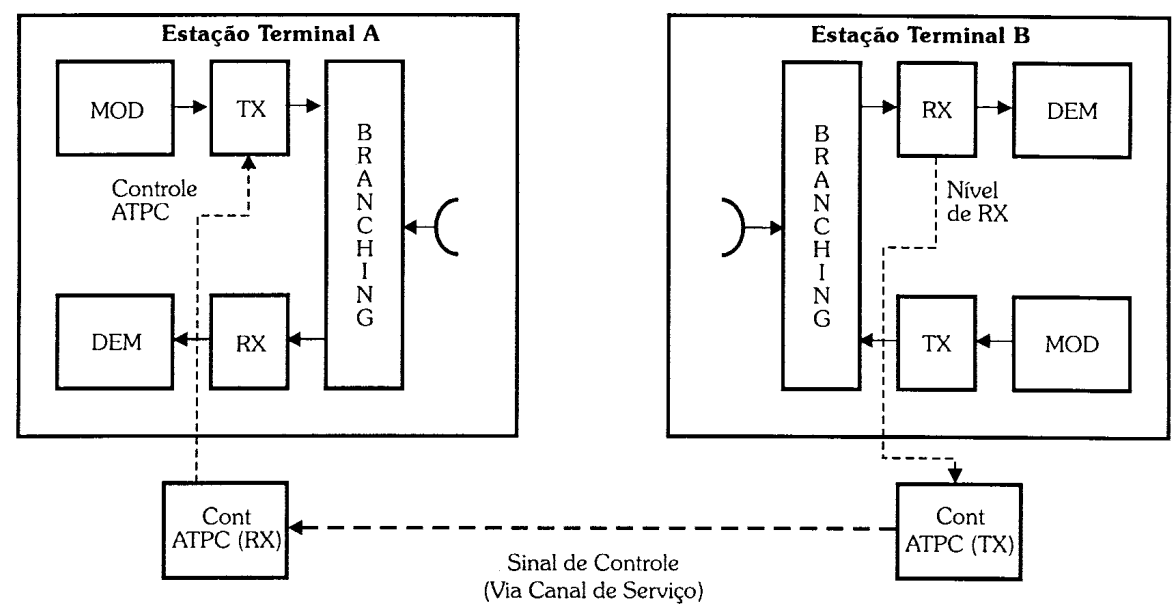

Figura 18. Funcionamento do ATPC.

\subsubsection{Reuso de Freqüência (XPIC)}

Os rádios, principalmente de alta capacidade, trabalham, normalmente, num plano de freqüências com polarização cruzada entre os canais pares e ímpares. O Reuso de Freqüência é o recurso utilizado para duplicar a capacidade do sistema, utilizando o Cancelador de Interferência de Polarização Cruzada (XPIC). Com este recurso, utilizam-se todos os canais nas duas polarizações (Vertical e Horizontal). Este artifício também é utilizado para o caso de interferência. A Fig. 19 mostra o plano intercalado ${ }^{[9]}$, enquanto a figura 20 mostra a situação para o reuso de freqüência ${ }^{[9]}$.

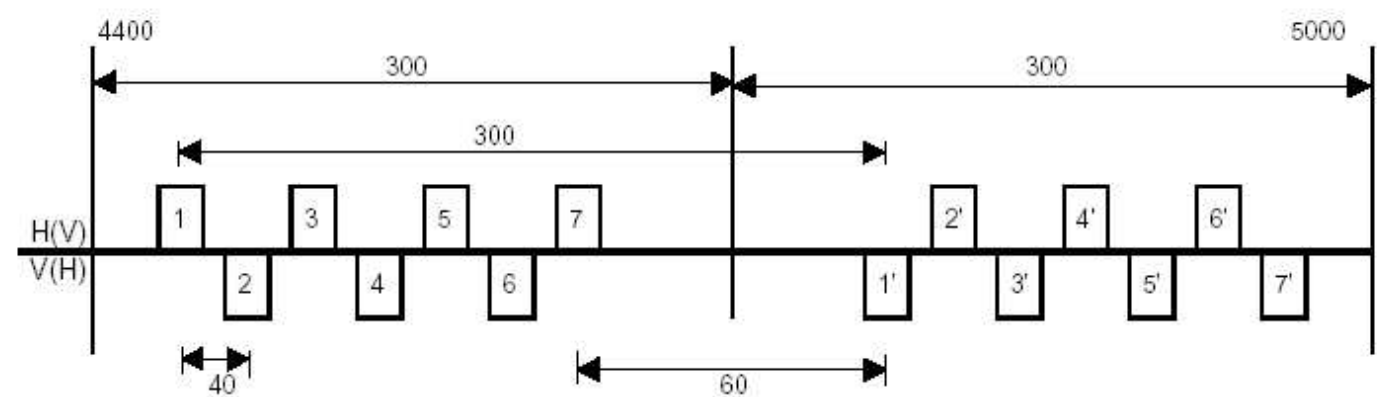

Figura 19. Plano intercalado para faixas de freqüências de $5 \mathrm{GHz}$.

O XPIC é utilizado para reduzir a interferência de um sinal com a mesma freqüência e polarização oposta em relação ao sinal desejado. A eficiência do XPIC é medida pelo parâmetro denominado ganho do XPIC, que é a redução (em dB) da 


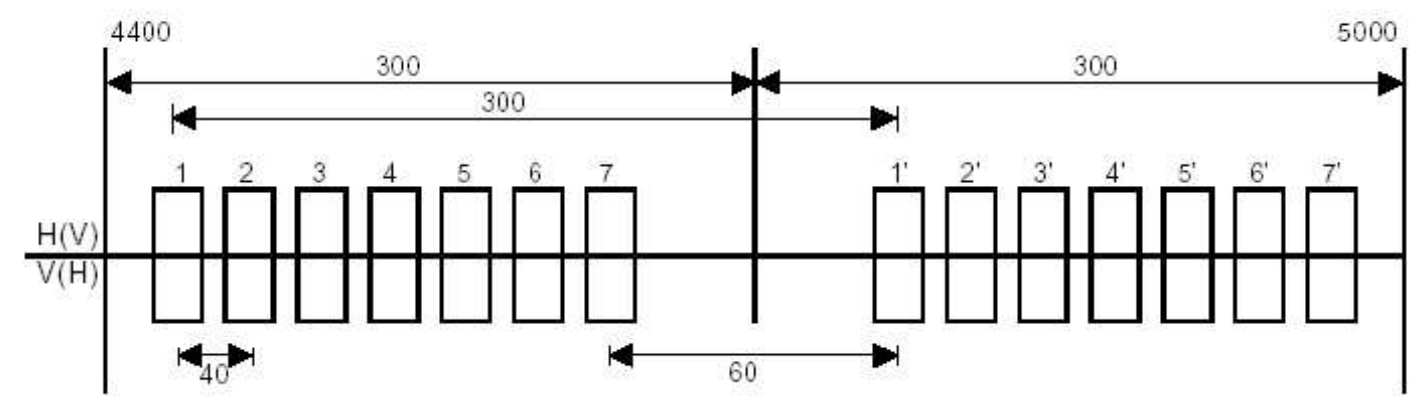

Figura 20. Reuso de freqüências para a faixa de $5 \mathrm{GHz}$.

\subsection{Sistema Aéreo}

Em sistemas rádios um dos problemas mais críticos é a saturação do espectro de freqüências. Desta forma, uma escolha inadequada da antena utilizada pode acarretar problemas de desempenho, conseqüentemente, na confiabilidade dos enlaces, podendo causar interferências em sistemas existentes.

O sistema aéreo é composto basicamente de:

$>\quad$ Antena;

$>\quad$ Cabo coaxial ou guia de onda;

$>\quad$ Conectores;

$>\quad$ Torres / Postes.

\subsubsection{Antenas}

Características principais ${ }^{[7]}$ :

Faixa de Operação (largura de banda da antena): É o intervalo de freqüência na qual a antena opera satisfatoriamente, mantendo suas características dentro das especificações estabelecidas.

Ganho da Antena (dBi): É definido como a relação entre a energia radiada na direção máxima do diagrama de radiação dessa antena e a que seria radiada por uma antena isotrópica ideal em uma direção qualquer, supondo que as duas aceitam a mesma potência total. 
Polarização: É definida pelas características mecânicas da antena e posicionamento do alimentador da mesma.

Discriminação de polarização cruzada (XPD): É a "isolação" do sinal de uma polaridade em relação à outra em uma mesma antena.

Diagrama de Radiação: Mostra de forma gráfica as características da antena no que se refere à potência radiada em relação ao ângulo. Esta característica é utilizada no cálculo de interferência.

Angulo de 1/2 potência: Ocorre quando o sinal transmitido sofre uma queda de $3 \mathrm{~dB}$ com relação a direção de radiação máxima.

Relação Frente-costa: Define-se a relação frente-costa como o nível relativo na direção oposta, pois as antenas radiam nesta direção, podendo interferir nos outros enlaces.

\section{Características mecânicas:}

- Área de exposição ao vento;

-Dimensões físicas;

-Peso.

A carga total da torre é calculada em função do seu peso mais o peso das ferragens de fixação, além de considerar sua área de exposição ao vento.

Como exemplo, tem-se na tabela 9 , as características para antena de microondas para a freqüência de $8,5 \mathrm{GHz}^{[10]}$.

Tabela 9. Características para antenas de microondas para freqüência de 8,5 GHz.

\begin{tabular}{|c|c|c|c|c|c|c|}
\hline Tipo & $\begin{array}{c}\text { Diâmetro } \\
(\mathrm{m})\end{array}$ & $\begin{array}{c}\text { Ganho } \\
\text { (dBi) }\end{array}$ & $\begin{array}{l}\text { Angulo de } \\
1 / 2 \text { potência }\end{array}$ & \begin{tabular}{|c|} 
Disc Pol \\
Cruzada \\
(dB) \\
\end{tabular} & $\begin{array}{c}\text { Relação } \\
\text { Frente/Costa } \\
\text { (dB) }\end{array}$ & $\begin{array}{l}\text { VSWR } \\
\text { máx (dB) }\end{array}$ \\
\hline \multicolumn{7}{|c|}{ HSX High Performance Antennas - Super High Cross Polarization Discrimination } \\
\hline HSX4-82 & 1,2 & 37,6 & 2,3 & 40 & 63 & 1,08 \\
\hline HSX6-82 & 1,8 & 41,8 & 1,4 & 40 & 67 & 1,06 \\
\hline HSX8-82 & 2,4 & 43,8 & 1,0 & 40 & 78 & 1,06 \\
\hline HSX10-82 & 3,0 & 45,4 & 0,8 & 40 & 78 & 1,06 \\
\hline \multicolumn{7}{|c|}{ HPX High Performance Antennas - Dual Polarized } \\
\hline HPX6-82 & 1.8 & 41,0 & 1,3 & 30 & 58 & 1,08 \\
\hline HPX8-82 & 2.4 & 43,5 & 1,0 & 30 & 67 & 1,06 \\
\hline
\end{tabular}


Cálculo de desempenho, disponibilidade e interferências para radioenlace

\begin{tabular}{|c|c|c|c|c|c|c|}
\hline \multicolumn{7}{|c|}{ HP High Performance Antennas - Simple Polarized } \\
\hline HP6-82 & 1,8 & 40,8 & 1,5 & 30 & 68 & 1,06 \\
\hline HP8-82 & 2,4 & 43,5 & 1,1 & 30 & 68 & 1,06 \\
\hline HP10-82 & 3,0 & 45,5 & 0,9 & 30 & 70 & 1,06 \\
\hline HP12-82 & 3,7 & 47,0 & 0,7 & 30 & 71 & 1,06 \\
\hline \multicolumn{7}{|c|}{ PL Standard Antennas - Simple Polarized Low VSWR } \\
\hline PL6-82 & 1,8 & 40,8 & 1,5 & 30 & 48 & 1,06 \\
\hline PL8-82 & 2,4 & 43,5 & 1,1 & 30 & 50 & 1,06 \\
\hline PL10-82 & 3,0 & 45,5 & 0,9 & 30 & 58 & 1,06 \\
\hline PL12-82 & 3,7 & 47,0 & 0,7 & 30 & 54 & 1,06 \\
\hline
\end{tabular}

\subsubsection{Guias de onda e cabo coaxial}

Características principais ${ }^{[7]}$ :

> Faixa de freqüência: Cada guia de onda possui sua faixa de freqüência determinada, onde seu comportamento é específico.

> Perda $(\mathrm{dB} / \mathrm{m})$ : è uma característica importante, sendo que as perdas crescem conforme o aumento da freqüência.

> VSWR: Para o conjunto antena + guia de onda / cabo coaxial, a VSWR deve estar dentro das margens especificada para que os níveis dos sinais refletidos não ultrapassem o limite permitido para o desempenho.

Além das características elétricas as características físicas e mecânicas devem ser consideradas, entre elas:

> Raio mínimo de curvatura (Plano E e Plano H): Para se ter um bom desempenho e a garantia da integridade do guia de onda devem ser obedecidos certos limites especificados pelo fabricante.

> Dimensões e pesos: Considerados no cálculo estrutural da torre.

Como exemplo, têm-se as características eletromecânicas do guia de onda elíptico dos tipos EWP64 e EW64 (tabelas 10 e 11) ${ }^{[10]}$. 
Tabela 10. Característica.

\begin{tabular}{|c||c||}
\hline Elétricas & Mecânicas \\
\hline Faixa de Freqüência & Raio mínimo de curvatura \\
\hline $5,3-7,75 \mathrm{GHz}$ & Plano E $260 \mathrm{~mm}$ \\
\hline & Plano H $685 \mathrm{~mm}$ \\
\hline
\end{tabular}

\subsubsection{Conectores}

Existem diversos tipos de conectores no mercado. Na especificação do cabo ou guia de onda, também estão contidos os tipos de conectores aplicáveis. Cada conector possui uma perda expressa em dB.

\subsubsection{Torres / Postes}

As torres/postes devem ser dimensionados por meio de um estudo de carga, considerando as antenas, guias de onda e cabos a serem instalados, inclusive levando em conta possíveis expansões futuras. Para a situação em que a torre é existente, é necessário fazer um estudo de carga e verificar se ela suporta realmente o projetado.

Existem vários tipos de torres:

- Autoportante: São projetadas para suportar uma grande quantidade de antenas com altura que pode chegar a mais de 120 metros. A Fig. 21 (a) mostra uma torre deste tipo. 
- Estaiada: Economicamente é mais vantajosa que a autoportante (maior capacidade), tendo como desvantagem a necessidade de um maior espaço devido à utilização de estaios. A Fig. 21 (b) mostra um caso.

- Postes: São utilizados quando a altura necessária não é muito grande $(\approx 40$ metros) e o número de antenas é baixo. A Fig. 21 (c) exemplifica um caso em particular.

- Cavaletes: São estruturas pequenas usadas para suportar antenas a um nível pouco acima do solo ou do topo do prédio. A Fig. 21 (d) mostra o exemplo de um cavalete auto-suportado.

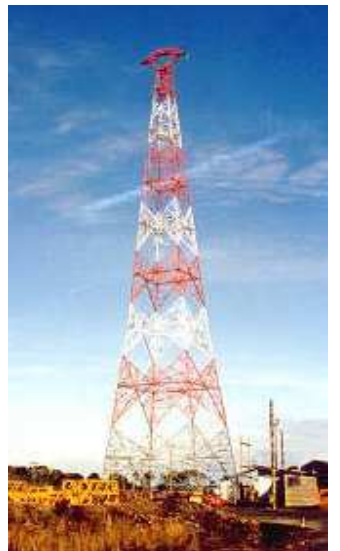

(a)

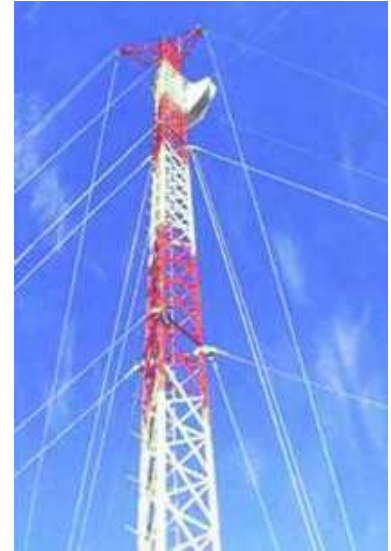

(b)

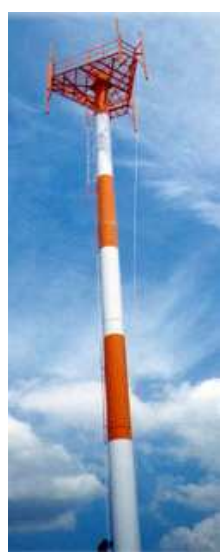

(c)

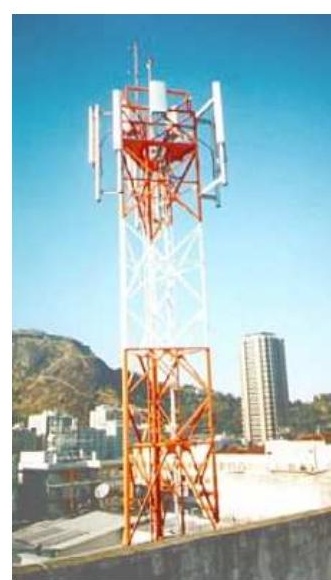

(d)

Figura 21. Tipos de Torres.

Este capítulo teve como objetivo principal mostrar as diversas possibilidades de configuração para sistemas via rádio digital, fornecendo ao projetista, em diversas situações, a oportunidade de avaliar a solução técnico/econômica mais apropriada. Outro aspecto importante é a interação entre as diferentes áreas da engenharia, pois no projeto/implantação de sistemas de radioenlace, é necessário que a área de Infraestrutura esteja presente, opinando na solução mais adequada, referente aos tipos de torres. Esta solução depende de implantações futuras que devem ser tomadas em conjunto com todas as partes envolvidas. 


\section{Capítulo 3 - Definição dos Parâmetros de Equipamentos}

Ainda relacionado com a configuração sistêmica, tem-se os principais parâmetros de equipamentos, cuja definição será utilizada posteriormente para o cálculo de desempenho e de interferência dos enlaces a serem calculados.

Os parâmetros de equipamentos são fornecidos pelos fabricantes/fornecedores, sendo divididos em valores típicos e valores garantidos. Os típicos são valores médios destes parâmetros. Os garantidos são aqueles que o fabricante garantem que todos os equipamentos atendem. Nos projetos sistêmicos são utilizados, normalmente, os valores típicos, onde a utilização dos valores garantidos conduz normalmente ao superdimensionamento. Assim, para garantir uma margem de segurança, somente em alguns parâmetros críticos utilizam-se os valores garantidos.

A seguir segue a definição dos principais parâmetros de equipamentos ${ }^{[7]}$.

Potência de Transmissão ( $\mathrm{W}, \mathrm{mW}, \mathrm{dBm})$ :

A potência de transmissão é normalmente especificada na saída do amplificador de potência.

\section{Perda no Branching (dB)}

A perda no Branching depende da configuração sistêmica. Na configuração $(n+1)$, à medida que aumenta a quantidade de $n$, a perda cresce devido ao aumento da quantidade de circuladores e cabos ou guias.

\section{> Taxa Bruta de Transmissão (Mbps)}

É a taxa total de transmissão, incluindo todos os "overheads" introduzidos pelos equipamentos, como canais de serviços, FEC.

\section{Largura de Faixa de Transmissão (MHz)}

A largura de faixa de transmissão é obtida por meio da divisão da taxa bruta de transmissão pelo nível de modulação. O ITU-R apresenta uma fórmula prática o cálculo da largura de faixa:

$$
B=\frac{1,06 \cdot B_{r} \cdot(1+\alpha)}{\log _{2} \cdot(N)}
$$


onde: $\quad \mathrm{B}_{\mathrm{r}}=$ taxa de transmissão (Mbps);

1,06 = estimativa para todos os "overheads" introduzidos;

$\mathrm{N}$ = numero de níveis de modulação;

$\alpha=$ fator de "roll-off".

É importante ressaltar que um valor mais preciso, para a largura de faixa, é encontrado nos manuais fornecidos pelos fabricantes.

\section{Figura de Ruído no Receptor (dB)}

A figura de ruído no receptor determina o nível de ruído térmico e o conseqüente nível de recepção para uma determinada $\mathrm{BER}$, em função do valor $\mathrm{C} / \mathrm{N}$ para esta taxa.

\section{Relação C/N para uma determinada BER (dB)}

É um parâmetro fundamental que depende da qualidade do equipamento e do tipo de modulação utilizada. A relação $\mathrm{C} / \mathrm{N}$ corresponde a BER que causa SES (segundos severamente errados).

\section{Nível de Recepção para uma determinada BER (dB)}

É um parâmetro que depende da relação $\mathrm{C} / \mathrm{N}$ descrito acima, sendo correspondente a BER que causa SES.

\section{$>$ Curva de Assinatura}

A curva de assinatura determina a maior ou menor imunidade aos fenômenos de desvanecimento seletivo. A curva de assinatura é obtida utilizando o retardo de referência de 6,3 ns e para as taxas de $10^{-3}$ a $10^{-6}$, sendo que a probabilidade de interrupção devido ao desvanecimento seletivo é proporcional à área da curva de assinatura.

O objetivo deste capítulo é introduzir conceitos e definições dos parâmetros dos rádios digitais, onde sua utilidade será comprovada no cálculo de desempenho e disponibilidade. 


\section{Capítulo 4 - Propagação}

\subsection{Zonas de Fresnel}

Ao se considerar uma ligação entre dois pontos $A$ e $B$, o espaço entre as duas localidades pode ser dividido em uma família de elipsóides, chamados de elipsóides de Fresnel. Se for feito um corte transversal das elipsóides de Fresnel, será encontrado as zonas de Fresnel, que são anéis circulares.

Como regra prática, um enlace é considerado com visada direta somente na situação onde não existe obstrução na primeira zona de Fresnel. O raio do elipsóide de uma zona de Fresnel pode ser obtido pela expressão ${ }^{[4]}$ :

$$
\mathrm{R}_{\mathrm{n}}=\left[\frac{\mathrm{n} \cdot \lambda \cdot \mathrm{d}_{1} \cdot \mathrm{d}_{2}}{\mathrm{~d}_{1}+\mathrm{d}_{2}}\right]^{\frac{1}{2}}
$$

Sendo $d_{1}$ e $d_{2}$ as distâncias (em km) entre os pontos A e B e o ponto onde será calculado o raio do elipsóide de Fresnel.

Como será visto mais adiante, todo o dimensionamento de alturas de torres e antenas é baseado no cálculo da porcentagem de liberação da primeira zona de Fresnel.

\subsection{Efeitos Atmosféricos na Propagação}

\subsubsection{Introdução}

Se a onda de rádio está se propagando no espaço livre, onde por definição, não existe atmosfera, a trajetória da onda a ser seguida seria uma linha reta. Contudo, quando se considera a propagação através da atmosfera terrestre, observam-se variações ao longo do percurso, como a capacidade de refração que a atmosfera possui. Observa-se então, que o caminho a ser percorrido pela frente de onda tornase curvo. Esta capacidade de refração atmosférica não afeta somente a curvatura da onda propagada (expressa pelo fator K), mas também contribui para o fenômeno do desvanecimento ${ }^{[4]}$. 


\subsubsection{Troposfera}

É a camada de maior influência para a propagação das ondas de rádios, sendo adjacente a superfície terrestre, atingindo altitude de aproximadamente $11 \mathrm{~km}$. Para uma onda propagada, verifica-se, o efeito da refração.

\subsubsection{Refração}

A refração pode ser definida como a mudança de direção de uma onda quando ela penetra em outro meio. Para o caso da refração das ondas de rádios será necessário o estudo da variação do índice de refração na troposfera, onde ocorre todo o fenômeno da propagação.

Um fator utilizado para calcular a intensidade dos efeitos da refração é o gradiente médio de refratividade $\mathrm{N}$, que é a diferença entre o índice de refração $(\mathrm{n}) \mathrm{a}$ uma altura de $1 \mathrm{~km}$ e $100 \mathrm{~m}$ acima do solo ${ }^{[7]}$.

Como se sabe, tanto a densidade do ar como o índice de refração decrescem com a altitude, assim, toda onda de rádio (UHF e VHF) que percorre a atmosfera faz um arco descendente, já que a onda tende a voltar para o meio com maior índice de refração.

> Fator K: É um fator de escala que auxilia a determinar (quantificar) a curvatura do caminho de uma onda emitida ${ }^{[4]}$. Para o caso de radioenlace é preciso se ter uma linha de visada do rádio, e não visual (geométrica), pois com o efeito da refração atmosférica pode-se alcançar comunicação via rádio $15 \%$ (isto é, $\mathrm{K}=1,33$ ) mais distante que o limite geométrico. A figura $22^{[6]}$ mostra este conceito de um modo simplificado, enquanto a figura $23^{[4]}$ mostra os efeitos das variações do fator $\mathrm{K}$ na curvatura da onda de rádio. Esta curvatura deve-se ao ângulo de refração.

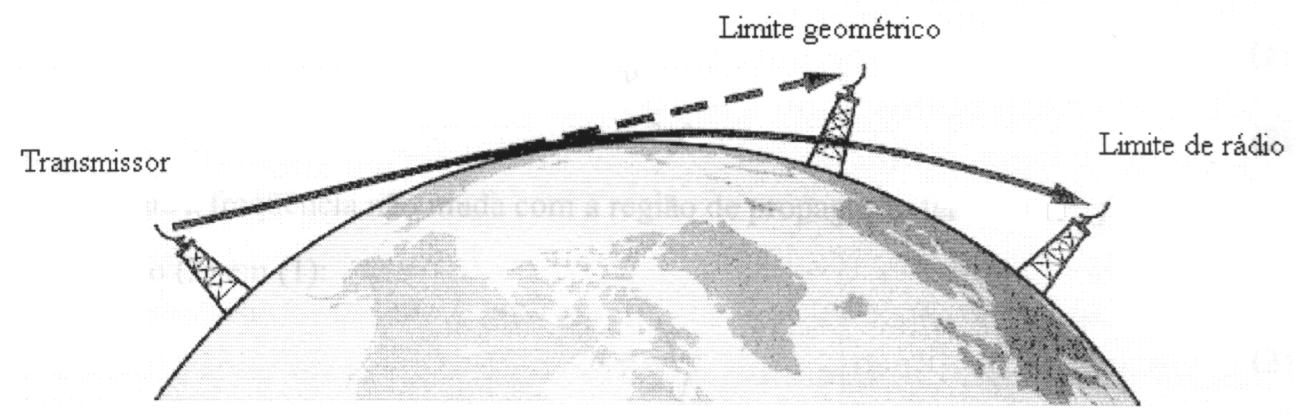




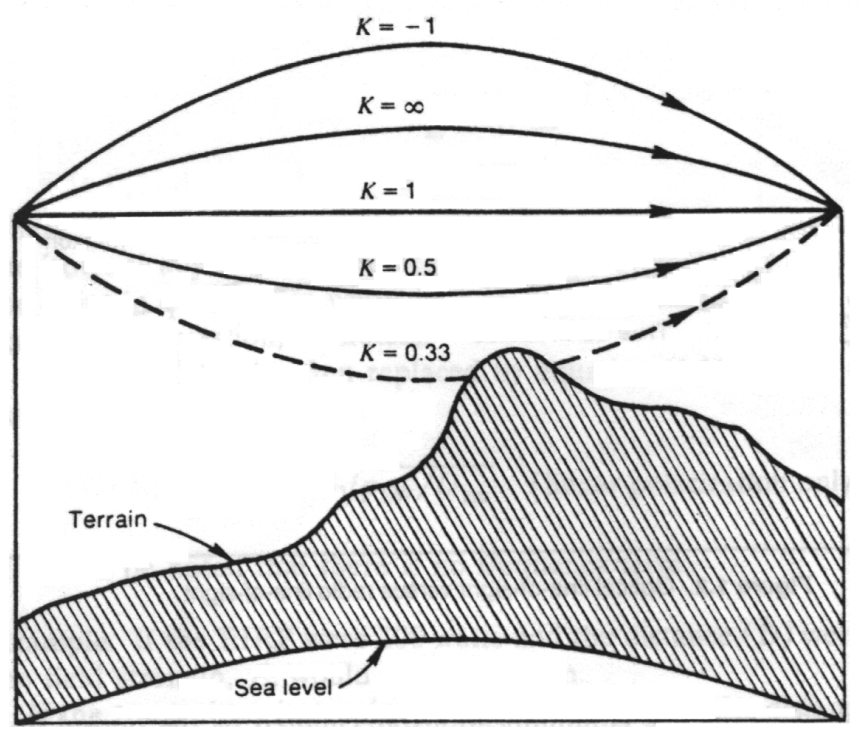

Figura 23. Efeitos da variação do fator K na atmosfera.

Esta curvatura pode ser relacionada diretamente com o raio de uma esfera. A primeira esfera, é a terra, cujo raio vale $6370 \mathrm{~km}$, e a segunda esfera é formada pela curvatura da onda de rádio que está centrado coincidentemente com a terra. $\mathrm{O}$ fator $\mathrm{K}$, pode ser definido como a razão dos dois raios como se segue ${ }^{[4]}$ :

$$
\mathrm{K} \cong \frac{\mathrm{r}}{\mathrm{r}_{0}}
$$

onde: $r=$ raio para a curvatura da onda;

$r_{0}=$ raio verdadeiro da terra;

$\mathrm{K}=$ raio terrestre equivalente.

Verificando a figura 23 onde se encontram diversos valores para $\mathrm{K}$, observa-se à condição de subrefração quando $0<\mathrm{K}<1$, onde o pior caso verificado e quando o sinal é interrompido pela superfície $(K=0,33)$. Em contrapartida, a situação mais freqüentemente encontrada é quando $\infty \geq K \geq 1$. Neste caso a onda possui curvatura próxima a curvatura da terra.

A variação do $\mathrm{K}$ é uma função do clima, da estação, da hora do dia, e/ou das condições do tempo, além de ser afetado pelo terreno e vegetação. Para o projeto de radioenlace, deve-se sempre corrigir o perfil da terra, aplicando dois fatores $\mathrm{K}^{[7]}$ : 
$>\mathrm{O}$ primeiro é o $\mathbf{K}_{\text {médio }}$ para a atmosfera padrão cujo valor definido vale $4 / 3$. Este valor é a média no índice de refração na atmosfera.

> O segundo é o $\mathbf{K}_{\text {mínimo }}$ cujo valor é dado pela recomendação 530-09 do ITU-R, em que o valor de $\mathrm{K}$ varia em função do comprimento do enlace considerado para 99,9\% do tempo no pior mês do ano.

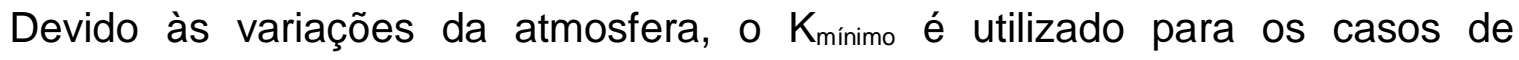
subrefração. Em virtude deste fato, deve-se aplicar uma correção de Terra equivalente para que ela se adeqüe a este fenômeno. Assim, o projetista de sistema deve sempre aplicar os dois fatores para K (médio e mínimo) avaliando os casos mais críticos, adotando-o para o projeto.

Não é difícil perceber que o $\mathrm{K}_{\text {mínimo }}$ será determinante para enlaces longos, pois 0 caminho percorrido será mais susceptível as variações do índice de refração. $\mathrm{Na}$ figura $24^{[7]}$ é mostrada a variação do $K_{\text {mínimo }}$ em função da distância.

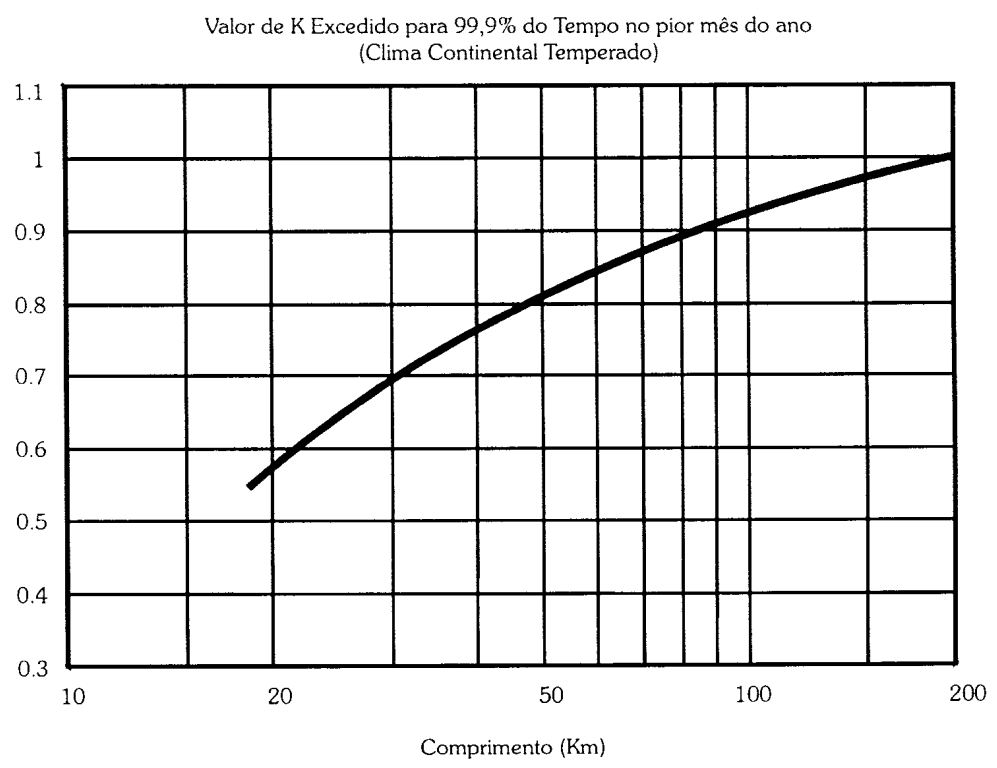

Figura 24. Variação do $K_{\text {mínimo }}$ com a distância.

\subsubsection{Difração}

A difração ocorre quando à frente de onda encontra um obstáculo que é maior comparado com o seu comprimento de onda. Para freqüências abaixo de $1 \mathrm{GHz}$ existe a difração ou desvio de obstáculo com uma crescente atenuação em função da obstrução do obstáculo ${ }^{[4]}$. Para freqüências acima de $1 \mathrm{GHz}$ a atenuação cresce ainda 

percorridos pela onda de rádio. A perda por obstrução depende da área da frente de onda obstruída e das propriedades de difração da obstrução.

Existem diversos tipos de obstáculos, tais como morros, edifícios, árvores e até mesmo a própria superfície terrestre. Outro fator importante que ocorre freqüentemente na prática é a obstrução (parcial ou total) das frentes de onda devido a fatores não existentes na ocasião do projeto. Como exemplo, tem-se o crescimento da vegetação do local. Com isso, deve-se levar em conta, no projeto, todo o tipo de vegetação, juntamente com sua taxa de crescimento.

A perda por difração em sistemas de propagação de rádios sobre terrenos irregulares não é uma ciência exata, isto se deve a grande variação nas formas dos obstáculos encontrados, ficando impossível à apresentação de um modelo matemático que satisfaça plenamente cada uma das obstruções.

Apesar da importância deste fenômeno, não será apresentada nenhuma recomendação, por não ser o objetivo principal deste projeto.

\subsubsection{Reflexão}

A reflexão é um fenômeno que modifica a direção da onda propagada que incidiu sobre uma interface que separa dois meios diferentes retornando para o meio inicial. Este fenômeno é prejudicial à qualidade do sinal recebido, devido à interferência ocorrida pelas multivias. As reflexões ocorrem basicamente entre dois meios:

> Camadas atmosféricas: São de curtas durações (temporárias), podendo ser minimizadas através de equalizadores adaptativos ou diversidade de espaço.

> Solo: Ao contrário da anterior, as reflexões de superfície são permanentes, sendo que quanto mais plana for à superfície, maior será o nível do sinal refletido, comparando até ao nível do sinal direto ${ }^{[7]}$.

\subsubsection{Atenuação devido a chuvas}

Como dito anteriormente, para freqüências superiores a $10 \mathrm{GHz}$, há a atenuação do sinal de rádio devido a chuvas, sendo um fator limitante no comprimento dos 
Cálculo de desempenho, disponibilidade e interferências para radioenlace enlaces, chegando a causar interrupções de sistemas. Coube então ao ITU-R elaborar uma recomendação de disponibilidade mínima para esta situação.

Um método para estimar o efeito da chuva é através de diagramas publicados pelo ITU-R, onde é possível retirar a intensidade de chuva de cada área e país do mundo. A tabela 12 mostra os dados retirados de um mapa da norma 837-1 do ITU-R, onde para o Brasil (zonas $\mathrm{N}$ e P) observa-se às taxas pluviométricas de $95 \mathrm{~mm} / \mathrm{h}$ e $145 \mathrm{~mm} / \mathrm{h}$ respectivamente para $0,01 \%$ do ano ${ }^{[7]}$.

Tabela 12. Taxas pluviométricas por região para várias porcentagens de tempo.

\begin{tabular}{|c||c|c||c||c|c|c|c|c||c|c||c||c||c||c||c||}
\hline $\begin{array}{c}\text { Porcentagem } \\
\text { de tempo (\%) }\end{array}$ & A & B & C & D & E & F & G & H & J & K & L & M & N & P & Q \\
\hline \hline 1 & 0,1 & 0,5 & 0,7 & 2,1 & 0,6 & 1,7 & 3 & 2 & 8 & 1,5 & 2 & 4 & 5 & 12 & 24 \\
\hline 0,3 & 0,8 & 2 & 2,8 & 4,5 & 2,4 & 4,5 & 7 & 4 & 13 & 4,2 & 7 & 11 & 15 & 34 & 49 \\
\hline 0,1 & 2 & 3 & 5 & 8 & 6 & 8 & 12 & 10 & 20 & 12 & 15 & 22 & 35 & 65 & 72 \\
\hline 0,03 & 5 & 6 & 9 & 13 & 12 & 15 & 20 & 18 & 28 & 23 & 33 & 40 & 65 & 105 & 96 \\
\hline 0,01 & 8 & 12 & 15 & 19 & 22 & 28 & 30 & 32 & 35 & 42 & 60 & 63 & 95 & 145 & 115 \\
\hline 0,003 & 14 & 21 & 26 & 29 & 41 & 54 & 45 & 55 & 45 & 70 & 105 & 95 & 140 & 200 & 142 \\
\hline 0,001 & 22 & 32 & 42 & 42 & 70 & 78 & 65 & 83 & 55 & 100 & 150 & 120 & 180 & 250 & 170 \\
\hline
\end{tabular}

O método utilizada neste projeto e aceito para o cálculo de indisponibilidade por chuvas é dado pelas recomendações 837,838 e 721-3, onde se define a atenuação específica $\left(\gamma_{\mathrm{R}}\right)$ para uma determinada freqüência, sendo dependente da polarização da onda e da taxa de precipitação pluviométrica excedida em mais que $0,01 \%$ do tempo do pior mês do ano. A expressão é dada por ${ }^{[1]}$ :

$$
\gamma_{\mathrm{R}}=\mathrm{K} \cdot \mathrm{R}^{\alpha}
$$

onde: $\gamma_{\mathrm{R}}=$ atenuação específica devido a chuva $(\mathrm{dB} / \mathrm{km})$;

$\mathrm{K}_{\mathrm{H}, \mathrm{V}}=$ coeficientes de regressão calculados para as gotículas de chuva. São dependentes da freqüência e polarização. A tabela 13 mostra os valores destes coeficientes de acordo com a recomendação 838.

$R$ = intensidade de precipitação pluviométrica ( $\mathrm{mm} / \mathrm{hora}$ ) excedida em mais de $0,01 \%$ do tempo, sendo obtida pela tabela $13^{[1]}$.

$\mathrm{Na}$ ocorrência de chuva com elevadas intensidades, apenas parte do enlace deve ser considerado no cálculo, já que para enlaces longos a probabilidade de ocorrência de chuva em todo o enlace é mínima. 
O parâmetro "r" define o percentual do enlace que deve haver chuva ${ }^{[1]}$ :

$$
\begin{gathered}
r=\frac{1}{1+\frac{d}{d 0}} \\
d 0=35 \cdot e^{-0,015 \cdot R}
\end{gathered}
$$

onde: $\quad \mathrm{d}=$ distância do enlace $(\mathrm{km})$;

$\mathrm{R}=$ taxa pluviométrica para $0,01 \%$.

Quando R for maior que $100 \mathrm{~mm} / \mathrm{h}$, deve-se utilizar na fórmula (11) o valor de $100 \mathrm{~mm} / \mathrm{h}$. Assim, o diâmetro efetivo da chuva ${ }^{[1]}$ :

$$
\mathrm{d}_{\text {eff }}(\mathrm{km})=\mathrm{r} . \mathrm{d}
$$

A atenuação total devido à chuva é calculada por:

$$
A_{R}=\gamma_{R} \cdot d_{e f f}=K \cdot R^{\alpha} \cdot d_{e f f}
$$

Tabela 13. Valores de K e $\alpha$ em função da polarização e frequiência.

\begin{tabular}{|c||c||c||c|c|}
\hline \hline Freqüência $\mathbf{( G H z )}$ & $\mathbf{K}_{\mathbf{H}}$ & $\mathbf{K}_{\mathbf{v}}$ & $\boldsymbol{\alpha}_{\mathbf{H}}$ & $\boldsymbol{\alpha}_{\mathbf{V}}$ \\
\hline \hline 1 & 0,0000387 & 0,0000352 & 0,912 & 0,880 \\
\hline 2 & 0,0001540 & 0,0001380 & 0,963 & 0,923 \\
\hline 4 & 0,0006500 & 0,0005910 & 1,121 & 1,075 \\
\hline 6 & 0,0017500 & 0,0015500 & 1,308 & 1,265 \\
\hline 7 & 0,0031000 & 0,0026500 & 1,332 & 1,312 \\
\hline 8 & 0,0045400 & 0,0039500 & 1,327 & 1,310 \\
\hline 10 & 0,0101000 & 0,0088700 & 1,276 & 1,264 \\
\hline 11,2 & 0,0132000 & 0,0118000 & 1,242 & 1,220 \\
\hline 12 & 0,0188000 & 0,0168000 & 1,217 & 1,200 \\
\hline 15 & 0,0367000 & 0,0335000 & 1,154 & 1,128 \\
\hline 18,7 & 0,0495000 & 0,0442000 & 1,110 & 1,091 \\
\hline 20 & 0,0751000 & 0,0691000 & 1,099 & 1,065 \\
\hline 22,4 & 0,0789000 & 0,0705000 & 1,067 & 1,049 \\
\hline 25 & 0,1240000 & 0,1130000 & 1,061 & 1,030 \\
\hline 30 & 0,1870000 & 0,1670000 & 1,021 & 1,000 \\
\hline 35 & 0,2630000 & 0,2330000 & 0,979 & 0,963 \\
\hline 40 & 0,3500000 & 0,3100000 & 0,939 & 0,929 \\
\hline & & & & \\
\hline
\end{tabular}


A atenuação causada pela atmosfera, apesar de ser muito menor que as causadas por fenômenos como chuvas e reflexões, deve ser considerada no projeto, principalmente para freqüências elevadas.

O oxigênio e vapor d'água são, basicamente, os dois componentes da atmosfera responsáveis pela atenuação causada. Existe um modelo desenvolvido pelo ITU-R P.76-4, cujo resultado encontra-se na figura $25^{[7]}$. A figura mostra a atenuação por $\mathrm{km}$ para freqüência de 1 a $350 \mathrm{GHz}$ no nível do mar para ar seco e vapor d'água com densidade de $7,5 \mathrm{~g} / \mathrm{m}^{3}$. Pela figura pode-se obter as seguintes conclusões:

> Até a freqüência de $8 \mathrm{GHz}$, tem-se, praticamente, apenas atenuação por ar seco, chegando a uma atenuação máxima de $0,54 \mathrm{~dB}$;

> A partir da freqüência de $11 \mathrm{GHz}$ verifica-se a atenuação por vapor d'água podendo chegar para $30 \mathrm{~km}$ uma atenuação de $0,42 \mathrm{~dB}$;

> Para as demais freqüências deste projeto $(15,18,23$ e $38 \mathrm{GHz})$ observa-se atenuação por ar seco e vapor d'água, podendo ter uma perda de até 1,6 dB.

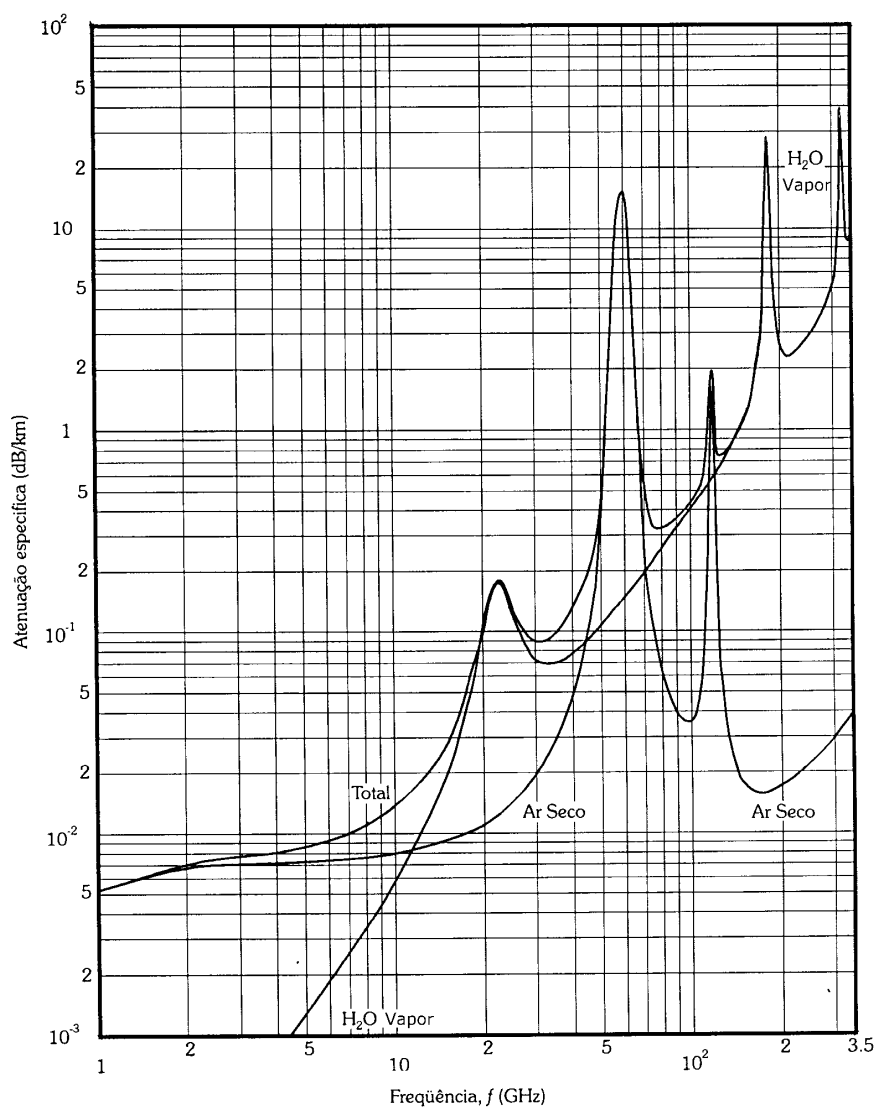

Figura 25. Atenuação devido à atmosfera devido ao ar seco e vapor d'água a 7,5g/m³. 


\subsubsection{Critérios de Visibilidade}

Aproveitando que o assunto é propagação, serão definidos os critérios de visibilidade. Para tal é preciso, primeiramente, conhecer o perfil do enlace que pode ser obtido pelas cartas topográficas ou levantamento de campo. Atualmente existem softwares de cálculo de desempenho e interferência que digitalizam as cartas topográficas sendo possível à obtenção de um perfil com mais agilidade e praticidade, além é claro da confiabilidade.

Após o conhecimento do perfil, deve-se aplicar o fator $\mathrm{K}$, para correção equivalente da curvatura da Terra. Esta correção é feita por algumas empresas para $\mathrm{K}_{\text {mínimo }}=2 / 3$ e $\mathrm{K}_{\text {médio }}=4 / 3$, independente da situação em questão. Este padrão adotado, em certas ocasiões, superdimensiona as alturas das antenas para enlaces longos, já que o valor de $\mathrm{K}_{\text {mínimo }}$ determinará esta altura.

Outro modo seria utilizar a recomendação do ITU-R 530-09 que determina $\mathrm{K}_{\text {mínimo }}$ para 99,9\% do tempo no pior mês do ano em função da distância (conforme figura 24), otimizando assim, diversos projetos de rádio enlace.

Corrigido o perfil, serão determinadas as alturas das antenas em função da porcentagem do raio de Fresnel que terá que ser liberado. A tabela 14 mostra o valor a ser utilizado de acordo com a freqüência ${ }^{[7]}$.

Tabela 14. Porcentagem do raio de Fresnel x Freqüência.

\begin{tabular}{|c|c|c||}
\hline$<\mathbf{1 ~ G H z}$ & Entre 1 e 3 GHz & Acima de $\mathbf{3 ~ G H z}$ \\
\hline $\begin{array}{c}30 \% \text { do raio de } \\
\text { Fresnel para } \mathrm{K}_{\text {médio }}\end{array}$ & $\begin{array}{c}60 \% \text { do raio de } \\
\text { Fresnel para } \mathrm{K}_{\text {médio }}\end{array}$ & $\begin{array}{c}100 \% \text { do raio de } \\
\text { Fresnel para } \mathrm{K}_{\text {médio }}\end{array}$ \\
\hline $\begin{array}{c}10 \% \text { do raio de } \\
\text { Fresnel para } \mathrm{K}_{\text {mínimo }}\end{array}$ & $\begin{array}{c}30 \% \text { do raio de } \\
\text { Fresnel para } \mathrm{K}_{\text {minimo }}\end{array}$ & $\begin{array}{c}60 \% \text { do raio de } \\
\text { Fresnel para } \mathrm{K}_{\text {mínimo }}\end{array}$ \\
\hline
\end{tabular}

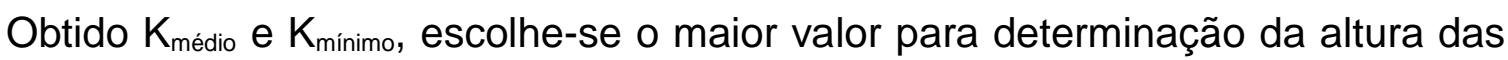
antenas do enlace em questão.

$\mathrm{Na}$ tabela 15, encontra-se um exemplo de dimensionamento das alturas das antenas. A freqüência do enlace é $4,7 \mathrm{GHz}$. Para o $\mathrm{K}_{\text {mínimo }}$ utilizou-se o valor de 0,67 , mas será verificado qual é a diferença para o valor de 0,75 encontrado para a distância de 35 km de acordo com a figura 24 . 
Cálculo de desempenho, disponibilidade e interferências para radioenlace

Tabela 15. Cálculo da altura das antenas para frequiência acima de $3 \mathrm{GHz}$.

\begin{tabular}{|c|c|c|c|c|c|}
\hline \multicolumn{6}{|l|}{ Cálculo de Altura das Antenas } \\
\hline Nome da Estação A & \multicolumn{5}{|c|}{ A } \\
\hline Nome da Estação B & \multicolumn{5}{|c|}{$\mathrm{B}$} \\
\hline Freqüência do enlace $(\mathrm{GHz})$ & \multicolumn{5}{|c|}{4,7} \\
\hline Coordenadas da estação A & \begin{tabular}{|l|l|}
15 & 47 \\
\end{tabular} & 56,0 & 47 & 46 & 80,0 \\
\hline Coordenadas da estação B & \begin{tabular}{|l|l|}
15 & 47 \\
\end{tabular} & 50,0 & 47 & 45 & 69,7 \\
\hline Distância do obstáculo à estação A (km) & \multicolumn{5}{|c|}{15,00} \\
\hline Distância do obstáculo à estação B (km) & \multicolumn{5}{|c|}{19,29} \\
\hline Altitude da estação A (m) & \multicolumn{5}{|c|}{18} \\
\hline Altitude da estação B (m) & \multicolumn{5}{|c|}{16} \\
\hline Altitude do obstáculo / ponto crítico (m) & \multicolumn{5}{|c|}{5} \\
\hline Valor de Kmínimo encontrado & \multicolumn{5}{|c|}{$0,67(0,75)$} \\
\hline Altura da Antena A, tida como referência ( $m$ ) & \multicolumn{5}{|c|}{40,1} \\
\hline Margem de crescimento de árvores no ponto crítico $(\mathrm{m})$ & \multicolumn{5}{|c|}{0} \\
\hline & \multicolumn{5}{|c|}{ Resultados Calculados } \\
\hline Distância total do enlace $(\mathrm{km})$ & \multicolumn{5}{|c|}{34,29} \\
\hline $100 \%$ do raio de fresnel no ponto crítico $(\mathrm{m})$ & \multicolumn{5}{|c|}{23,21} \\
\hline $60 \%$ do raio de fresnel no ponto crítico $(\mathrm{m})$ & \multicolumn{5}{|c|}{13,92} \\
\hline Correção da curvatura da Terra para $K_{\text {médio }}=4 / 3(\mathrm{~m})$ & \multicolumn{5}{|c|}{17,03} \\
\hline Correção da curvatura da Terra para $\mathrm{K}_{\text {mímimo }}(\mathrm{m})$ & \multicolumn{5}{|c|}{$33,90(30,28)$} \\
\hline $100 \%$ do raio de fresnel + Correção da curvatura da Terra para $K_{\text {médio }}=4 / 3(\mathrm{~m})$ & \multicolumn{5}{|c|}{40,24} \\
\hline $60 \%$ do raio de fresnel + Correção da curvatura da Terra para $\mathrm{K}_{\text {mímimo }}(\mathrm{m})$ & \multicolumn{5}{|c|}{$47,82(44,21)$} \\
\hline Altura da Antena B para $K_{\text {médio }}=4 / 3$ & \multicolumn{5}{|c|}{13,63} \\
\hline Altura da Antena B para $\mathrm{K}_{\text {minimo }}$ & \multicolumn{5}{|c|}{$30,96(22,69)$} \\
\hline
\end{tabular}

Pela tabela 15 verifica-se que dado à altura da antena da estação $A$ de 40,1 metros é preciso de uma altura de 31,31 metros da antena para a estação B. Caso o valor do $\mathrm{K}_{\text {mínimo }}$ for de 0,75 , observa-se que para a mesma altura da antena na estação A, a estação B precisará de uma antena na altura de 22,69 metros. Com este exemplo fica evidente que um superdimensionamento pode causar gastos desnecessários, como na altura da torre, cabos/guias, etc...

Será verificado como se encontram os valores apresentados na tabela $16^{[7]}$.

> Freqüência do enlace (f): É medida em $\mathrm{GHz}$, indicando a freqüência central de operação do enlace;

> Distância do Enlace (d): Distância total do enlace em km. É calculado a partir das coordenadas das estações $A$ e B, com a seguinte expressão ${ }^{[7]}$ :

$$
\text { Dist.A.B }=\sqrt{(\text { Dist. } \mathrm{x})^{2}+(\text { Dist.y })^{2}}
$$




$$
\begin{aligned}
& \left\{\begin{array}{l}
\text { Dist.x }=111,18 . A B S(\text { Long.A }- \text { Long.B }) . C O S((\pi / 180) .(\text { Lat.A + Lat.B }) / 2) \\
\text { Dist.y }=111,18 . A B S .(\text { Lat.A }+ \text { Lat.B })
\end{array}\right. \\
& \left\{\begin{array}{l}
\text { Lat }=\text { Lat.(graus) }+\frac{\text { Lat.(minuto })}{60}+\frac{\text { Lat.(segundos) }}{3600} \\
\text { Long }=\text { Long.(graus) }+\frac{\text { Long.(minuto) }}{60}+\frac{\text { Long.(segundos })}{3600}
\end{array}\right.
\end{aligned}
$$

Distância ao obstáculo à estação $\mathbf{A}$ (d1): diferença, em km, da estação $A$ até o ponto mais crítico;

> Distância ao obstáculo à estação B (d2): diferença, em km, da estação $B$ até o ponto mais crítico;

> Altitude a estação A (hA): Indica a altitude da estação A com relação ao nível médio do mar;

> Altitude a estação B (hB): Indica a altitude da estação B com relação ao nível médio do mar;

> Altitude do obstáculo / ponto crítico (hpc): Indica a altitude do obstáculo com relação ao nível médio do mar;

$>100 \%$ do raio de Fresnel no ponto crítico (RF): O cálculo é feito com o auxílio da expressão (9) com o valor de $n=1$;

$>60 \%$ do raio de Fresnel no ponto crítico (RF'): Equivale a $60 \%$ do valor de $\mathrm{RF}$, para o caso de freqüências acima de $3 \mathrm{GHz}$.

Correção equivalente da curvatura da terra para $K=4 / 3(\mathrm{Hm})$ : No caso deste exemplo a correção equivalente da curvatura da Terra somente será para o ponto mais crítico. A fórmula utilizada é:

$$
H_{m}=\frac{d_{1} \cdot d_{2}}{K \cdot(12 \cdot 740)}
$$

onde $\quad K=$ fator médio a ser utilizado;

12.740 = diâmetro médio da terra em km;

> Correção equivalente da curvatura da terra para $\mathbf{K}_{\text {mínimo }}\left(\mathbf{H m}^{\prime}\right)$ : Semelhante ao item anterior com o valor de $\mathrm{K}_{\text {mínimo; }}$ 
Correção equivalente da curvatura da terra para $K=4 / 3+100 \%$ do raio de Fresnel no ponto crítico (Hc): soma dos itens Hm + RF;

$>$ Correção equivalente da curvatura da terra para $K_{\text {minimo }}+60 \%$ do raio de Fresnel no ponto crítico (Hc'): soma dos itens Hm' + RF';

> Altura da antena tida como referência $(\mathrm{hA})$ : Utiliza-se como referência a altura da antena A para depois calcular a necessidade da B;

> Margem de crescimento de árvores no ponto crítico (MC): Devido ao crescimento da vegetação local, deve-se levar em conta o seu crescimento.

> Para o cálculo da altura da antena na estação B para $k_{\text {médio }}(h 2)$ e $K_{\text {mínimo }}$ (h2') utilizaram-se as seguintes fórmulas:

$$
\begin{aligned}
& \mathrm{h} 2=\frac{\mathrm{d} \cdot(\mathrm{hpc}+\mathrm{HC}+\mathrm{MC}-\mathrm{hB})-\mathrm{d} 2 \cdot(\mathrm{hA}+\mathrm{h} 1-\mathrm{hB})}{\mathrm{d} 1} \\
& \mathrm{~h}^{\prime}=\frac{\mathrm{d} \cdot(\mathrm{hpc}+\mathrm{HC}+\mathrm{MC}-\mathrm{hB})-\mathrm{d} 2 \cdot(\mathrm{hA}+\mathrm{h} 1-\mathrm{hB})}{\mathrm{d} 1}
\end{aligned}
$$

O capítulo 4 foi dedicado à propagação através da atmosfera terrestre, verificando seus efeitos, tais como a refração, difração e reflexão. A análise da zona de Fresnel e do fator $K$ também foi realizada, mostrado suas aplicações na determinação das alturas das antenas, que foi o objetivo principal nesta parte do projeto. Um exemplo prático foi realizado, assim como, a verificação das atenuações devido a chuvas e a atmosfera (ar seco e vapor d'água). 


\section{Capítulo 5 - Dimensionamento de radioenlaces}

\subsection{Introdução}

O projeto de rádio enlace envolve três atividades principais:

> Plano de freqüência;

> Cálculo de desempenho e disponibilidade;

> Cálculo de interferência.

Para explorar todas as possibilidades na solução do projeto, é preciso antes de seu início, coletar e organizar todo o tipo de informação, tais como:

> Poligonal da rota, contendo os enlaces existentes e os que serão inclusos no futuro, com suas respectivas faixas de freqüências;

> Tabelas com os planos de freqüência das faixas a serem utilizadas;

> Dados da Anatel com as freqüências utilizadas nos enlaces cadastrados;

> Parâmetros sistêmicos de todos os equipamentos a serem usados;

> Idem, para o sistema aéreo;

> Parâmetros climáticos e topográficos da região.

A seleção da faixa de freqüências é de suma importância para o projeto de radioenlace, onde uma escolha inadequada, pode causar problemas futuros, como interferências elevadas, dificuldade de expansão devido à saturação. Assim, uma análise dos sistemas existentes torna-se necessário. Para o caso de uma rede metropolitana, onde os enlaces são ditos de acesso, é necessário utilizar as faixas de $15,18,23$ e $38 \mathrm{GHz}$ para prover as capacidades de 4 a $16 \mathrm{E} 1$. Nesta situação a faixa de freqüência é escolhida em função da distância, devido à atenuação por chuva, como pode ser verificado na tabela $16^{[7]}$.

Tabela 16. Frequiência de 15, 18, 23 e 38 GHz x Distância do enlace.

\begin{tabular}{|c|c|c|c|c|}
\hline Freqüência & $15 \mathrm{GHz}$ & $18 \mathrm{GHz}$ & $23 \mathrm{GHz}$ & $38 \mathrm{GHz}$ \\
\hline Distância* & 6 a $15 \mathrm{~km}$ & 3 a $6 \mathrm{~km}$ & $1 \mathrm{a} 3 \mathrm{~km}$ & até $1 \mathrm{~km}$ \\
\hline
\end{tabular}

* As distâncias citadas dependem das especificações de disponibilidade por enlace. 
Para rádios com maior capacidade e longa distância, as faixas de 4, 5, 6, 7,5

e $8 \mathrm{GHz}$ são utilizadas, ficando apenas na dependência da saturação e da existência de rotas paralelas de outra operadora (interferências). Entre estas faixas a de melhor opção seria a de $5 \mathrm{GHz}$, pois para faixas abaixo de $10 \mathrm{GHz}$ é a única com espaçamento de $40 \mathrm{MHz}^{[9]}$, permitindo utilizar uma modulação menos complexa. Com exceção da freqüência de $5 \mathrm{GHz}$, as melhores opções são as faixas de 6 e $8 \mathrm{GHz}$, devido à permissão de expansão até $(7+1)$. Para o caso da faixa de $7,5 \mathrm{GHz}$ tem-se que esta faixa não é exclusiva para alta capacidade, variando desde 1E1 até STM-1.

Para o caso de rotas de longa distância e capacidade média, as opções mais adequadas seria as faixas de 6, 7, 7,5 e 8,5, onde a única faixa disponível para utilizar a capacidade de $32 \mathrm{E} 1$ é a de $6,7 \mathrm{GHz}$.

Para o caso de rotas longas e baixas capacidades tem-se as opções de 400 $\mathrm{MHz}, 1,5,7,5$ e $8,5 \mathrm{GHz}$, com a vantagem de implementação de enlaces semiobstruídos nas freqüências de $400 \mathrm{MHz}$ ou 1,5 GHz.

Como a faixa de $7,5 \mathrm{GHz}$ é a mais diversa, podendo operar em várias capacidades, será utilizada como exemplo. A tabela 17 mostra um resumo da capacidade nesta freqüência, retirado da canalização nesta faixa (figura 26) ${ }^{[8]}$.

Tabela 17. Capacidade que a faixa de $7,5 \mathrm{GHz}$ pode operar.

\begin{tabular}{|c|c|c|c|c|}
\hline $\begin{array}{c}\text { Número } \\
\text { de canais }\end{array}$ & $\begin{array}{l}\text { Largura } \\
\text { de Faixa }\end{array}$ & $\begin{array}{c}\text { Taxa de } \\
\text { Transmissão }\end{array}$ & $\begin{array}{c}\text { Quantidade de } \\
\text { E1's }\end{array}$ & $\begin{array}{l}\text { Canais } \\
\text { de Voz }\end{array}$ \\
\hline 41 de & 3,5 MHz & 2 ou 4 Mbps & $1 \mathrm{E} 1$ ou $2 \mathrm{E} 1$ & 30 ou 60 \\
\hline 20 de & $7,0 \mathrm{MHz}$ & $8 \mathrm{Mbps}$ & $4 \mathrm{E} 1$ & 120 \\
\hline 10 de & $14,0 \mathrm{MHz}$ & 17 ou $51 \mathrm{Mbps}$ & $8 \mathrm{E} 1$ a $24 \mathrm{E} 1$ & 240 a 720 \\
\hline 5 de & $28,0 \mathrm{MHz}$ & $140 / 155 \mathrm{Mbps}$ & 63E1 ou STM-1 & 1920 \\
\hline
\end{tabular}

Como um exemplo considere um enlace A-B existente cujos canais 1,3 e 5 (155Mbps), na faixa de 7,5 GHz, estão sendo utilizados. Deseja-se introduzir mais dois enlaces novos, A-C e A-D, com capacidade igual a 4E1 e 2E1, respectivamente.

Pelo exposto, observa-se que o enlace A-B ocupa três canais de $28 \mathrm{MHz}$, existindo para os restantes dos enlaces apenas o espaço correspondente a dois canais (canais 2 e 4). Assim, para o enlace A-C pode-se escolher qualquer canal entre os canais de 5 a 8 e entre os canais de 13 a 16 correspondente a faixa de 7 

10 e 16 e entre os canais 26 a 32 da faixa de $3,5 \mathrm{MHz}$.

Como sugestão, escolhe-se para 0 enlace A-C $\circ$ canal 7 (para a faixa de 7 $\mathrm{MHz}$ ), o que implica que os canais 13,14 e 15 da faixa de $3,5 \mathrm{MHz}$ não poderão ser mais utilizados, restando para a escolha os canais de 10 a 12 e o 16, além dos canais 26 a 32, ficando a cargo do projetista a escolha de um destes canais. 

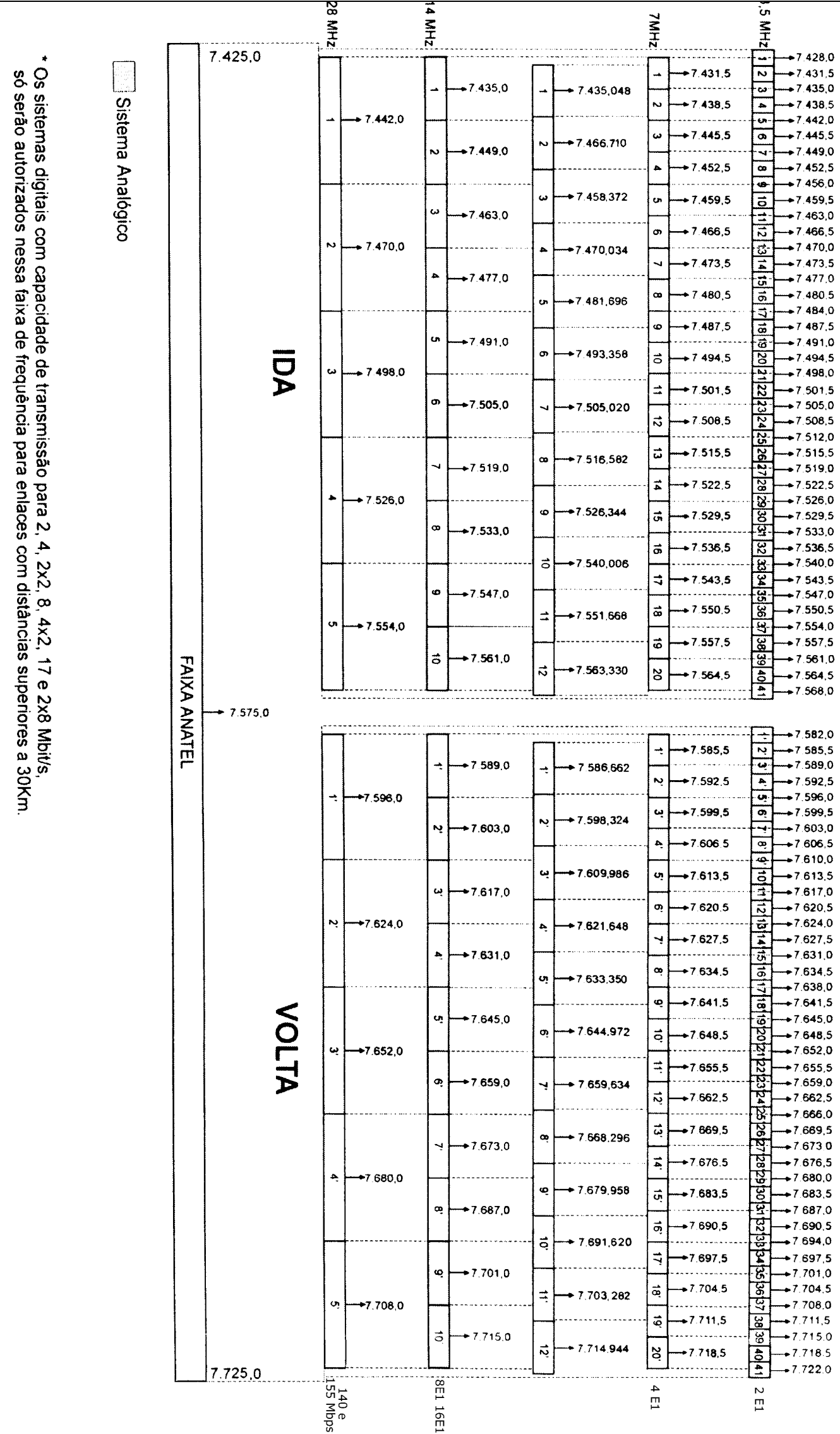

Figura 26. Canalização na Freqüência de $7,5 \mathrm{GHz}$. 


\subsection{Elaboração do Plano de Freqüências}

A elaboração do plano de freqüências é realizado de forma preliminar e definitiva. A elaboração do plano preliminar é feita por meio da análise da topologia da rede, contendo todos os enlaces existentes na região. Estes enlaces existentes podem ser obtidos pelos dados cadastrados no SITAR.

Os dados do SITAR podem ser obtidos "on line" via internet, necessitando apenas de uma autorização por parte da Anatel. Como os dados no SITAR são muito extensos, deve-se fazer a filtragem e ordenamento seguindo critérios de distância ou freqüência, para a análise de possíveis fontes de interferências. Os limites de freqüência e distância a serem considerados na filtragem dependem do tipo e característica do sistema a ser projetado.

Como exemplo tem-se que para projetos de sistemas de longa distância, enlaces situados a $100 \mathrm{~km}$ e afastamento de mais de um canal não deve ser levado em consideração. Outro caso, seria os enlaces próximos utilizando canais próximos, mas com ângulo de interferência muito grande.

O plano de freqüência definitivo, é baseado no preliminar, sendo elaborado através de cálculo de desempenho e interferências. Para o caso de um plano preliminar bem feito, verificam-se poucas mudanças no definitivo.

O plano definitivo de uma rota é apresentado por meio de um diagrama, como pode ser verificado na figura $27^{[7]}$, onde se tem uma rota em $5 \mathrm{GHz}$ na configuração $(3+1)$, que futuramente será expandida para $(6+1)$.

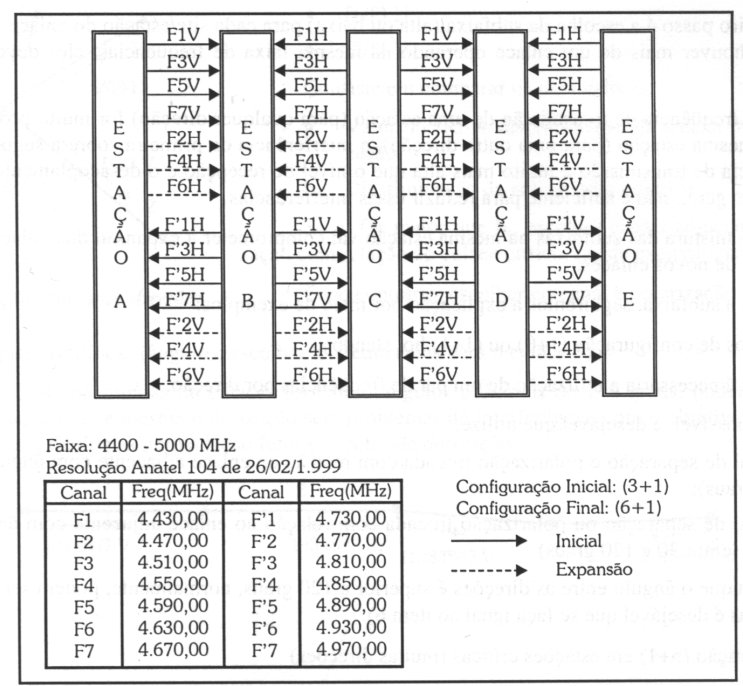

Figura 27. Plano de frequiência da rota A-E. 
Para faixas de freqüências de $15 \mathrm{GHz}$ em diante, a elaboração do plano de freqüência em regiões onde o número de enlaces é elevado, como nas regiões metropolitanas, é aconselhável fazer uma seleção inicial dos pares de freqüências menos utilizados. Existem situações onde o cálculo de interferência torna-se impraticável devido a este excesso de enlaces.

Serão apresentados critérios básicos para a escolha dos pares de freqüências e polarização dos novos enlaces, minimizando, assim, as interferências.

1. Escolha da subfaixa para cada estação do enlace. Caso se verifique, numa mesma estação, mais de um enlace utilizando a mesma faixa de freqüência, estes devem operar na mesma subfaixa ${ }^{[7]}$.

Motivo: Isto deve ocorre na tentativa de evitar que a freqüência de transmissão seja muito próxima da freqüência de recepção, pois é sabido que a potência de transmissão é muito mais alta que o nível de recepção, e a diretividade das antenas não é suficiente, em geral, para reduzir estas interferências.

2. Outros critérios serão verificados através de exemplos:

\subsection{Configuração $(1+0)$ ou $(1+1)$ hot standby ${ }^{[7]}$}

Nesta situação é necessária a utilização de um par de freqüências por direção, sendo que:

- Para ângulo menor que 30 graus: Um canal de separação e polarização trocada com relação ao enlace adjacente;

- Para ângulo entre 30 e 120 graus: Um canal de separação ou polarização trocada com relação ao enlace adjacente.

$\mathrm{Na}$ situação em que o ângulo entre as direções é superior a 120 graus, normalmente, pode-se utilizar co-canal e co-polarização cruzada.

2.2 Configuração $(n+1)$ em estações críticas (muitas direções) ${ }^{[7]}$

Como exemplo será verificado uma estação com quatro enlaces existentes, onde se deseja implantar um quinto enlace, sendo que todos se encontram na configuração (1+1). Verificar a figura 28. 


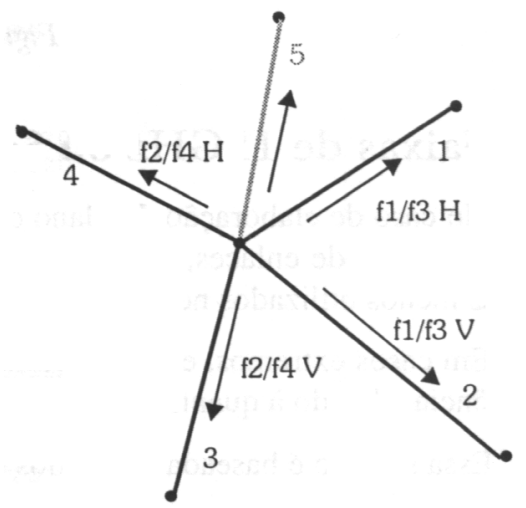

Figura 28. Implantação de um quinto enlace.

O critério normal de escolha é o afastamento máximo, da freqüência e polarização, com relação ao enlace que forma o menor ângulo, que para o enlace 5, são os enlaces 1 e 4 . Os enlaces 2 e 3 formam ângulos maiores, de forma que as interferências são menos críticas.

Como o enlace 1 opera em f1/f3 $\mathrm{H}$ e o enlace $4 \mathrm{em} \mathrm{f2/f4} \mathrm{H}$, a melhor polarização para o enlace novo é a vertical. Para o caso da freqüência observa-se que o menor ângulo entre os dois é para o enlace 1 , tendo como referência o enlace 5 . Portanto, os pares de freqüências a serem escolhidos são f2/f4, na tentativa de minimizar a interferência com o ângulo mais crítico. Assim, para o novo enlace, a melhor opção de plano é f2/f4 V.

De acordo com a figura 29, tem-se uma rota quase retilínea cujo ângulo formado pelos enlaces, formam 180 graus, podendo utilizar normalmente as mesmas freqüências e polarização sem problemas de interferência. Este medida economiza canais de RF facilitando a implantação de rotas futuras.

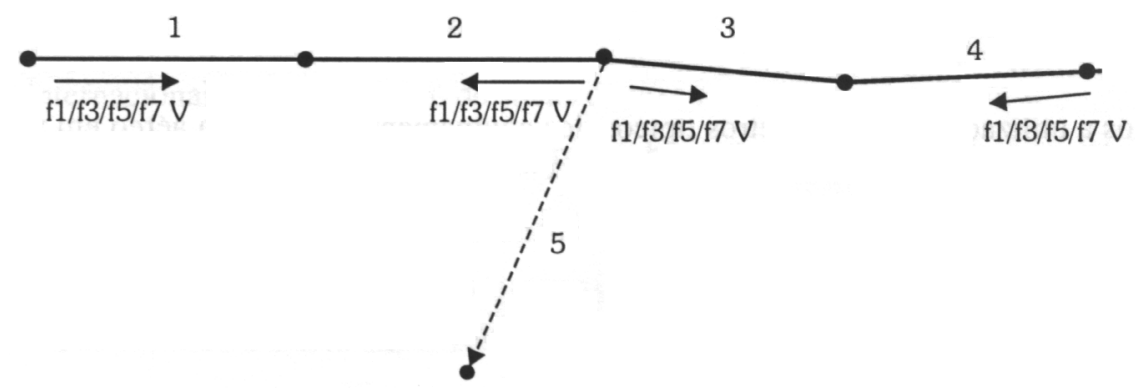

Figura 29. Rotas quase retilíneas. 
Neste exemplo, seguindo as orientações acima, tem-se que a adição de um novo enlace de expansão é facilitado, podendo escolher para o enlace 5 as freqüências f1/f3/f5/f7 H. É importante salientar que a utilização da mesma freqüência e polarização é válida somente para o caso de rotas onde as distâncias envolvidas são consideradas.

Estes critérios estabelecidos são regras gerais, que possui o objetivo de dimensionar enlaces com desempenho satisfatório, atendendo as especificações de desempenho e disponibilidade.

Em casos extremos, pode-se concluir que para uma certa faixa de freqüência é inviável sua utilização em uma determinada região, devendo ser adotada uma solução alternativa, como utilizar uma outra faixa de freqüência.

\subsection{Cálculo de Desempenho e Disponibilidade}

\subsubsection{Introdução}

Quando o sistema é dimensionado na configuração $(n+1)$, tem-se que o cálculo de desempenho e disponibilidade de um radioenlace nesta configuração não é uniforme para todos os canais, diferindo também de acordo com o sentido de transmissão. Esta variação, pequena para a maioria dos casos, principalmente os níveis de interferência que variam de canal a canal e sentido de transmissão. A rigor, dever-se-ia fazer o cálculo separadamente para cada canal de RF e sentido de transmissão, mas, na prática, é feito somente para o canal com pior desempenho ou disponibilidade por razões práticas.

Antes do cálculo do desempenho e disponibilidade, deve-se definir alguns itens como se segue ${ }^{[7]}$ :

\subsubsection{Especificações de desempenho e disponibilidade (SPEC) ${ }^{[7]}$}

SPEC é o objetivo de desempenho que o enlace deve atingir para o atendimento das recomendações do ITU-T. Os tipos mais utilizados são:

Recomendação G821: especifica os parâmetros e objetivos de desempenho e disponibilidade de conexões internacionais para transportes de 
sinais de até 64 kbps. Esta recomendação será utilizada para o caso deste projeto.

> Recomendações G826 e G827: especifica os parâmetros e objetivos de desempenho e disponibilidade de conexões internacionais para transportes de sinais de taxa maior ou igual a 2 Mbps.

> Recomendação G828: especifica parâmetros e objetivos de características de erro para trajetos digitais síncronos. Assim, esta recomendação é aplicável as redes digitais síncronas na hierarquia SDH.

\subsubsection{Tipos de configurações dos equipamentos}

O tipo de equipamento utilizado e suas configurações são fundamentais para o processo de elaboração do Cálculo de Desempenho. Com os dados dos equipamentos obtêm-se suas características. Além dos equipamentos rádio propriamente dito, as características das antenas e do guia de onda também são importantes para o dimensionamento.

\subsubsection{Metodologia do Cálculo de Desempenho e Disponibilidade}

Esta metodologia é aplicável aos enlaces diretos sem repetição passiva.

Todo o cálculo de desempenho visa ao atendimento do parâmetro mais crítico, relativo ao SES. Se após os cálculos preliminares, considerando uma configuração inicial adotada, mostrar um percentual de interrupção e indisponibilidade menor que as especificações adotadas, pode-se considerar que o sistema irá funcionar dentro dos padrões estabelecidos. Caso esses valores não sejam obtidos, um novo cálculo deverá ser realizado variando algum parâmetro.

\section{> Atenuação no Espaço Livre $\left(A_{e}\right)$}

A atenuação no espaço livre (em dB) é dada pela seguinte fórmula ${ }^{[4]}$ :

$$
A_{e}=32,4+20 \cdot \log .(f . d)
$$

onde: $f=$ freqüência central em $\mathrm{MHz}$;

$\mathrm{d}=$ distância em km. 


\section{> Atenuação devido à absorção pela Atmosfera $\left(\mathrm{A}_{\mathrm{ab}}\right)$}

De acordo com a figura 25, para uma determinada freqüência, é possível determinar a atenuação devido à absorção pela atmosfera. Uma maneira alternativa é utilizando a expressão $0^{[1]}$ :

$$
A_{a b}=\left(\gamma_{0}+\gamma_{W}\right) \cdot d
$$

onde: $\gamma_{0}=$ atenuação específica do ar seco/oxigênio em dB/km;

$\gamma_{\mathrm{w}}=$ atenuação específica do ar úmido/vapor d'água em $\mathrm{dB} / \mathrm{km}$;

$d$ = distância do enlace.

Os valores de $\gamma_{0}$ e $\gamma_{\mathrm{w}}$ podem ser encontrados a partir das expressões ${ }^{[1]}$ :

$$
\begin{gathered}
\gamma_{0}=\left(7,19 \cdot 10^{-3}+\frac{6,09}{\mathrm{f}^{2}+0,227}+\frac{4,81}{(\mathrm{f}-57)^{2}+1,5}\right) \cdot \mathrm{f}^{2} \cdot 10^{-3} \\
\gamma_{\mathrm{W}}=\left(0,05+0,0021 \cdot \rho+\frac{3,6}{(\mathrm{f}-22,2)^{2}+8,5}+\frac{10,6}{(\mathrm{f}-183,3)^{2}+9}+\frac{8,9}{(\mathrm{f}-325,4)^{2}+26,3}\right) \cdot \rho \cdot f^{2} \cdot 10^{-4}
\end{gathered}
$$

As equações acima são válidas para uma faixa de pressão atmosférica $\pm 50 \mathrm{hPa}$ em torno do valor de referência, ao nível do mar, de $1013 \mathrm{hPa}$ à temperatura de 15 ${ }^{\circ} \mathrm{C}$. Para temperatura diferente basta introduzir uma correção de $-1 \%$ por grau centígrado a partir de $15 \stackrel{\circ}{\circ}$ para $\circ$ ar seco e de $-0,6 \%$ por grau centígrado para o vapor d'água, pois a atenuação cresce à medida que a temperatura decresce.

Em termos da faixa de freqüência válida, tem-se as duas equações são válidas para uma freqüência inferior a $57 \mathrm{GHz}$.

\section{Atenuação do guia de onda/cabo coaxial $\left(A_{c}\right)$}

$$
\mathrm{A}_{\mathrm{c}}=\frac{\text { Perda no cabo }}{\text { metro }} \cdot \mathrm{L}_{\mathrm{c}}
$$

onde: $A_{c}=$ atenuação no cabo $(d B / m)$;

$\mathrm{L}_{\mathrm{c}}=$ comprimento do cabo $(\mathrm{m})$. 


\section{Atenuação Total Líquida $\left(\mathbf{A}_{\mathrm{t}}\right)$}

A atenuação total líquida é dada por ${ }^{[1]}$ :

$$
A_{t}=A_{e}+A_{a b}+A_{r m f}+A_{c A B}+A_{a t} T_{x} \cdot R_{x}+A_{\text {outras }}-\left(G_{T}+G_{R}\right)
$$

onde: $A_{e}=$ atenuação no espaço livre $(d B)$;

$A_{a b}=$ atenuação devido à absorção na atmosfera $(\mathrm{dB})$;

$A_{r m f}=$ atenuação total no circuito de ramificação $(T x$ e $R x)(d B)$;

$A_{c A B}=$ atenuação no guia / cabo $(T x$ e $R x)(d B)$;

$A_{a t} T_{x} R_{x}=$ valor do atenuador lado $T x$ e $R x(d B)$;

$A_{\text {outras }}=$ valor das outras perdas;

$\mathrm{G}_{\mathrm{T}}$ e $\mathrm{G}_{\mathrm{R}}=$ Ganhos das antenas de transmissão e recepção (dBi).

> Nível de Recepção Nominal (sem desvanecimento) $\left(P_{\mathrm{RN}}\right)$

O nível (potência) de recepção nominal é dado por ${ }^{[7]}$ :

$$
\mathrm{P}_{\mathrm{RN}}=\mathrm{P}_{\mathrm{T}}-\mathrm{A}_{\mathrm{t}}
$$

onde: $P_{\mathrm{RN}}=$ nível (potência) de recepção nominal $(\mathrm{dBm})$;

$\mathrm{P}_{\mathrm{T}}=$ potência de transmissão $(\mathrm{dBm})$;

$A_{t}=$ atenuação total líquida $(\mathrm{dB})$.

\section{> Degradações por interferência $\left(D_{t}\right)$}

No dimensionamento do sistema deve-se levar em conta alguns fatores que podem ser divididos em dois grupos: fixos e os variáveis.

1. Interferências fixas ${ }^{[7]}$

É o caso onde a relação portadora/interferência (C/I) se mantém constante independente das condições de propagação, assim, quando o sinal desejado sofre atenuação, a interferência sofre a mesma atenuação, mantendo a relação entre eles constante. As interferências fixas causam degradação no valor do $\mathrm{C} / \mathrm{N}_{\mathrm{SES}}$, onde a expressão para encontrá-lo é ${ }^{[7]}$ :

$$
C / N_{S E S}=\left(10 \frac{-C / N_{\text {SESTEоRICO }}}{10}+10^{\frac{-C / N_{\text {ECO }}}{10}}+10^{\frac{-C / I_{\text {FIXA }}}{10}}\right)
$$


onde: $\mathrm{C} / \mathrm{N}_{\text {SES }}=$ valor de $\mathrm{C} / \mathrm{N}$ correspondente ao evento SES, considerando a degradação devido às interferências fixas.

$\mathrm{C} / \mathrm{N}_{\text {SESTEORICO }}=$ valor de $\mathrm{C} / \mathrm{N}$ correspondente à taxa de erro de bit de $\mathrm{SES}$ sem degradações devido à interferência, sendo um parâmetro fornecido pelo fabricante, medido em condições ideais (sem ruído térmico).

A diferença entre $C / N_{S E S}$ e $\circ \mathrm{C} / \mathrm{N}_{\text {SESTEORICO }}$ é a degradação causada pelas interferências fixas, dada em $\mathrm{dB}^{[7]}$.

$$
D_{f}=C / N_{S E S}-C / N_{\text {SESTEORICO }}
$$

Na prática o valor desta degradação é muito pequeno (décimos de $\mathrm{dB}$ ), sendo, na maioria das vezes desprezada.

\section{Interferências variáveis ${ }^{[7]}$}

São interferências que dependem das condições de propagação, sendo que, quando ocorre um fading do sinal desejado, a interferência não sofre fading com a mesma intensidade, de forma que a relação sinal $\mathrm{C} / \mathrm{l}$ decresce nesta situação. Este tipo de interferência é mais prejudicial que as interferências fixas, causando assim, uma maior degradação.

Existem diversos tipos de interferências variáveis, entre elas:

2.1 Interferências do mesmo enlace: É a situação onde a configuração do sistema é $(n+1)$, devendo ser consideradas apenas as interferências co-canal e canal adjacente. As interferências de canais de RF de duas ou mais freqüências de separação são desprezíveis.

2.1.1 Interferência do canal adjacente, polarização oposta $\left(C / l_{\text {adj }}\right)$

$$
\mathrm{C} / \mathrm{I}_{\mathrm{adj}}=\mathrm{IRF}+\mathrm{XPD}_{0}+\mathrm{Q} \quad(\mathrm{em} \mathrm{dB})
$$

em que: $\quad$ IRF = fator de rejeição de interferência;

$\mathrm{XPD}_{0}=$ valor do XPD (discriminação cruzada de polarização para a direção de máxima radiação - valor obtido do catálogo do fabricante de antena); 
Adota-se o valor de $10 \mathrm{~dB}$ para este parâmetro (valor prático, resultado de medidas em campo).

2.1.2 Interferência co-canal, polarização oposta $\left(C / I_{\text {cox }}\right)$

$$
\mathrm{C} / \mathrm{I}_{\text {cox }}=\mathrm{G}_{\mathrm{XPIC}}+\mathrm{XPD}_{0}+\mathrm{Q}
$$

em que: $G_{\text {XPIC }}=$ melhoria devido ao dispositivo XPIC. Este valor é cerca de 20 $\mathrm{dB}$, dependendo do fabricante.

2.2 Interferências de outros enlaces: Serão obtidas nos cálculos de interferências, podendo ser causadas por outros enlaces pertencentes ao mesmo sistema (intra-sistema) e/ou causadas por outros sistemas (intersistema). São calculadas separadamente, possuindo assim duas componentes: $\mathrm{C} / \mathrm{I}_{\text {intra }}$ e $\mathrm{C} / \mathrm{l}_{\text {inter }}$. Nos cálculos preliminares, em que as interferências de outros enlaces normalmente não são calculadas, utilizam-se "valores default" para esses cálculos. Adotam-se os valores de 60 e 65 dB em rádios acima de $4 \mathrm{GHz}$ e de 50 e $55 \mathrm{~dB}$ em rádios abaixo de $4 \mathrm{GHz}$ para as interferências intra e intersistemas, respectivamente.

2.3 Ruído Ambiental: Para faixas de freqüência abaixo de $2 \mathrm{GHz}$, os ruídos causados pela ignição de veículos devem ser considerados, sendo que estes níveis de ruídos dependem da localização da torre, altura e tipo de antena. A contribuição desta componente é dada pela expressão:

$$
\mathrm{C} / \mathrm{I}_{\mathrm{amb}}=\mathrm{P}_{\mathrm{RN}}-\mathrm{N}_{\mathrm{amb}}(\mathrm{dB})
$$

em que: $\quad P_{\mathrm{RN}}=$ nível (potência) de recepção nominal;

$\mathrm{N}_{\mathrm{amb}}=$ nível médio do ruído ambiental.

2.4 Ruído Térmico: O nível do ruído térmico é obtido pela expressão:

$$
\mathrm{N}_{\text {térmico }}=10 . \log .(\mathrm{KTB})+\mathrm{F}(\mathrm{dBm})
$$

onde: $\mathrm{K}=$ constante de Boltzmann $=\left(1,38.10^{-23}\right)$; 


$$
\begin{aligned}
& T=\text { temperatura ambiental }=300^{\circ} \mathrm{K} ; \\
& \mathrm{B}=\text { largura de faixa do sinal }(\mathrm{Hz}) ; \\
& \mathrm{F}=\text { figura de ruído do receptor }(\mathrm{dB}) .
\end{aligned}
$$

Assim, a relação $\mathrm{C} / \mathrm{N}_{\text {térmico }}$ é dada por:

$$
\mathrm{C} / \mathrm{N}_{\text {térmico }}=\mathrm{P}_{\mathrm{RN}}-\mathrm{N}_{\text {térmico }}(\mathrm{dB})
$$

Outra maneira é a partir da margem bruta do enlace (ver próximo item):

$$
\mathrm{C} / \mathrm{N}_{\text {térmico }}=-\mathrm{C} / \mathrm{N}_{\text {SES TEÓRICO }}+\mathrm{M}_{\mathrm{t}}(\mathrm{dB})
$$

Assim, a degradação total devido às interferências variáveis $\left(D_{v}\right)$ é calculada pela expressão:

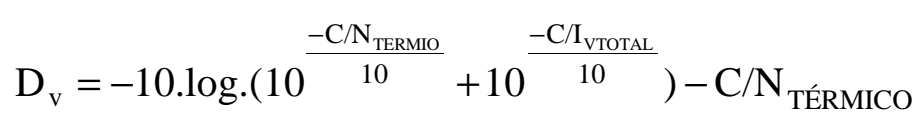

onde: $\quad \mathrm{C} / \mathrm{I}_{\mathrm{V} \text { total }}=-10 \cdot \log \cdot\left(10^{\frac{-\mathrm{C} / \mathrm{C}_{\text {ajj }}}{10}}+10^{\frac{-\mathrm{C} / \mathrm{I}_{\text {coxj }}}{10}}+10^{\frac{-\mathrm{C} / \mathrm{I}_{\text {itra }}}{10}}+10^{\frac{-\mathrm{C} / \mathrm{I}_{\text {iuter }}}{10}}\right)$

Quando alguns componentes são desprezíveis, utiliza-se um valor alto de $\mathrm{C} / /_{\text {vtotal, }}$, por exemplo, $100 \mathrm{~dB}$, para não afetar o cálculo final.

A degradação por interferência (fixa e variável) é dada por:

$$
D_{t}=D_{f}+D_{v} \quad(d B)
$$

\section{> Margem sobre o Limiar (Líquida) do Enlace (FFM)}

A margem líquida do enlace para desvanecimento plano é calculada a partir do nível nominal de recepção e da degradação devido a interferências. Antes de calcular este valor, será calculado a margem bruta do enlace, que é a margem teórica, em condições sem interferência (apenas com ruído térmico).

A expressão para a margem bruta do enlace é calculada ${ }^{[7]}$ :

$$
\mathrm{M}_{\mathrm{t}}=\mathrm{P}_{\mathrm{RN}}-\mathrm{P}_{\mathrm{RSES}} \quad(\mathrm{em} \mathrm{dB})
$$

onde: $P_{\mathrm{RSES}}=$ nível (potência) recebida para BER $10^{-3}$ ou $10^{-6}$. 
Assim, a margem líquida (real) do enlace é dada pela expressão ${ }^{[7]}$ :

$$
\mathrm{FFM}=\mathrm{M}_{\mathrm{t}}-\mathrm{D}_{\mathrm{t}} \quad(\mathrm{em} \mathrm{dB})
$$

Este parâmetro determina a percentagem de interrupção devido ao desvanecimento plano e na indisponibilidade causadas pela chuva.

\section{Probabilidade de Interrupção devido a fading Plano e Seletivo}

As causas de interrupção devido às condições de um enlace são:

- Desvanecimento Plano: devido à diminuição do sinal (atenuação por chuva, por obstáculos...), tudo se passa como se o ruído aumentasse.

- Desvanecimento Seletivo: devido à diferença de percurso entre raios de um mesmo feixe, ocorre na recepção à interferência intersimbólica que distorce o sinal recebido devido à diferença de amplitude e de fase entre o sinal principal e os "atrasados".

Será descrito a seguir o cálculo da probabilidade da BER atingir o limiar correspondente ao SES devidos aos dois tipos de desvanecimentos citados.

\section{A) Fator de Ocorrência do Desvanecimento Plano ( $\left.P_{0}\right)$}

Para que ocorra o SES, é necessário que ocorra o desvanecimento plano com profundidade suficiente para que o nível do sinal de recepção caia abaixo do limiar do SES.

De acordo com a recomendação P 530-9 do ITU-R, o fator de ocorrência do desvanecimento plano $\mathrm{P}_{\mathrm{O}}$ é dado pela expressão ${ }^{[7]}$ :

$$
\mathrm{P}_{\mathrm{O}}=\mathrm{K} \cdot \mathrm{d}^{3,6} \cdot \mathrm{f}^{0,89}\left(1+\left|\varepsilon_{\mathrm{p}}\right|\right)^{-1,4}
$$

em que: $\mathrm{K}=$ fator climático;

$\mathrm{d}=$ comprimento do enlace;

$f=$ freqüência central;

$\varepsilon_{\mathrm{p}}=$ inclinação do enlace $(\mathrm{mrad})$.

A inclinação do enlace é dada por ${ }^{[7]}$ : 


$$
\varepsilon_{\mathrm{p}}=\frac{\left(\mathrm{h}_{1}-\mathrm{h}_{2}\right)}{\mathrm{d}}
$$

onde: $h_{1}, h_{2}=$ altitude das antenas (em metros) em relação ao nível do mar.

O fator climático é dado pela expressão ${ }^{[1]}$ :

$$
\mathrm{K}=10^{-0,1 \cdot\left(\mathrm{C}_{0}-\mathrm{C}_{\mathrm{Lat}}-\mathrm{C}_{\mathrm{Lon}}\right)} \cdot \mathrm{p}_{\mathrm{L}}{ }^{1,5}
$$

onde: $\mathrm{C}_{0}=$ fator que depende da altitude das antenas e tipo de terreno. Seu valor esta conforme a tabela $18^{[1]}$.

O coeficiente de latitude $\mathrm{C}_{\text {Lat }}$ depende da latitude $\xi$, conforme se segue:

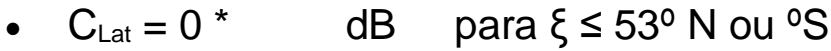

- $\mathrm{C}_{\text {Lat }}=-53+\xi \mathrm{dB}$ para $53^{\circ} \mathrm{N}$ ou ${ }^{\circ} \mathrm{S}<\xi<60^{\circ} \mathrm{N}$ ou ${ }^{\circ} \mathrm{S}$

- $\mathrm{C}_{\text {Lat }}=7 \quad \mathrm{~dB} \quad$ para $\xi \geq 60^{\circ} \mathrm{N}$ ou $\stackrel{\circ}{S}$

E o coeficiente de longitude $\mathrm{C}_{\text {Lon }}$ :

- $\mathrm{C}_{\mathrm{Lon}}=3 \quad \mathrm{~dB}$ para longitudes da Europa e África

- $\mathrm{C}_{\mathrm{Lon}}=-3^{*} \mathrm{~dB}$ para longitudes da América do Sul e Norte

- $\mathrm{C}_{\text {Lon }}=0 \quad \mathrm{~dB}$ para os demais casos

* valores aplicáveis no Brasil.

Tabela 18. $\mathrm{C}_{0}$ em função da altitude das antenas e tipo de terreno.

\begin{tabular}{|c||c||}
\hline Altitude da antena mais baixa e o tipo de terreno & $\mathbf{C}_{0}(\mathbf{d B})$ \\
\hline \hline Antena mais baixa abaixo de $700 \mathrm{~m}$ & 6,5 \\
\hline Antena mais baixa acima de $700 \mathrm{~m}^{* *}$ & 7,1 \\
\hline $\begin{array}{c}\text { Enlaces sobre água, áreas costeiras próximas } \\
\text { ao mar e regiões de muitos lagos }\end{array}$ & 5,9 \\
\hline $\begin{array}{c}\text { Enlaces sobre grandes massas de água e áreas } \\
\text { costeiras sobre o mar (ilhas, etc...) }\end{array}$ & 5,5 \\
\hline
\end{tabular}

${ }^{* *}$ Valores característicos à região Centro-Oeste.

O fator $p_{L}$ é o percentual do tempo em que o gradiente do índice de refração é inferior a $-100 \mathrm{~N} / \mathrm{km}$ no pior mês do ano. Este valor pode ser obtido pela figura 30 , onde se tem os valores de $p_{\llcorner}$para os piores meses do ano.

No cálculo deve ser utilizado o pior (maior) dos quatros valores obtidos nas curvas. Para o caso do Brasil, este valor encontra-se entre 15 a 25\%. Para o caso específico da região Centro-Oeste, tem-se que pıé igual a 20\%. 


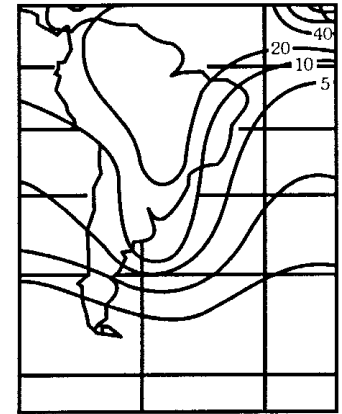

PL (Fevereiro)

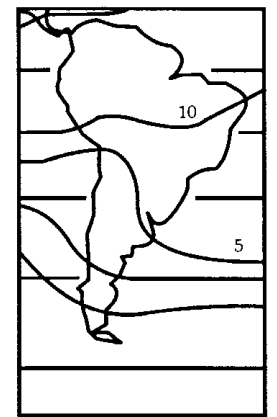

PL (Maio)

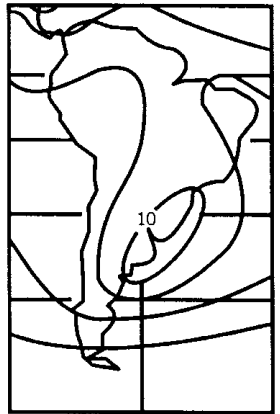

PL (Agosto)

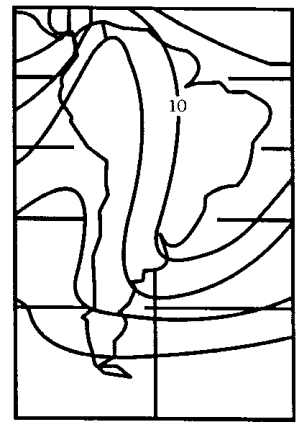

PL (Novembro)

Figura 30. $\mathrm{p}_{\mathrm{L}}$ para os messes de Fevereiro, Maio, Agosto e Novembro.

\section{B) Probabilidade de Ocorrência do SES devido ao Fading Plano}

Para a configuração sem diversidade de freqüência e sem diversidade de espaço, a probabilidade de o desvanecimento plano atingir a profundidade suficiente para o nível de recepção cair abaixo do limiar de SES é é $^{[7]}$

$$
\mathrm{P}_{\mathrm{f}}=\mathrm{P}_{\mathrm{O}} \cdot 10^{\frac{-\mathrm{FFM}}{10}}
$$

\section{C) Fator de Ocorrência do Desvanecimento Seletivo (n)}

De acordo com a recomendação P 530-9 do ITU-R, o fator de ocorrência do desvanecimento seletivo $\eta$ é calculado como se segue ${ }^{[1]}$ :

$$
\eta=1-e^{-0,2 \cdot\left(\frac{P_{0}}{100} 0^{0.75}\right.}
$$

onde: $P_{0}=$ fator de ocorrência do desvanecimento plano.

O fator de desvanecimento seletivo é menor que a causada por desvanecimento plano, sendo da ordem de 20 a $30 \%$ para enlaces longos.

\section{D) Probabilidade de Ocorrência do SES devido ao Fading Seletivo}

A probabilidade de o desvanecimento seletivo atingir um "notch" suficiente para causar o evento SES é calculada pela expressão $0^{[1]}$ : 


$$
\mathrm{P}_{\mathrm{S}}=\frac{0,43 \cdot \eta \cdot \mathrm{S}_{\mathrm{f}} \cdot \tau_{\mathrm{m}}^{2}}{\tau_{0}}
$$

onde: $\mathrm{S}_{\mathrm{f}}=$ característica de assinatura do modulador do rádio para $\mathrm{BER}=10^{-3} \mathrm{e}$ $10^{-6}$

$$
\tau_{\mathrm{m}}=\text { retardo médio devido ao eco do enlace (em ns). Dado por }{ }^{[1]} \text { : }
$$

$$
\tau_{\mathrm{m}}=0,7 .\left(\frac{\mathrm{d}}{50}\right)^{1,5}(\mathrm{~ns})
$$

$$
\tau_{0}=\text { retardo devido ao eco utilizado durante as medidas das curvas de }
$$
características da assinatura do modulador. Utiliza-se normalmente o valor de 6,3 ns como referência para este o cálculo.

Lembrando mais uma vez que esse valor obtido é válido somente para a configuração sem diversidade de freqüência e sem diversidade de espaço.

Para o caso de melhoria com a utilização de diversidade de espaço e/ou freqüência, tanto para o desvanecimento plano como o seletivo, tem-se:

\section{E) Melhoria de diversidade de freqüência}

O fator de melhoria de diversidade de freqüência para a configuração $(1+1)$ é dado pela fórmula ${ }^{[7]}$ :

$$
\mathrm{I}_{\mathrm{DF}}(1+1)=\frac{80}{\mathrm{f} \cdot \mathrm{d}} \cdot\left(\frac{\Delta \mathrm{f}}{\mathrm{f}}\right) \cdot 10^{\frac{\mathrm{FFM}}{10}}
$$

onde: $\Delta f=$ espaçamento entre portadoras $(\mathrm{GHz})$.

Para a situação da configuração $(n+1)$, verifica-se a redução de eficiência da diversidade de freqüência devido ao compartilhamento do canal reserva com $n$ canais. O fator piora é calculado, de acordo com a tabela $19^{[1]}$.

Tabela 19. Fator de piora para diversidade na configuração $(n+1)$.

\begin{tabular}{|c|c|c||c|c|c|c|c|}
\hline Configuração & $(1+1)$ & $(2+1)$ & $(3+1)$ & $(4+1)$ & $(5+1)$ & $(6+1)$ & $(7+1)$ \\
\hline \hline Fator de Piora & 1,0 & 1,5 & 1,75 & 1,92 & 2,04 & 2,13 & 2,22 \\
\hline
\end{tabular}

A melhora devido à diversidade de freqüência na configuração $(n+1)$ é calculada conforme se segue $e^{[]]}$: 


$$
\mathrm{I}_{\mathrm{DF}}(\mathrm{n}+1)=\frac{\mathrm{I}_{\mathrm{DF}}(1+1)}{F_{p}} \quad\left(1 \leq \mathrm{I}_{\mathrm{DF}}(\mathrm{n}+1) \leq 20\right)
$$

Os limites estabelecidos são devido a razões de segurança de projeto.

E.1)Probabilidade de Ocorrência do SES devido ao Fading Total com diversidade de freqüência

$$
P_{f}(n+1)=\frac{P_{f}(1+0)}{I_{D F}(n+1)}
$$

\section{F) Melhoria de diversidade de Espaço}

O fator de melhoria devido à diversidade de espaço é dado pela fórmula ${ }^{[1]}$ :

$$
\mathrm{I}_{\mathrm{DS}}=\left[1-e^{-3,34 \cdot 10^{-4} \cdot h_{v}^{0.87} \cdot f^{-0,12} \cdot d^{0,48} \cdot\left(\frac{P_{0}}{100}\right)^{-1,04}}\right] \cdot 10^{\frac{(\mathrm{FFM}-\Delta \mathrm{G})}{10}}\left(5 \leq \mathrm{I}_{\mathrm{sf}} \leq 100\right)
$$

em que: $f$ = freqüência central $(e m \mathrm{GHz})$;

$\mathrm{d}=$ comprimento do enlace $(\mathrm{km})$;

$h_{v}=$ espaçamento vertical entre as antenas $(m)$;

$P_{0}=$ fator de ocorrência de desvanecimento plano;

$\Delta \mathrm{G}=$ diferença de ganho da antena principal e de diversidade;

F.1) Probabilidade de Ocorrência do SES devido ao Fading Total com diversidade de espaço

$$
\mathrm{P}_{\mathrm{S}}(\mathrm{n}+1)=\frac{\mathrm{P}_{\mathrm{S}}(1+0)}{\mathrm{I}_{\mathrm{DS}}}
$$

É importante lembrar, que o uso de diversidade (freqüência e/ou espaço) é recomendado sempre que, nas condições normais de projeto, o desempenho do enlace não atenda ou esteja próximo dos objetivos (margens) estabelecidos pelo ITU$R$ calculados para o enlace em questão.

\section{G) Probabilidade Total de Ocorrência do SES}

Como a probabilidade de ocorrência do SES é normalmente medido nas BER = $10^{-3}$ ou $10^{-6}$, tem-se que a probabilidade total de que essas taxas de erros sejam 
superadas é dada pela soma das probabilidades de que esta mesma taxa de erros sejam superadas pelos desvanecimentos plano e seletivo.

$$
\mathrm{P}_{\mathrm{t}}=\mathrm{P}_{\mathrm{f}}+\mathrm{P}_{\mathrm{S}}(\%)
$$

O tempo de interrupção $\left(T_{i}\right)$ pode ser calculado pela fórmula ${ }^{[7]}$ :

$$
\mathrm{T}_{\mathrm{i}}(\mathrm{s})=\frac{\mathrm{P}_{\mathrm{t}}(\%) \cdot 30 \cdot 24 \cdot 60 \cdot 60}{100}
$$

Caso o valor do tempo de interrupção supere o valor especificado, o sistema deve ser reprojetado para atender à especificação.

\section{$>\quad$ Cálculo da Indisponibilidade}

O cálculo de indisponibilidade é realizado para a média anual, diferentemente do cálculo de desempenho, que é feito para o pior mês. A indisponibilidade de sistema rádio pode ser causada por diversos fatores, entre eles: Indisponibilidade devido às chuvas; Indisponibilidade devido à falha de equipamento; Indisponibilidade devido ao desvanecimento (plano e seletivo) de longa duração. Estas parcelas serão calculadas separadamente, para depois serem somadas.

\section{A) Indisponibilidade devido às chuvas}

Nos cálculos da probabilidade de interrupção do enlace são consideradas as condições normais de propagação e as possibilidades estatísticas de ocorrência dos desvanecimentos. Entretanto, quando há ocorrência de chuvas uma atenuação adicional à do espaço livre é acrescentada, provocada pela dispersão da onda nas gotículas de chuva. Para freqüências maiores que $10 \mathrm{GHz}$ o valor desta atenuação pode ser muito elevada, podendo causar interrupção do enlace.

A probabilidade de ocorrência de interrupção devido ao desvanecimento por chuva é dada pela expressão ${ }^{[1]}$ :

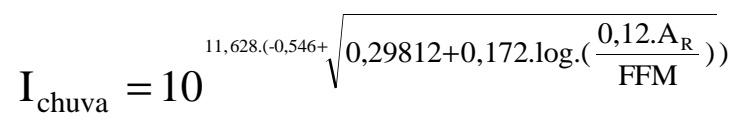


Fazer $\frac{A_{R}}{F F M}=0,155$ se $\frac{A_{R}}{F F M}<0,154023$ na equação acima.

Os valores limites máximos para a indisponibilidade devido a chuvas de acordo com a recomendação 695 do ITU-R, pode ser calculado como se segue:

$$
\mathrm{P}_{\text {máx }}=\frac{0,1 \cdot \mathrm{L}}{2500}(\%)
$$

onde: $\quad P_{\max }=$ Indisponibilidade máxima devido a chuvas em percentual;

$\mathrm{L}=$ comprimento do rota ou enlace em $\mathrm{km}$.

\section{B) Indisponibilidade devido ao equipamento}

É calculado a partir da porcentagem em que o equipamento fica fora de operação, através da expressão seguinte ${ }^{[7]}$ :

$$
\mathrm{I}_{\mathrm{EQ}}=\frac{2 \cdot \mathrm{MTTR}}{\mathrm{MTBF}} \cdot 100(\%)
$$

onde: $\mathrm{MTTR}$ = tempo médio entre reparos;

MTBF = tempo médio entre falhas do sistema.

O fator multiplicativo 2 da expressão acima é para o cálculo da indisponibilidade bidirecional, considerando as falhas nos dois sentidos de transmissão.

\section{C) Indisponibilidade devido ao desvanecimento plano e seletivo}

De acordo com a definição do ITU-R, é preciso que o fenômeno de indisponibilidade devido ao desvanecimento plano e seletivo aconteça de forma a causar o evento SES com duração superior a dez segundos. É dado pela expressão seguinte ${ }^{[7]}$ :

$$
\mathrm{I}_{\mathrm{desv}}=\mathrm{P}_{\mathrm{t}} \cdot \mathrm{F}_{\mathrm{C}}
$$

onde: $P_{t}=$ probabilidade total de ocorrência do evento SES calculado anteriormente;

$$
F_{C}=\text { fator de correção para o pior mês para a média anual. Adota-se o }
$$
valor de 0,3 para este fator.

Observações: 
Nos enlaces abaixo de $10 \mathrm{GHz}$, a especificação de desempenho é o determinante (especificação crítica) nos projetos, de forma que os enlaces que atendem à especificação de SES, atendem com folga à especificação de disponibilidade.

Nos enlaces acima de $10 \mathrm{GHz}$, ao contrário, a especificação determinante é disponibilidade. Nestes casos, a indisponibilidade devido às chuvas é o item mais crítico, sendo que a indisponibilidade devido ao desvanecimento torna-se desprezível.

\section{D) Indisponibilidade Total}

É dada pelas parcelas das indisponibilidades:

$$
\mathrm{I}_{\mathrm{t}}=\mathrm{I}_{\mathrm{EQ}}+\mathrm{I}_{\text {chuva }}+\mathrm{I}_{\text {desv }}(\%)
$$

O tempo de indisponibilidade em segundos, é dado pela seguinte fórmula ${ }^{[7]}$ :

$$
\mathrm{T}_{\text {ind }}(\mathrm{s})=\frac{\mathrm{P}_{\mathrm{t}}(\%) \cdot 365 \cdot 60 \cdot 60 \cdot 24}{100}
$$

\subsubsection{Margens de Desempenho e Disponibilidade}

Para comprovar o atendimento das especificações, devem-se calcular as margens de desempenho e disponibilidade.

Uma forma de apresentar os dados é em $\mathrm{dB}^{[7]}$ :

$$
\text { Margem de desempenho=10.log. }\left(\frac{\text { especificação de desempenho }(\%)}{\mathrm{P}_{\mathrm{t}}(\%)}\right)
$$

$$
\text { Margem de indisponibilidade }=10 \cdot \log .\left(\frac{\text { especificação de indisponibilidade }(\%)}{\mathrm{I}_{\mathrm{t}}(\%)}\right)
$$

Ambas as margens devem dar valores positivos, caso contrário, o enlace não atende as especificações.

\subsubsection{Parâmetros Típicos para Cálculo de Desempenho e de Disponibilidade}

No sistema rádio, o desempenho e disponibilidade, dependem de parâmetros sistêmicos que podem ser classificados em: parâmetros de equipamentos; parâmetros de sistema aéreo; e parâmetros de propagação. 
Cálculo de desempenho, disponibilidade e interferências para radioenlace

$\mathrm{Na}$ tabela 20, segue um exemplo através de uma planilha de cálculo de desempenho e disponibilidade. $\mathrm{O}$ exemplo em questão encontra-se na faixa de 4 $\mathrm{GHz}$, onde devido a problemas de desvanecimento é utilizado diversidade de freqüência para que o enlace atenda as especificações exigidas.

Tabela 20. Exemplo planilha de cálculo de desempenho e disponibilidade.

\begin{tabular}{|l||l}
\hline \multicolumn{2}{|c|}{ Cálculo de Desempenho e Disponibilidade } \\
\hline \multicolumn{2}{|l|}{ Enlace: EST 001 - EST 002} \\
Item & Denominação \\
\hline \hline & \\
\hline 1.1 & Altitude da estação \\
1.2 & Altura da antena \\
1.3 & Distância \\
1.4 & PL \\
1.5 & Indice de precipitação \\
1.6 & Polarização \\
1.7 & K \\
1.8 & a \\
1.9 & Degradação devido a interferência \\
1.10 & Outras perdas \\
\hline
\end{tabular}

EST A EST B Unidade

Dados do Enlace

\begin{tabular}{|c|c|c|c|c|}
\hline \multicolumn{5}{|c|}{ Dados do Equipamento } \\
\hline 2.1 & Potência de Transmissão & \multicolumn{2}{|c|}{28} & $\mathrm{dBm}$ \\
\hline 2.2 & Frequência central & \multicolumn{2}{|c|}{4000} & $\mathrm{MHz}$ \\
\hline 2.3 & Perda no branching $(T x+R x)$ & 2,2 & 2,2 & $\mathrm{~dB}$ \\
\hline 2.4 & Atenuador $(T x+R x)$ & 0 & 0 & $\mathrm{~dB}$ \\
\hline 2.5 & Potência recebida para $10 \mathrm{E}-3$ & \multicolumn{2}{|c|}{-73} & $\mathrm{dBm}$ \\
\hline 2.6 & Potência recebida para 10E-6 & \multicolumn{2}{|c|}{$-69,5$} & $\mathrm{dBm}$ \\
\hline 2.7 & Característica de Assinatura para 10E-3 & \multicolumn{2}{|c|}{2} & \\
\hline 2.8 & Característica de Assinatura para 10E-6 & \multicolumn{2}{|c|}{1,5} & \\
\hline 2.9 & MTBF do sistema para configuração $(1+1)$ Hot standby & \multicolumn{2}{|c|}{2000000} & $\mathrm{~h}$ \\
\hline 2.10 & MTTR & \multicolumn{2}{|c|}{5} & $\mathrm{~h}$ \\
\hline
\end{tabular}

\begin{tabular}{|c|c|c|c|}
\hline \multicolumn{4}{|c|}{ Sistema Aéreo } \\
\hline 3.1 & Ganho da Antena & 39,3 & $\mathrm{dBi}$ \\
\hline 3.1.1 & Ganho Total & \multirow{2}{*}{$\begin{array}{c}78,6 \\
0,0213\end{array}$} & $\mathrm{~dB}$ \\
\hline 3.2 & Perda no Guia de onda / Cabo coaxial & & $\mathrm{dB} / \mathrm{m}$ \\
\hline 3.3 & Comprimento do Guia de onda / Cabo coaxial & $60 \quad \mid \quad 72$ & $\mathrm{~m}$ \\
\hline \multicolumn{4}{|c|}{ Diversidade } \\
\hline 4.1 & Espaçamento entre portadoras para a divers. de frequência & 28 & $\mathrm{MHz}$ \\
\hline 4.2 & Valor de $n$ na configuração $(n+1)$ & 1 & \\
\hline 4.3 & Espaçamento entre antena principal e de divers. de espaço & 0 & $\mathrm{~m}$ \\
\hline 4.4 & Ganho da antena de diversidade de espaço & 0 & $\mathrm{dBi}$ \\
\hline \multicolumn{4}{|c|}{ Objetivo do ITU-R - Desempenho } \\
\hline 5.1 & Especificação do desempenho (Medium grade class) & 1 & \\
\hline 5.2 & Objetivo do desempenho para BER $=10 \mathrm{E}-3$ & 0,000857 & $\%$ \\
\hline
\end{tabular}


Cálculo de desempenho, disponibilidade e interferências para radioenlace

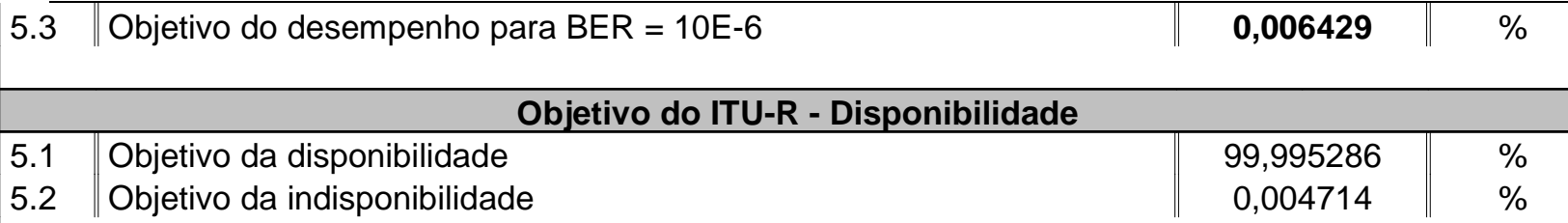

\begin{tabular}{|c|c|c|c|}
\hline \multicolumn{4}{|c|}{ Resultados } \\
\hline 6.1 & Atenuação no Espaço Livre & 136,48 & $d B$ \\
\hline 6.2 & Atenuação devido à absorção pela Atmosfera & 0,29 & $d B$ \\
\hline 6.3 & Atenuação do Guia de onda / Cabo coaxial & 2,8116 & $\mathrm{~dB}$ \\
\hline 6.4 & Atenuação Total Líquida & 66,38 & $\mathrm{~dB}$ \\
\hline 6.5 & Nível (potência) de Recepção & $-38,4$ & $\mathrm{dBm}$ \\
\hline 6.6 & Margem Líquida do enlace para $B E R=10 \mathrm{E}-3$ & 33,6 & $\mathrm{~dB}$ \\
\hline 6.7 & Margem Líquida do enlace para $\mathrm{BER}=10 \mathrm{E}-6$ & 30,1 & $\mathrm{~dB}$ \\
\hline \multicolumn{4}{|c|}{ Probabilidade de Ocorrência de SES (configuração sem proteção) } \\
\hline 6.8 & Devido ao fading plano & & \\
\hline 6.8 .1 & Altitude da antena mais baixa & 475 & $\mathrm{~m}$ \\
\hline 6.8 .2 & Fator climático & 1,41757E-05 & \\
\hline 6.8 .3 & Fator de ocorrência do fading plano $\left(\mathrm{P}_{0}\right)$ & 2,741239 & \\
\hline 6.8 .4 & Prob. de ocorrência de SES (fading plano) $p / B E R=10 E-3$ & 0,001191 & $\%$ \\
\hline 6.8 .5 & Prob. de ocorrência de SES (fading plano) $p / B E R=10 E-6$ & 0,002666 & $\%$ \\
\hline 6.9 & Devido ao fading seletivo & & \\
\hline 6.9 .1 & Fator de ocorrência de fading seletivo ( $\eta$ ) & 0,013383 & \\
\hline 6.9 .2 & Retardo médio (tm) & 0,500879 & ns \\
\hline 6.9 .3 & Prob. de ocorrência de SES (fading seletivo) $p / B E R=10 E-3$ & 0,000458 & $\%$ \\
\hline 6.9 .4 & Prob. de ocorrência de SES (fading seletivo) $p / B E R=10 E-6$ & 0,000344 & $\%$ \\
\hline 6.10 & Prob. de ocorrência de SES (fading total) $p / B E R=10 E-3$ & 0,001649 & $\%$ \\
\hline 6.11 & Prob. de ocorrência de SES (fading total) p/ BER $=10 E-6$ & 0,003010 & $\%$ \\
\hline 6.12 & Margem de desempenho para BER $=10 \mathrm{E}-3$ & $-2,84$ & $d B$ \\
\hline 6.13 & Margem de desempenho para BER $=10 \mathrm{E}-6$ & 3,30 & $d B$ \\
\hline \multicolumn{4}{|c|}{ Probabilidade de Ocorrência de SES (configuração com diversidade) } \\
\hline 7.1 & Diversidade de Frequência (fading plano) & & \\
\hline 7.1.1 & Fator de melhoria de divers. de frequência $p / B E R=10 E-3$ & 8,06 & \\
\hline 7.1 .2 & Fator de melhoria de divers. de frequência $p / B E R=10 E-6$ & 3,60 & \\
\hline 7.1.3 & Prob. de ocorrência de SES (fading total) $p / B E R=10 E-3$ & 0,000205 & $\%$ \\
\hline 7.1 .4 & Prob. de ocorrência de SES (fading total) $p / B E R=10 E-6$ & 0,003010 & $\%$ \\
\hline 7.2 & Margem de desempenho para BER $=10 \mathrm{E}-3$ & 6,22 & $d B$ \\
\hline 7.3 & Margem de desempenho para $\mathrm{BER}=10 \mathrm{E}-6$ & 3,30 & $d B$ \\
\hline 7.4 & Diversidade de Espaço (fading seletivo) & & \\
\hline 7.4.1 & Fator de melhoria de divers. de espaço $\mathrm{p} / \mathrm{BER}=10 \mathrm{E}-3$ & 0,00 & \\
\hline 7.4 .2 & Fator de melhoria de divers. de espaço $p / B E R=10 E-6$ & 0,00 & \\
\hline 7.4.3 & Prob. de ocorrência de SES (fading total) $p / B E R=10 E-3$ & 0,000205 & $\%$ \\
\hline 7.4 .4 & Prob. de ocorrência de SES (fading total) p/ BER = 10E-6 & 0,003010 & $\%$ \\
\hline 7.5 & Margem de desempenho para BER $=10 \mathrm{E}-3$ & 6,22 & $\mathrm{~dB}$ \\
\hline 7.6 & Margem de desempenho para BER $=10 \mathrm{E}-6$ & 3,30 & $\mathrm{~dB}$ \\
\hline \multicolumn{4}{|c|}{ Indisponibilidade Total } \\
\hline 8.1 & Devido a chuva & & \\
\hline 8.1 .1 & Distância equivalente & 6,53 & $\mathrm{~km}$ \\
\hline 8.1 .2 & Atenuação específica & 0,11 & $\mathrm{~dB} / \mathrm{km}$ \\
\hline 8.1.3 & Atenuação total por chuva & 0,74 & $\mathrm{~dB}$ \\
\hline
\end{tabular}




\begin{tabular}{||l|l||c||c||}
\hline 8.1 .4 & Indisponibilidade por chuva & 0,000001 & $\%$ \\
8.2 & Indisponibilidade devido ao equipamento & 0,000500 & $\%$ \\
8.3 & Indisponibilidade devido ao fading total & 0,000061 & $\%$ \\
8.4 & Indisponibilidade Total & $\mathbf{0 , 0 0 0 5 6 2}$ & $\%$ \\
8.5 & Margem de Indisponibilidade & 9,24 & $\mathrm{~dB}$ \\
\hline
\end{tabular}

Pelos resultados obtidos no cálculo de desempenho e disponibilidade (na tabela 21), verifica-se, que como a freqüência do enlace em questão, encontra-se abaixo de $10 \mathrm{GHz}$, a especificação de desempenho é o determinante, por mais crítica. Assim, nestas situações, observa-se que os enlaces que atendem a especificação de desempenho, atendem com folga a especificação de disponibilidade.

Caso a freqüência do enlace fosse superior a $10 \mathrm{GHz}$, a especificação determinante (crítica), seria a de disponibilidade, devido a atenuação devido à chuvas. Neste situação, a indisponibilidade devido ao desvanecimento seria desprezível.

\subsection{Cálculo de Interferências}

Os sinais interferentes causam degradação na margem do enlace, que, por conseguinte, degradação no desempenho e disponibilidade do enlace. Essas interferências podem ser classificadas $\mathrm{em}^{[7]}$ :

- Interferências do mesmo enlace: É causada por outros canais de RF pertencentes ao mesmo enlace, no caso das configurações $(1+1)$ e $(n+1)$ com diversidade de freqüência.

- Interferências intra-sistema: É caudada por outros enlaces pertencentes ao mesmo sistema projetado.

- Interferências de outros sistemas (digitais e analógicos).

Verifica-se que todas as interferências descritas devem ser escopo no cálculo de desempenho e na escolha do tipo de antena, assim como, no canal de RF a ser escolhido e a polarização adequada, que depende dos níveis de interferências existentes.

É importante observar que as interferências causadas nos sistemas existentes devem ser também calculadas, não se limitando apenas nas interferências a serem recebidas. 
As interferências podem ser classificadas de acordo com as suas fontes e também em fixas e variáveis, onde as interferências fixas e variáveis, já foram descritas no item anterior.

\subsubsection{Curvas de sensibilidade a interferências}

Uma característica importante para a análise das interferências, são as curvas de sensibilidade a interferências, onde os fabricantes de rádios digitais seguem normais internacionais próprias para cada tipo de aplicação. As curvas de sensibilidade à interferência são, normalmente apresentados nos manuais. Segue as duas curvas de sensibilidade às interferências:

\section{$\underline{5.4 .1 .1}$ Interferência do co-canal $^{[3]}$}

$\mathrm{Na}$ configuração co-canal, ou quando se utiliza para o sinal interferente a mesma freqüência do sinal interferido, utiliza-se as curvas teóricas BER $x \quad S / I$ (sinal/interferência) para diversos níveis de modulação (ver fig. 31).

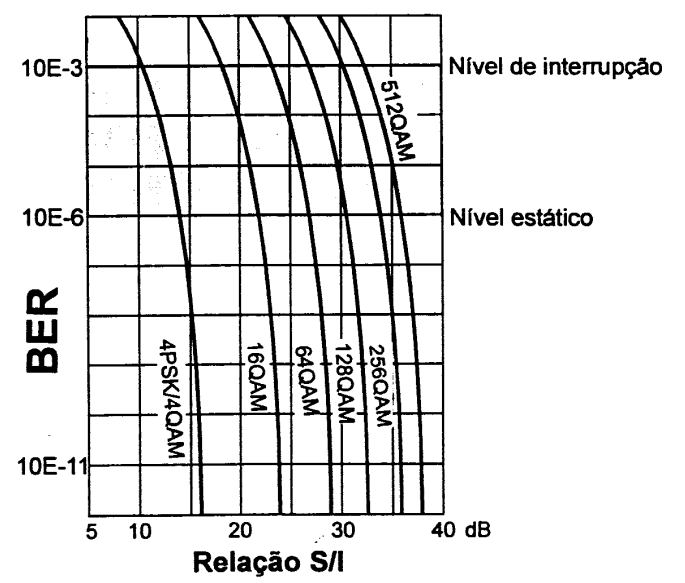

Figura 31. Curva BER x S/I para interferência co-canal.

Observa-se pela figura que a relação $S / l$ deve ser maior que $27 \mathrm{~dB}$ para 64 QAM, $31 \mathrm{~dB}$ para 128 QAM, $33 \mathrm{~dB}$ para 256 QAM e $36 \mathrm{~dB}$ para 512 QAM.

\section{$\underline{5.4 .1 .2}$ Interferência do canal adjacente $^{[3]}$}


A tabela 21 mostra valores da interferência para canal adjacente correspondentes a um fabricante.

Os valores apresentados na tabela não devem ser ultrapassados. Na prática, os planos de freqüências que utilizam canais adjacentes devem ser elaborados utilizando polarização cruzada nas antenas. Assim, obtém-se uma separação adicional de $30 \mathrm{~dB}$ ente os canais de polarizações diferentes, que satisfaz qualquer valor apresentado na tabela 22. Isto significa, por exemplo, que para o caso da freqüência de $7,5 \mathrm{GHz}$ os canais 1, 3 e 5 na polarização vertical, enquanto os canais 2 e 4 utilizam polarização horizontal.

Tabela 21. Interferência canal adjacente.

\begin{tabular}{|c|c|c|c|c|}
\hline & & $4,5,6$ e $8 \mathrm{GHz}$ & $7 \mathrm{GHZ}$ & $13 \mathrm{GHz}$ \\
\hline \multirow{2}{*}{ BER $=10^{-3}$} & $S / 1$ & $3 \mathrm{~dB}$ & $7 \mathrm{~dB}$ & $7 \mathrm{~dB}$ \\
\hline & Nível de Rx & $-67,5 \mathrm{dBm}$ & $-67,5 \mathrm{dBm}$ & $-66,5 \mathrm{dBm}$ \\
\hline \multirow{2}{*}{ BER $=10^{-6}$} & $\mathrm{~S} / \mathrm{l}$ & $7 \mathrm{~dB}$ & $11 \mathrm{~dB}$ & $11 \mathrm{~dB}$ \\
\hline & Nível de Rx & $-65 \mathrm{dBm}$ & $-65 \mathrm{dBm}$ & $-64 \mathrm{dBm}$ \\
\hline
\end{tabular}

\subsubsection{Tipos de interferências}

\subsubsection{Interferência intercanal ${ }^{[3]}$}

A interferência intercanal depende da separação entre os canais de $R F$ e do fator de "roll-off" do equipamento rádio. Esta interferência é calculada através de curvas fornecidas pelo fabricante. Para que não haja necessidade do cálculo da degradação para a interferência intercanal, basta utilizar os planos de freqüências de acordo com as recomendações do ITU-R e as especificações do fabricante.

\subsubsection{Interferência por descasamento ${ }^{[3]}$}

Situação em que existem pontos de descasamento entre a antena e guia de onda (lado de transmissão e recepção), fazendo com que o sinal refletido seja recebido com atraso, causando interferência semelhante à de reflexões na superfície ou na atmosfera. Para assegurar que esta interferência tenha nível desprezível, é preciso manter a VSWR do sistema aéreo o mais baixo possível (abaixo de 1,15 ou no máximo 1,2).

\subsubsection{Interferência do co-canal $^{[3]}$}


A interferência do co-canal ocorre quando se utiliza o mesmo par de freqüências em toda a rota (como é o caso da fig. 29). A figura 32 mostra uma outra situação possível.

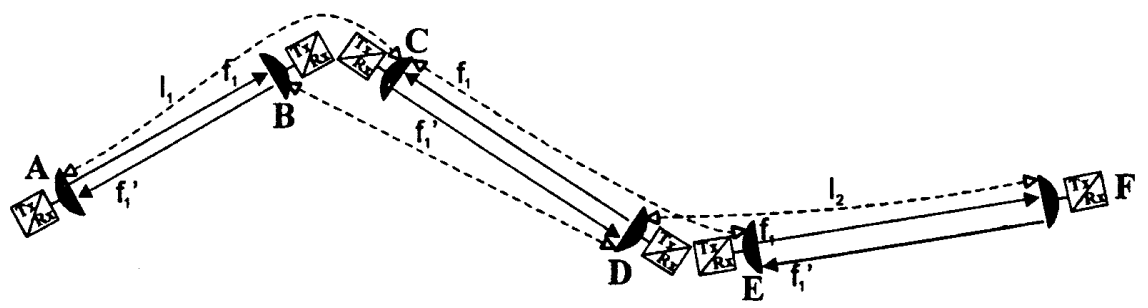

Figura 32. Cálculo interferência co-canal.

Pela figura 32, observam-se todas as possibilidades de interferência. Entretanto, para exemplificar o processo de cálculo, será escolhido apenas dois sinais interferentes $\left(I_{1} \quad\right.$ e $\left.I_{2}\right)$. Não foram consideradas interferências com distâncias correspondentes a mais de um enlace, por serem pouco significativas. Assim, as potências dos sinais interferentes, $\mathrm{l}_{1}$ e $\mathrm{I}_{2}(\mathrm{dBm})$, podem ser calculados:

$$
\begin{aligned}
& \mathrm{I}_{1}=\mathrm{P}_{\mathrm{T}(\mathrm{A})}-\mathrm{A}_{\mathrm{rmf}(\mathrm{A})}-\mathrm{A}_{\mathrm{C}(\mathrm{A})}+\mathrm{G}_{\mathrm{T}(\mathrm{A})}-\mathrm{A}_{\mathrm{A}(\mathrm{A})}-\mathrm{A}_{\mathrm{e}(\mathrm{AC})}+\mathrm{G}_{\mathrm{R}(\mathrm{C})}-\mathrm{A}_{\mathrm{A}(\mathrm{C})}-\mathrm{A}_{\mathrm{C}(\mathrm{C})}-\mathrm{A}_{\mathrm{rmf}(\mathrm{C})} \\
& \mathrm{I}_{2}=\mathrm{P}_{\mathrm{T}(\mathrm{D})}-\mathrm{A}_{\mathrm{rmf}(\mathrm{D})}-\mathrm{A}_{\mathrm{C}(\mathrm{D})}+\mathrm{G}_{\mathrm{T}(\mathrm{D})}-\mathrm{A}_{\mathrm{A}(\mathrm{D})}-\mathrm{A}_{\mathrm{e}(\mathrm{DF})}+\mathrm{G}_{\mathrm{R}(\mathrm{F})}-\mathrm{A}_{\mathrm{A}(\mathrm{F})}-\mathrm{A}_{\mathrm{C}(\mathrm{F})}-\mathrm{A}_{\mathrm{rmf}(\mathrm{F})}
\end{aligned}
$$

onde: $I_{1}=$ Potência do sinal interferente recebida pelo receptor $C(\mathrm{dBm})$;

$\mathrm{P}_{\mathrm{T}(\mathrm{A})}=$ Potência de transmissão fornecida pela antena $\mathrm{A}(\mathrm{dBm})$;

$\mathrm{G}_{\mathrm{T}(\mathrm{A})}=$ Ganho da antena de transmissão $\mathrm{A}(\mathrm{dBi})$;

$\mathrm{G}_{\mathrm{R}(\mathrm{C})}=$ Ganho da antena de recepção $\mathrm{C}(\mathrm{dBi})$;

$A_{e}(A C)=$ Atenuação espaço livre no trajeto $A-C$;

$\mathrm{A}_{\mathrm{rmf}(\mathrm{A})}=$ Atenuação no branching em $\mathrm{Tx}$ de $\mathrm{A}(\mathrm{dB})$;

$A_{\mathrm{rmf}(\mathrm{C})}=$ Atenuação no branching em $\mathrm{Rx}$ de $\mathrm{C}(\mathrm{dB})$;

$A_{C(A)}=$ Atenuação do guia de onda da antena $A(d B)$;

$A_{C(C)}=$ Atenuação do guia de onda da antena $C(d B)$;

$A_{A(A)}=$ Atenuação antena $A$ na direção do sinal interferente $C(d B)$;

$A_{A(C)}=$ Atenuação antena $C$ na direção do sinal interferente $A(d B)$; 


\subsubsection{Interferência de sobrealcance $^{[7]}$}

A interferência de sobrealcance ocorre por uma condição anômala de propagação, onde duas estações, que não possuem visada direta, com esta anormalidade, passam a possuir. A figura 33 mostra o caso onde a antena de recepção $D$ é interferida pela antena de transmissão $A$.

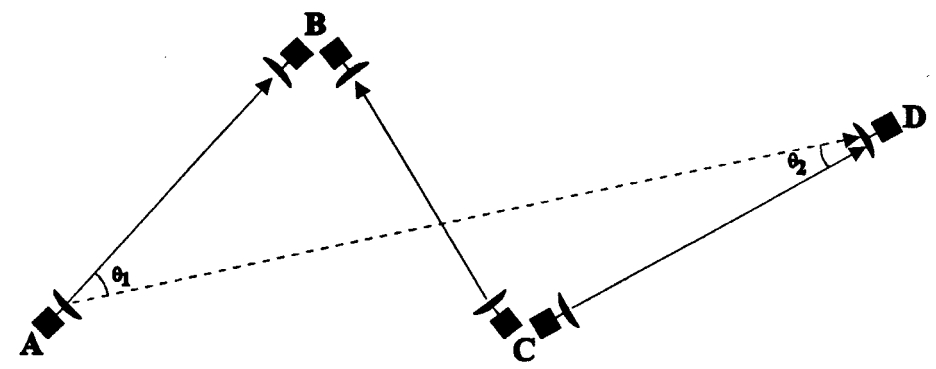

Figura 33. Interferência sobrealcance.

O cálculo da potência do sinal interferente que chega ao receptor $D$ é calculado de acordo com a expressão (65) com seus parâmetros adaptados para a nova situação.

\subsubsection{Interferência de outros sistemas ${ }^{[7]}$}

São causadas por outros sistemas operando na mesma faixa de freqüências. Assim, deve-se verificar nos documentos do SITAR a existência de enlaces em operação para fazer as análises necessárias. A figura 34 ilustra uma possibilidade de interferências.

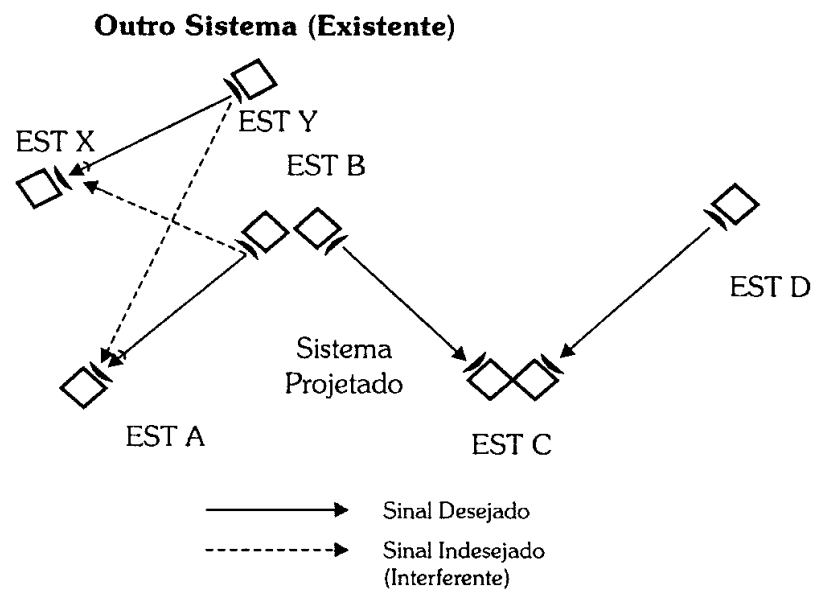

Figura 34. Interferências intersistemas. 
Da mesma maneira que do caso da interferência de sobrealcance, o sinal interferente é calculado com o auxílio da expressão (65) com as devidas modificações criadas.

Todas as interferências devem ser calculadas individualmente. Devem ser considerados os seguintes tipos de interferências: Co-canal, mesma polarização; Cocanal, polarização cruzada; Canal adjacente, co-polarização; Canal adjacente, polarização cruzada.

\subsubsection{Interferência por ruído de ignição $^{[7]}$}

É outra fonte de interferência que atinge rádios que operam nas faixas de freqüências abaixo de $2 \mathrm{GHz}$ (VHF e UHF), pois os veículos emitem ruídos de banda larga nesta faixa de freqüência. Como os rádios em VHF e UHF não possuem antenas diretivas, esses ruídos causam degradações no desempenho que pode chegar a atingir níveis de $10 \mathrm{~dB}$, dependendo da localização da estação. Uma contramedida para reduzir este efeito, seria colocar a antena a uma altura mínima de 20 metros, principalmente nas situações onde a torre encontra-se próxima a uma estrada ou rodovia.

\subsubsection{Degradação devido a interferências}

Como a interferência é qualquer sinal indesejável que causa degradação na qualidade do sistema rádio, tem-se que a interferência pode ser originada pelo mesmo sistema ou em sistema próximos operando na mesma freqüência. Sendo assim, uma análise criteriosa deve ser realizada, identificando todas as possibilidades existentes com a identificação de todos os parâmetros do sinal interferente.

A degradação devido a interferências pode ser calculada pela expressão ${ }^{[3]}$ :

$$
\mathrm{D}_{\mathrm{t}}=10 \cdot \log \cdot\left[1+10^{\left(\mathrm{I}-\mathrm{N}_{\text {TÉRMICO }}\right)}\right]
$$

onde: $D_{t}=$ degradação total devido a interferência $(d B)$;

$\mathrm{I}$ = potência do sinal interferente $(\mathrm{dBm})$;

$\mathrm{N}_{\text {térmico }}=$ potência do ruído térmico na ausência de interferências $(\mathrm{dBm})$; 
O ruído térmico pode ser calculado de acordo com a expressão (35), que ao ser simplificada vale:

$$
\mathrm{N}_{\text {TÉRMICO }}=10 \cdot \log \cdot \mathrm{B}+\mathrm{F}-113,83
$$

onde: $B=$ largura da faixa do canal de $R F(M H z)$;

$F=$ figura de ruído $(\mathrm{dB})$.

Caso exista mais de um sinal interferente, o cálculo da degradação deve ser feito para cada sinal interferente, e no final, somar todas as degradações calculadas.

Este valor de degradação calculado pela expressão (68), deve ser descontado na margem sobre o limiar (margem líquida do enlace - FFM), para $B E R=10^{-3}$ e BER $=10^{-6}$, para que se possa fazer (ou refazer, dependo da situação) o cálculo de desempenho e disponibilidade. Assim, o efeito do sinal interferente é computado como uma degradação dos limiares de recepção para BER $=10^{-3}$ e $\mathrm{BER}=10^{-6}$ obtidas da curva potência de recepção x BER, na ausência de sinais interferentes, fornecidos pelo fabricante do equipamento.

A figura 35 mostra a curva em questão para um equipamento que opera com a freqüência de $8 \mathrm{GHz}$ com taxa de transmissão de $34 \mathrm{Mbps}^{[3]}$ :

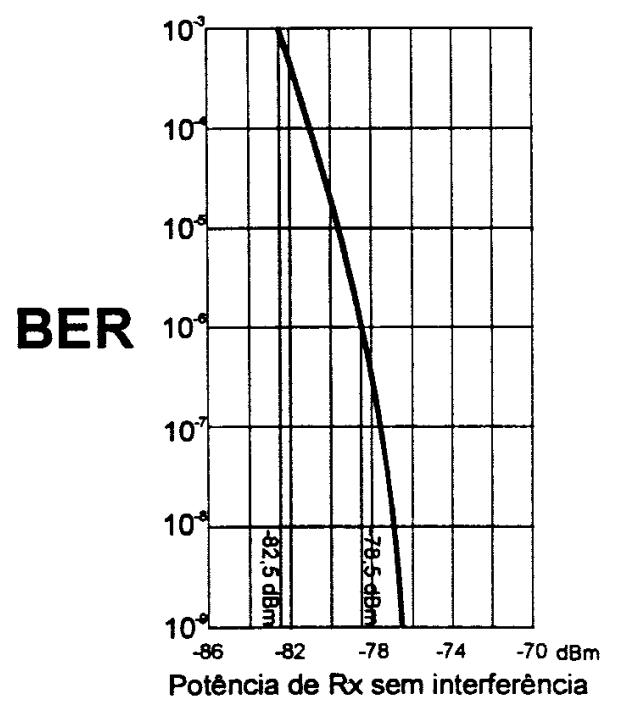

Figura 35. Potência de recepção sem interferências x BER.

Como a degradação devido a interferência rebaixa os limiares de recepção, e por conseguinte, a margem sobre o limiar (margem líquida), uma especificação de projeto desejável seria obter uma margem sobre o limiar mínima de $30 \mathrm{~dB}$. Esta 

especificação seria uma margem de erro para o cálculo da degradação por interferências, que em muitos casos, não podem ser calculados com uma precisão absoluta.

\subsubsection{Características das antenas de alto desempenho}

Devido à poluição crescente do espectro devido à introdução de novos sistemas radioenlaces digital, as características técnicas das antenas vêm sendo cada vez mais aperfeiçoadas. As antenas parabólicas de alta desempenho são caracterizadas por ter melhores especificações de atenuação de lóbulos laterais, alta relação frentecosta, melhor eficiência do alimentador.

Os diagramas de radiação das antenas parabólicas são normalmente apresentados na forma cartesiana, onde se encontram quatro curvas, que varia de acordo com a polarização utilizada, $\mathrm{HH}, \mathrm{VH}, \mathrm{HV}$ e VV. A figura 36 mostra o caso de uma antena parabólica que opera na faixa de $8,2-8,5 \mathrm{MHz}$ com um ganho de $45,5 \mathrm{dBi}$, onde este diagrama é válido tanto para a transmissão como para a recepção, devido ao teorema da reciprocidade ${ }^{[7]}$.

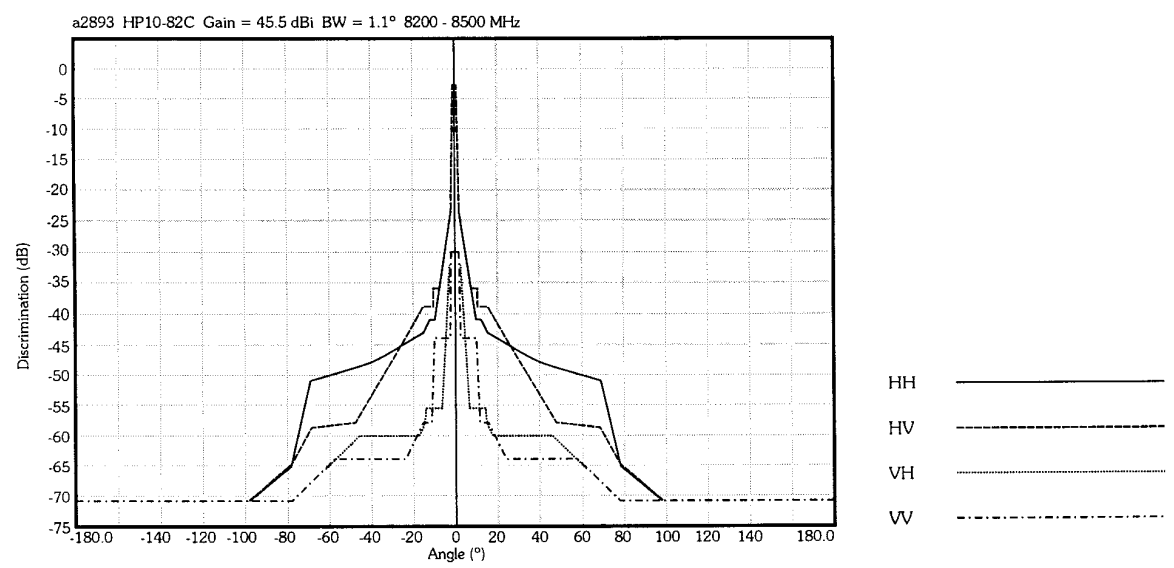

Figura 36. Diagrama de radiação.

Pelo diagrama observam-se quatro tipos de polarizações utilizadas. Como exemplo, a curva $\mathrm{VH}$ mostra o nível relativo do sinal interferente transmitido na polarização $\mathrm{H}$, para uma dada direção com ângulo ALFA, em relação ao sinal 
Cálculo de desempenho, disponibilidade e interferências para radioenlace desejado, transmitido em V. Para a mesma antena como receptora, a mesma curva mostra o nível relativo (para este mesmo ângulo) recebido pela antena na polarização $\mathrm{H}$ em relação ao sinal desejado, recebido em $\mathrm{V}$.

\subsubsection{Exemplo de cálculo de interferência}

Será mostrado um exemplo de cálculo de interferência onde um novo enlace, na faixa de 7,5 GHz ,16E1 e polarização Horizontal, será implantado. Na localidade em questão existe um outro sistema que também opera na mesma freqüência $\mathrm{e}$ polaridade, mudando apenas a sua capacidade que é de $155 \mathrm{Mbps}$.

A antena utilizada foi a HPX6 - 71W com ganho de 40,4 dBi, cujo fabricante é a Andrew. O diagrama de radiação desta antena encontra-se na figura $37^{[10]}$. Na figura 38 encontra-se a situação a ser analisada.

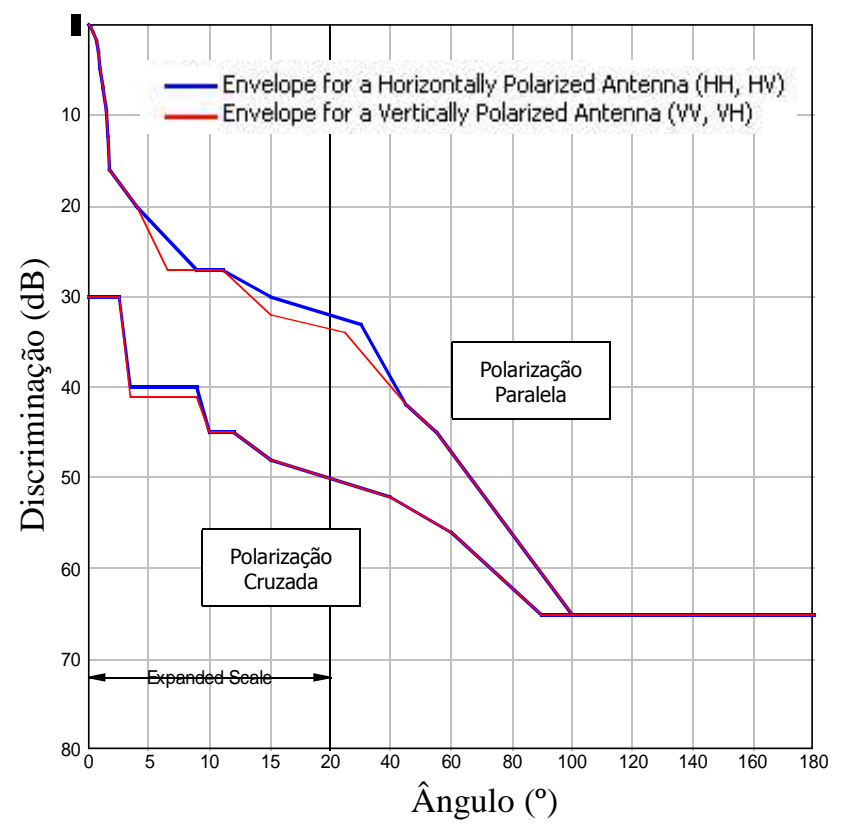

Figura 37. Diagrama de radiação da antena HPX6-71W 


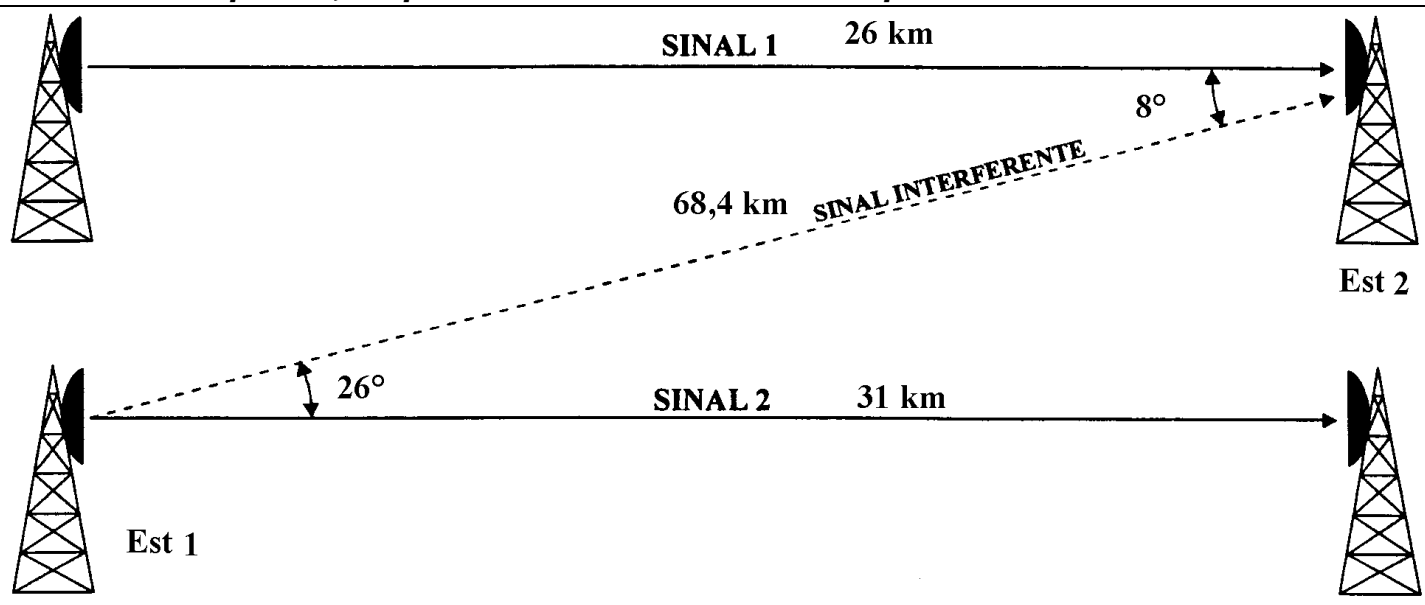

Figura 38. Descrição dos sistemas interferentes.

Nas tabelas 22 e 23, encontra-se o cálculo de interferência, onde a diferença entre as duas tabelas é o sentido de transmissão. Para o caso da tabela 22 a estação transmissora é a EST1, e para o caso da tabela 24, é a EST2.

Tabela 22. Cálculo de interferência (EST1-EST2).

\begin{tabular}{|c|c|c|c|c|c|c|}
\hline \multicolumn{7}{|c|}{$\begin{array}{l}\text { Cálculo de Interferência } \\
\text { Enlace: EST } 1 \text { - EST } 2\end{array}$} \\
\hline Item & Denominação & \multicolumn{2}{|c|}{ Co-Pol. } & \multicolumn{2}{|c|}{ Pol. Cruzada } & Unidade \\
\hline \multicolumn{7}{|c|}{ Dados do Equipamento } \\
\hline 1.1 & Potência de Transmissão & \multicolumn{2}{|c|}{29} & \multicolumn{2}{|c|}{29} & $\mathrm{dBm}$ \\
\hline 1.2 & Frequência central & \multicolumn{2}{|c|}{7575} & \multicolumn{2}{|c|}{7575} & $\mathrm{MHz}$ \\
\hline 1.3 & Perda no branching $(T x+R x)$ & 3,25 & 3,9 & 3,25 & 3,9 & $\mathrm{~dB}$ \\
\hline 1.4 & Potência recebida para $10 \mathrm{E}-3$ & \multicolumn{2}{|c|}{$-81,5$} & \multicolumn{2}{|c|}{$-81,5$} & $\mathrm{dBm}$ \\
\hline 1.5 & Potência recebida para 10E-6 & \multicolumn{2}{|c|}{-78} & \multicolumn{2}{|c|}{-78} & $\mathrm{dBm}$ \\
\hline 1.6 & Taxa de transmissão & \multicolumn{2}{|c|}{34} & \multicolumn{2}{|c|}{34} & Mbps \\
\hline 1.7 & Nível de modulação & \multicolumn{2}{|c|}{16} & \multicolumn{2}{|c|}{16} & \\
\hline \multicolumn{7}{|c|}{ Sistema Aéreo } \\
\hline 2.1 & Ganho da Antena & 40,4 & 40,4 & 40,4 & 40,4 & $\mathrm{dBi}$ \\
\hline 2.2 & Perda no guia de onda & \multicolumn{2}{|c|}{0,06} & \multicolumn{2}{|c|}{0,06} & $\mathrm{~dB} / \mathrm{m}$ \\
\hline 2.3 & Comprimento do guia de onda & 57 & 50 & 57 & 50 & $\mathrm{~m}$ \\
\hline \multicolumn{7}{|c|}{ Nível do sinal interferente } \\
\hline 3.1 & Distância do enlace útil & \multicolumn{2}{|c|}{31} & \multicolumn{2}{|c|}{31} & $\mathrm{~km}$ \\
\hline 3.2 & Distância do enlace interferente & \multicolumn{2}{|c|}{68,4} & \multicolumn{2}{|c|}{68,4} & $\mathrm{~km}$ \\
\hline 3.3 & Ruído térmico & \multicolumn{2}{|c|}{-101} & \multicolumn{2}{|c|}{-101} & $\mathrm{dBm}$ \\
\hline \multirow{2}{*}{3.4} & Figura de ruído no receptor & \multirow{2}{*}{\multicolumn{2}{|c|}{3}} & \multirow{2}{*}{\multicolumn{2}{|c|}{3}} & $\mathrm{~dB}$ \\
\hline & Interferências Tx e Rx & & & & & \\
\hline 3.5 & Ângulo de interferência (Tx e Rx) & 26 & 8 & 26 & 8 & $\underline{0}$ \\
\hline 3.6 & Polarização da antena (Tx e Rx) & $\mathrm{H}$ & $\mathrm{H}$ & $\mathrm{V}$ & $\mathrm{V}$ & \\
\hline 3.7 & Discriminação da antena (Tx e Rx) & 32 & 28 & 35 & 28 & $d B$ \\
\hline \multicolumn{7}{|c|}{ Resultados } \\
\hline 4.1 & Nível de recepção & \multicolumn{2}{|c|}{$-43,62$} & \multicolumn{2}{|c|}{$-43,62$} & $\mathrm{dBm}$ \\
\hline 4.2 & Nível de interferência & & & & & $\mathrm{dBm}$ \\
\hline 4.3 & Degradação devido à interferência & & & & & $\mathrm{dB}$ \\
\hline
\end{tabular}


Tabela 23. Cálculo de interferência (EST2-EST1).

Cálculo de Interferência

Enlace: EST 2 - EST 1

Item Denominação

\begin{tabular}{|l|l|l|}
\hline Co-Pol. & Pol. Cruzada & Unidade \\
\hline
\end{tabular}

1.1 Potência de Transmissão

Dados do Equipamento

30 $\mathrm{dBm}$ 
Cálculo de desempenho, disponibilidade e interferências para radioenlace

\begin{tabular}{|c|c|c|c|c|c|c|}
\hline 1.2 & Frequência central & \multicolumn{2}{|c|}{7575} & \multicolumn{2}{|c|}{7575} & $\mathrm{MHz}$ \\
\hline 1.3 & Perda no branching $(T x+R x)$ & 3,9 & 3,25 & 3,9 & 3,25 & $\mathrm{~dB}$ \\
\hline 1.4 & Potência recebida para 10E-3 & \multicolumn{2}{|c|}{$-72,7$} & \multicolumn{2}{|c|}{$-72,7$} & $\mathrm{dBm}$ \\
\hline 1.5 & Potência recebida para 10E-6 & \multicolumn{2}{|c|}{$-69,9$} & \multicolumn{2}{|c|}{$-69,9$} & $\mathrm{dBm}$ \\
\hline 1.6 & Taxa de transmissão & \multicolumn{2}{|c|}{155} & \multicolumn{2}{|c|}{155} & Mbps \\
\hline 1.7 & Nível de modulação & \multicolumn{2}{|c|}{128} & \multicolumn{2}{|c|}{128} & \\
\hline \multicolumn{7}{|c|}{ Sistema Aéreo } \\
\hline 2.1 & Ganho da Antena & 40,4 & 40,4 & 40,4 & 40,4 & $\mathrm{dBi}$ \\
\hline 2.2 & Perda no guia de onda & \multicolumn{2}{|c|}{0,06} & \multicolumn{2}{|c|}{0,06} & $\mathrm{~dB} / \mathrm{m}$ \\
\hline 2.3 & Comprimento do guia de onda & 50 & 57 & 50 & 57 & $\mathrm{~m}$ \\
\hline \multicolumn{7}{|c|}{ Nível do sinal interferente } \\
\hline 3.1 & Distância útil & \multicolumn{2}{|c|}{26} & \multicolumn{2}{|c|}{26} & $\mathrm{~km}$ \\
\hline 3.2 & Distância interferente & \multicolumn{2}{|c|}{68,4} & \multicolumn{2}{|c|}{68,4} & $\mathrm{~km}$ \\
\hline 3.3 & Ruído térmico & \multicolumn{2}{|c|}{$-97,4$} & \multicolumn{2}{|c|}{$-97,4$} & $\mathrm{dBm}$ \\
\hline \multirow[t]{2}{*}{3.4} & Figura de ruído no receptor & \multirow{2}{*}{\multicolumn{2}{|c|}{2,5}} & \multirow{2}{*}{\multicolumn{2}{|c|}{2,5}} & $\mathrm{~dB}$ \\
\hline & Interferências Tx e Rx & & & & & \\
\hline 3.5 & Ângulo de interferência (Tx e Rx) & 8 & 26 & 8 & 26 & $\underline{0}$ \\
\hline 3.6 & Polarização da antena (Tx e Rx) & $\mathrm{H}$ & $\mathrm{H}$ & $\mathrm{V}$ & V & \\
\hline 3.7 & Discriminação da antena (Tx e Rx) & 28 & 32 & 28 & 35 & $\mathrm{~dB}$ \\
\hline \multicolumn{7}{|c|}{ Resultados } \\
\hline 4.1 & Nível de recepção & \multicolumn{2}{|c|}{$-41,10$} & \multicolumn{2}{|c|}{$-41,10$} & $\mathrm{dBm}$ \\
\hline 4.2 & Nível de interferência & \multicolumn{2}{|c|}{$-109,50$} & \multicolumn{2}{|c|}{$-112,50$} & $\mathrm{dBm}$ \\
\hline 4.3 & Degradação devido à interferência & \multicolumn{2}{|c|}{0,2599} & \multicolumn{2}{|c|}{0,1322} & $\mathrm{~dB}$ \\
\hline
\end{tabular}

Verificando as tabelas e a metodologia de cálculo utilizada, constatá-se que é possível realizar as medidas da degradação devido a interferências para qualquer situação. O único problema encontrado seria o trabalho de descrever todos os sistemas envolvidos na interferência de um novo enlace, para os casos mais complexos.

Para o caso do sistema calculado, tem-se que a interferência é pequena, não interferindo em nada no cálculo de desempenho e disponibilidade, até porque no exemplo tem-se apenas um enlace interferente com uma distância razoável considerada.

\section{Conclusões}

No projeto decorrido, foi desenvolvido uma metodologia mostrando todos os cálculos a serem realizados, juntamente com as expressões necessárias. Em cima deste estudo foi elaborada três planilhas no programa "Excel", com as seguintes finalidades: 
1. Cálculo das alturas das antenas, onde a partir da freqüência do enlace e de um estudo realizado em campo (obtenção do perfil), é possível, realizar o estudo das alturas mínimas necessárias para que o sinal não seja desobstruído, levando em conta a propagação da onda de rádio, através do fator $\mathrm{K}$.

2.

Cálculo de desempenho e disponibilidade, onde a partir dos dados do enlace, dados do equipamento, dados referente ao sistema aéreo e toda a metodologia desenvolvida, é possível verificar se um determinado enlace atenda ou não todas as especificações estabelecidas pelo ITU-T, através da margem de desempenho e disponibilidade. Caso não seja atendido, o enlace deve utilizar algumas contramedidas, como a utilização de diversidade.

3.

Cálculo de interferência, onde a partir dos dados fornecidos para 0 cálculo de desempenho e disponibilidade, e a obtenção dos dados dos sistemas interferentes (cadastrado SITAR), é possível através da metodologia explicada, encontrar qualquer interferência que se desejar. Lembrando mais uma vez que em certas localidades, a poluição espectral impossibilita tal cálculo, sendo necessário o uso da experiência adquirida para filtrar certos sistemas onde a degradação não interfere a nível relevante.

Todas as tabelas foram desenvolvidas de maneira prática, onde uma nova situação com novos dados podem ser inseridos, obtendo as respostas sem maiores dificuldades, necessitando apenas de pequenas adequações.

Do mais, conclui-se que este projeto foi desenvolvido para ser utilizado na prática, sem maiores restrições. Os capítulos introdutórios (capítulos 1 ao 4) foram a base da sustentação do capítulo de dimensionamento de sistemas, situando o leitor ao conteúdo necessário para a compreensão completa do cálculo de desempenho, disponibilidade e interferências.

\section{Glossário}

ANATEL - Agência Nacional de Telecomunicações.

ATPC - Controle Automático de Potência.

$\boldsymbol{B E} \boldsymbol{R}$ - taxa de erro de bit (bit error rate). 
$\mathbf{C} / \mathbf{N}$ - Relação portadora-ruído

DM - Minutos Degradados.

ES - Segundos com pelo menos um bit errado.

FEC - Códigos Corretores de Erros.

FI - Freqüência Intermediária.

HP - High Performance Antennas.

HPX - High Performance Antennas - Dual Polarized.

HSX - High Performance Antennas - Super High Cross Polarization Discrimination.

IDU - Indoor Unit.

IRF - Fator de Rejeição de Interferência.

ITU - International Telecomunications Union.

ITU-R - União Internacional de Telecomunicações - Radiocomunicação

ODU - Outdoor Unit.

PCM - Modulação por Códigos de Pulsos.

$\boldsymbol{P D H}$ - Plesiochronous Digital Hierarchy.

$\boldsymbol{R F}$ - Radiofreqüência.

SDH - PSinchronous Digital Hierarchy.

SES - Segundos Severamente Afetados.

SITAR - Sistema de Informações Técnicas para Administração das Radiocomunicações.

STM-N - Módulo de Transporte Síncrono - Nível-N.

SPEC - Especificações de Desempenho e Disponibilidade.

UIT - União Internacional de Telecomunicações.

UHF - de $300 \mathrm{MHz}$ a $3 \mathrm{GHz}$ (Ultra High Frequency).

VSWR - Voltage Standing Wave Ratio.

VHF - de $30 \mathrm{MHz}$ a $300 \mathrm{MHz}$ (Very High Frequency).

$X P D$ - Discriminação de polarização cruzada.

XPIC - Cancelador de Interferência de Polarização Cruzada.

\section{Referências Bibliográficas}

[1] Nince, Uvemar Sidney; Curso de planejamento e dimensionamento de rádio digital; ELO Telecomunicações; 1999; Brasil. 
[2] Nince, Uvemar Sidney; "Sistema irradiante"; Curso ELO Telecomunicações; 1998; Brasil.

[3] Nince, Uvemar Sidney; "Plano de freqüência"; Curso ELO Telecomunicações; 1999; Brasil.

[4] Freeman, L. Roger; "Radio system design for telecommunications"; $2^{\mathrm{a}}$ edição; 1997; Editora Wiley;

[5] Matsumoto, Takashi; "Microwave system design - How to plan e design microwavw system"; 1ำ edição; 1966; Editora Giken company; Japão.

[6] Andrade, Graziella Brunale \& Dias, Rodrigo Freire; "Estudo de propagação de ondas eletromagnéticas com ênfase na faixa de celular"; Projeto Final; UnB; 2/1999. Brasil.

[7] Miyoshi, Edson Mitsugo \& Sanches, Carlos Alberto; "Projetos de sistemas rádio"; 1a edição; 2002; Editora Érica; Brasil;

[8] Agência Nacional de Telecomunicações - Anatel; "Regulamento sobre canalização e condições de uso da faixa de 7,5 GHz"; www.anatel. gov.br.

[9] Agência Nacional de Telecomunicações - Anatel; "Regulamento sobre canalização e condições de uso da faixa de $5 \mathrm{GHz}$; www.anatel. gov.br.

[10] Andrew Corporation; "Catalog 38, Systems Planning - Product Specifications Services"; www.andrew. com. 